\title{
Genetic variation and inheritance of seed fibre content in winter oilseed rape (Brassica napus L.)
}

\author{
Dissertation \\ to obtain the Ph. D. degree \\ in the International Ph. D. Program for Agricultural Sciences in Göttingen (IPAG) \\ at the Faculty of Agricultural Sciences \\ Georg-August-Universität Göttingen, Germany
}

\author{
presented by \\ Edy Suprianto \\ born in Jakarta, Indonesia
}

Göttingen, May 2014 
D7

Supervisor

Co-supervisor

Date of dissertation
: Dr. Christian Möllers

: Prof. Dr. Elke Pawelzik

: 22 May 2014 


\section{ACKN OWLEDGEMEN TS}

First of all, I would like to express my deep gratitude to my supervisor Dr. Christian Möllers for his patient supervision, guidance, kindness, and encouragement throughout the entire period of my study. I am grateful to Prof. Heiko C. Becker for giving me the opportunity to join Plant Breeding Division and for his support and constructive advices. I would also like to express my gratitude to Prof. Elke Pawelzik for agreeing to be my co-supervisor and to Prof. Johannes Isselstein for agreeing to be the examiner in my final disputation.

I would like to show my thankfulness to the people who helped me during the research: Gunda Asselmeyer, Uwe Ammermann, Carmen Mensch, Rolf Jeromin, Barbara Hohlmann, Birgit Olberg, and Julia Mühlhause. My special thank goes to my fellow PhD students, Nina Behnke and Lishia Teh for daily discussions, encouragement, and togetherness in all kind of activities, and to all PhD students in Plant Breeding Division for their great supports, in particular to Anthimos Kampouridis, Sebastian Miersch, Haiko Brandes, Siyang Liu, Ahmed Sallam, Mareile Stever and Ariana Istar Valdés-Velasquez.

This study would not have been possible without financial support from my company, Indonesian Oil Palm Research Institute (IOPRI); for that I would like to thank Dr. Witjaksana Darmosarkoro, Dr. Edy Sigit Sutarta, Dr. A. Razak Purba and Dr. Hasril Hasan Siregar as the Management Board of IOPRI.

I dedicate my deepest gratitude to my beloved wife Sat Rahayuwati, my lovely daughter Shafa Humaira Ramadhiani and my son Ahsan Cakrawangsa Rahadianto for their limitless patience and encouragement during my study in Germany. This works is also dedicated to my mother, my late father and to all my big family in Indonesia. Their continuous support, love and prayers are what kept me going and made all this possible. I am very grateful for everything they have done. 


\section{TABLE OF CONTENTS}

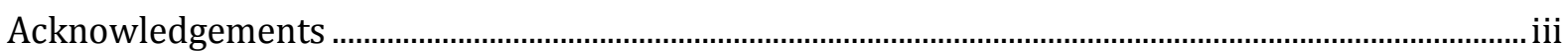

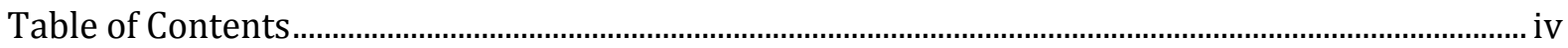

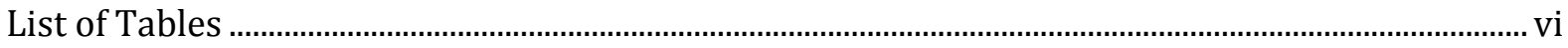

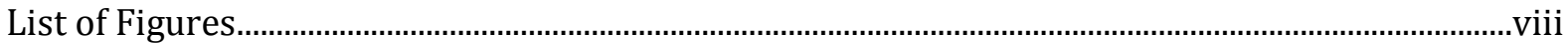

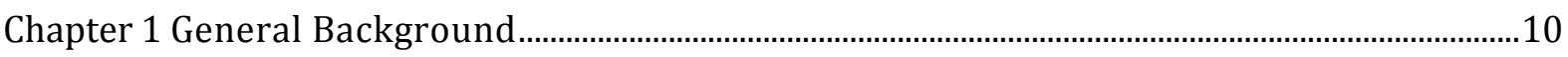

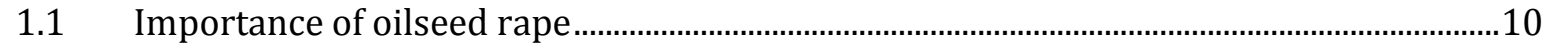

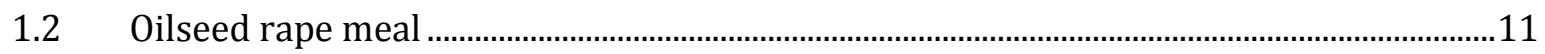

$1.3 \quad$ Antinutritive components in oilseed rape meal ……...........................................................13

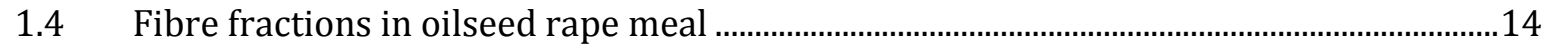

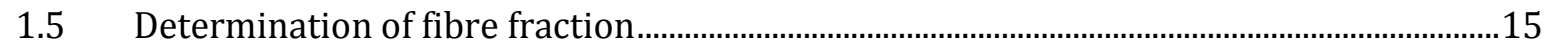

1.6 Relevance of seed hull to oilseed rape meal quality............................................................17

$1.7 \quad$ Oilseed rape breeding for improved meal quality ...................................................................18

1.8 Mapping of QTL associated with fibre components in B. napus...........................................20

1.9 The use of Near-Infrared Reflectance Spectroscopy for fibre content determination ..23

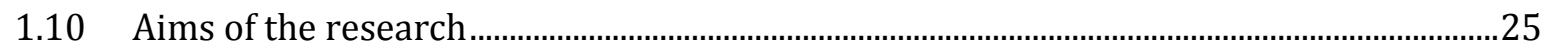

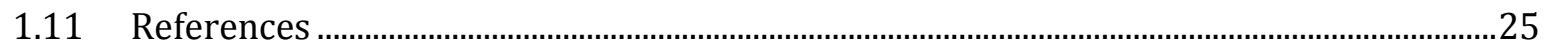

Chapter 2 Genetic variation for seed hull and fibre content in a collection of European winter oilseed rape material (Brassica napus L.) and development of NIRS calibrations......33 Chapter 3 Genetic analysis and QTL mapping of fibre content and seed hull proportion in three doubled haploid populations of black-seeded winter oilseed rape (Brassica napus L.)

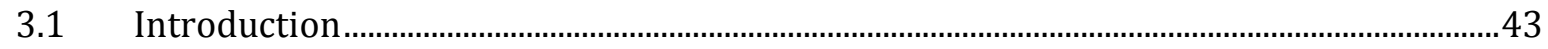

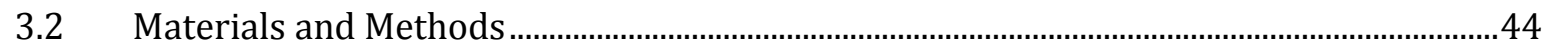

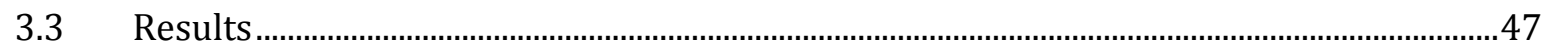

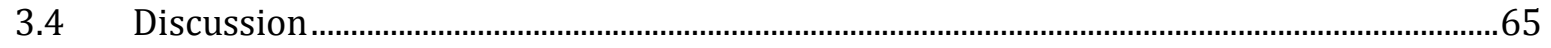

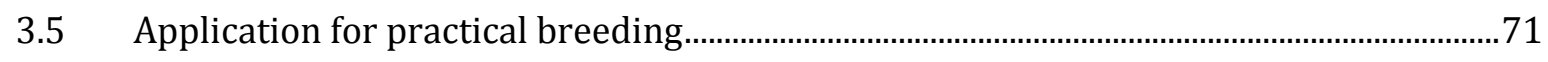

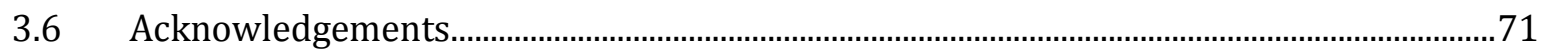


Chapter 4 Genetic variation and association mapping for seed fibre content in canola quality winter oilseed rape cultivars (Brassica napus L.) ....................................................................................

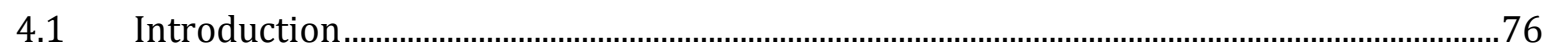

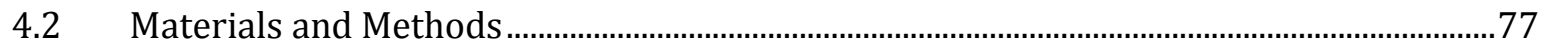

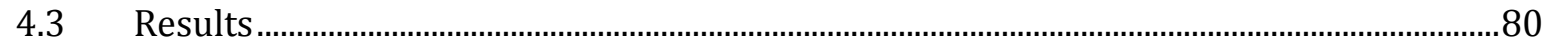

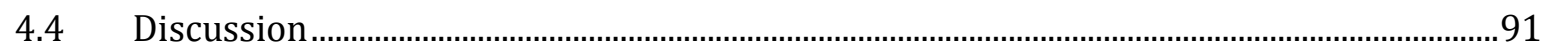

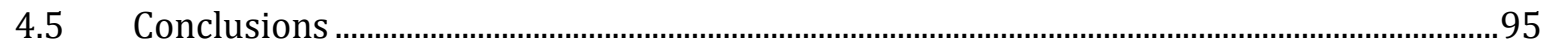

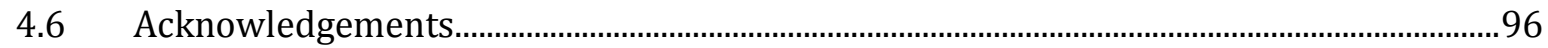

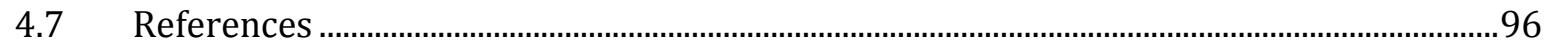

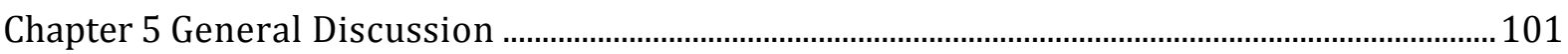

5.1 Variation in seed fibre content and seed hull proportion.................................................... 102

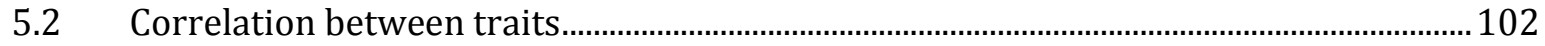

5.3 Identification of QTL associated with fibre content by linkage analysis and association

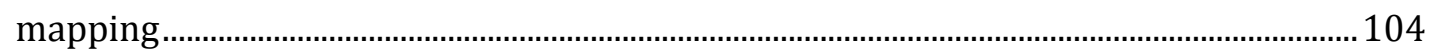

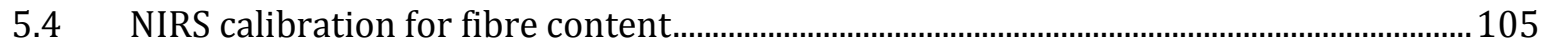

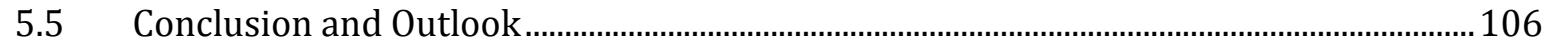

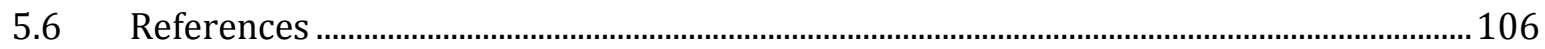

Summary

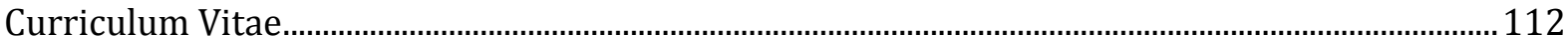




\section{LIST OF TABLES}

Table 1.1 Chemical composition of oilseed rape and soybean meal

Table 3.1 Components of variance and heritabilities for NDF, ADF, ADL, hemicelluloses (HC), and cellulose content (C) (\% of defatted meal), seed hull proportion (\%) and thousand kernel weight (TKW in g) in three DH populations of winter oilseed rape.

Table 3.2 Minimum, maximum and mean values for NDF, ADF, ADL, hemicellulose (HC) and cellulose (C) content (\% of defatted meal) in three DH populations of winter oilseed rape

Table 3.3 Minimum, maximum and mean values for NDF, ADF, ADL, hemicellulose (HC) and cellulose (C) content (\% of seed basis), seed hull proportion (\%), thousand kernel weight (TKW in g), seed oil (\%), seed protein (\%), protein of defatted meal (\%), glucosinolate (GSL in $\mu \mathrm{mol} / \mathrm{g}$ ) and erucic acid (\%) in seeds of three DH populations of winter oilseed rape.

Table 3.4 Spearman's rank correlation of fibre fractions of defatted meal (suffix m), seed oil, protein content of defatted meal, seed hull proportion and thousand kernel weight

Table 3.5 Spearman's rank correlation for seed fibre content (suffix s) and other quality traits

Table 3.6 Mapped QTL and their most likely positions for NDF, ADF, ADL, hemicellulose (HC) and cellulose (C) content (\%) on the basis of defatted meal (suffix m) and seeds (suffix s) in the Sollux x Gaoyou population . .58

Table 3.7 Mapped QTL and their most likely positions for NDF, ADF, ADL, hemicellulose (HC) and cellulose (C) content (\%) on the basis of defatted meal (suffix m) and seeds (suffix s) and other quality traits in Express617 x R53 population .59

Table 3.8 Mapped QTL and their most likely positions for NDF, ADF, ADL, hemicellulose (HC) and cellulose (C) content (\%) on the basis of defatted meal (suffix m) and seeds (suffix s) and other quality traits in SG DH14 x Express 617 population.....61

Table 4.1 Variance components and heritabilities for NDF, ADF, ADL, hemicellulose (HC) and cellulose (C) content ( $\%$ of defatted meal - suffix $m$ and $\%$ of seed basis suffix s), seed hull proportion (Hull, \%), thousand kernel weight (TKW, g), seed oil and seed protein content (\%), and protein content of defatted meal (PodM, \%) of 81 canola quality winter oilseed rape cultivars

Table 4.2 Minimum, maximum and mean values for NDF, ADF, ADL, hemicellulose (HC) and cellulose (C) content ( $\%$ of defatted meal - suffix m and \% of seed basis - suffix s), seed hull proportion (Hull, \%), thousand kernel weight (TKW, g), seed oil and seed protein content(\%), and protein content of defatted meal (PodM in \%) of 81 canola quality winter oilseed cultivars. . .82 
Table 4.3 Spearman's rank correlation between fibre fractions and other quality seed traits .83

Table 4.4 Summary of the association analysis results by using the means of phenotypic data across 19 locations....................................................................................................

Table 4.5 Results from the association analysis in 81 canola quality winter oilseed rape cultivars. . .86 


\section{LIS T OF FIGURES}

Figure 1.1 World vegetable oil supply

Figure 1.2 World supply major protein meals (in million tons) and distribution (USDA 2014).

Figure 1.3 The detergent fibre system according to Van Soest et al. (1991) and adapted from $\mathrm{ANKOM}^{\mathrm{TM}}$ detergent fibre analysis system with filter bag technology (ANKOM Model 220; ANKOM Technology, Macedon, NY, USA; ANKOM 2013; ANKOM 2011a; ANKOM 2011b)

Figure 1.4 Development of NIRS calibration equation. 23

Figure 3.1 Frequency distribution of neutral detergent fibre (NDF) content of defatted meal in DH populations of winter oilseed rape: (I) Sollux x Gaoyou; (II) Express $617 \mathrm{x}$ R53; (III) SG DH14 x Express617

Figure 3.2 Frequency distribution of acid detergent fibre (ADF) content of defatted meal in DH populations of winter oilseed rape: (I) Sollux x Gaoyou; (II) Express $617 \mathrm{x}$ R53; (III) SG DH14 x Express617

Figure 3.3 Frequency distribution of acid detergent lignin (ADL) content of defatted meal in DH populations of winter oilseed rape: (I) Sollux x Gaoyou; (II) Express $617 \mathrm{x}$ R53; (III) SG DH14 x Express617 . .53

Figure 3.4 Correlation between seed glucosinolate and cellulose content of defatted meal in three DH populations.

Figure 3.5 QTL associated to fibre content showed overlapping confidence interval with QTL involved in other quality traits on linkage groups C08 of Sollux x Gaoyou, linkage group C03 of Express 617 x R53, and linkage group C03 of SG DH14 x Express 617.

Figure 3.6 Linkage group in Population III SG DH14 x Express 617 showed favorable QTL that have an effect to reducing fibre content and simultaneously increasing oil content (A08 and C05) and protein of defatted meal (A08) . .70

Figure 4.1 QTL associated with fibre-related traits (NDFs-12_AM, ADFs_3_AM, ADLs-5_AM markers in red) in canola quality winter oilseed rape cultivars collocated with QTL responsible for NDF, ADF and ADL previously mapped on linkage group C03 of Express 617 x R53 (markers in black), and QTL associated with oil content (Oil-13_AM) and hemicellulose content (HCm-4_AM) collocated with QTL for oil and hemicellulose content on linkage group C09 in DH population Express $617 \mathrm{x}$ R53 (see Chapter 3). Dark red area on linkage group C03 and C09 represents confidence interval of QTL for ADL content of seed and seed oil content in DH population Express 617 x R53, respectively. . .90

Figure 4.2 Selection of canola quality winter oilseed rape cultivars for further breeding in improved meal quality based on seed oil content and NDF of defatted meal. The 
dash lines represent the means of oil content and of NDF of defatted meal (see Table 4.2)

Figure 5.1 An SNP marker p28950 associated with fibre content located on linkage group C05 at the position $35 \mathrm{cM}$ showed clustering between genotypes bringing SG DH14 allele (black colour) and Express 617 allele (red colour) based on ADL content. 


\section{CHAPTER 1}

\section{General Background}

\subsection{Importance of oilseed rape}

Oilseed rape (Brassica napus L.) is the third largest source of vegetable oil and the most important oil crop in Europe and other temperate regions. The production of oilseed rape oil in 2012 was 24.5 million tons (Fig. 1.1) and contributed to about 15\% of the global vegetable oil supply (OVID 2013, www.ovid-verband.de). The major regions for rapeseed oil production are located in European Union countries (EU-28), China, Canada, India and Japan. About 9.5 million tons of rapeseed oil was produced in the EU-28 countries, which is equivalent to $37 \%$ of total oilseed rape production. Cultivation area of oilseed rape is predicted to increase, particularly in European regions where renewable sources of energy are becoming more important to national and regional interest.

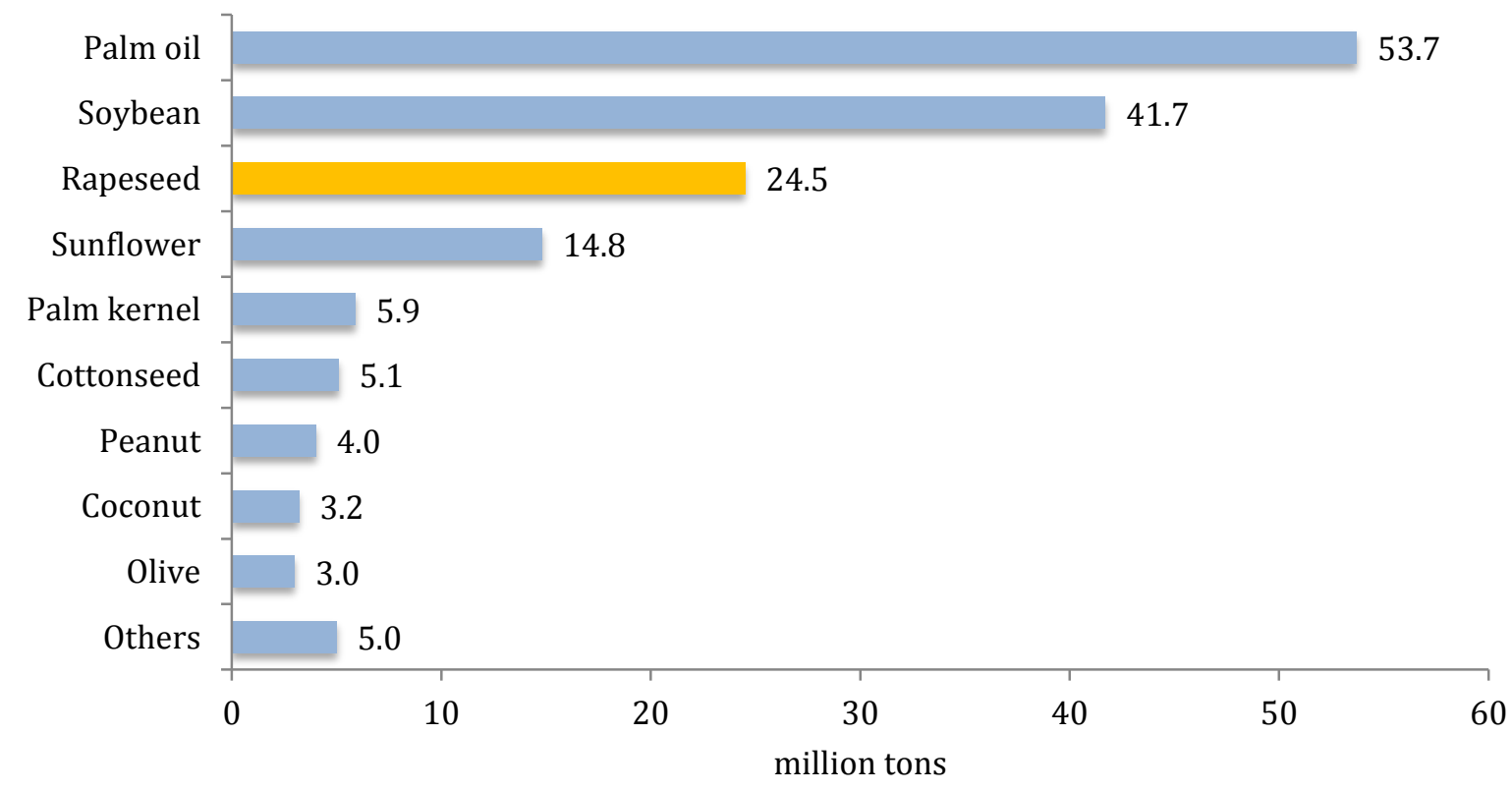

Figure 1.1 World vegetable oil supply (OVID 2013, www.ovid-verband.de)

Oil from oilseed rape is known as high quality vegetable oil for human consumption as well as best source for environment-friendly products such as biodiesel (Abbadi and Leckband 2011; $\mathrm{Wu}$ and Muir 2008). To meet the demand of vegetable oil for food and biofuel, most parts of the 
world grow 'canola'- or 'double low' quality oilseed rape with low erucic acid and low seed glucosinolate content. Other oilseed rape cultivars for oleochemical industry have also been available with high erucic content (Nath et al. 2008). For the crushing industry, the main value of oilseed rape is determined by the high oil content of the harvested seed, in spite of some value of the protein fractions for the feed industry (Nesi et al. 2008).

\subsection{Oilseed rape meal}

Apart from being cultivated for its high oil content for food and fuel industries, the meal from oilseed rape as a by-product of processing industry is a valuable product. Total production of oilseed rape meal in EU countries is about 12.7 million tons (FEDIOL 2013), and it will increase in accordance to the growing demand of rapeseed oil for food and fuel. USDA (2014) reported that oilseed rape meal contributed about $14 \%$ of the total 281.5 million tons major protein meals supply (Fig. 1.2). The use of protein meal from oilseeds, including oilseed rape, soybean and sunflowers is projected to grow faster in the coming ten years due to the faster development of livestock production and increasing feed intensity of protein meal (FAO 2013).

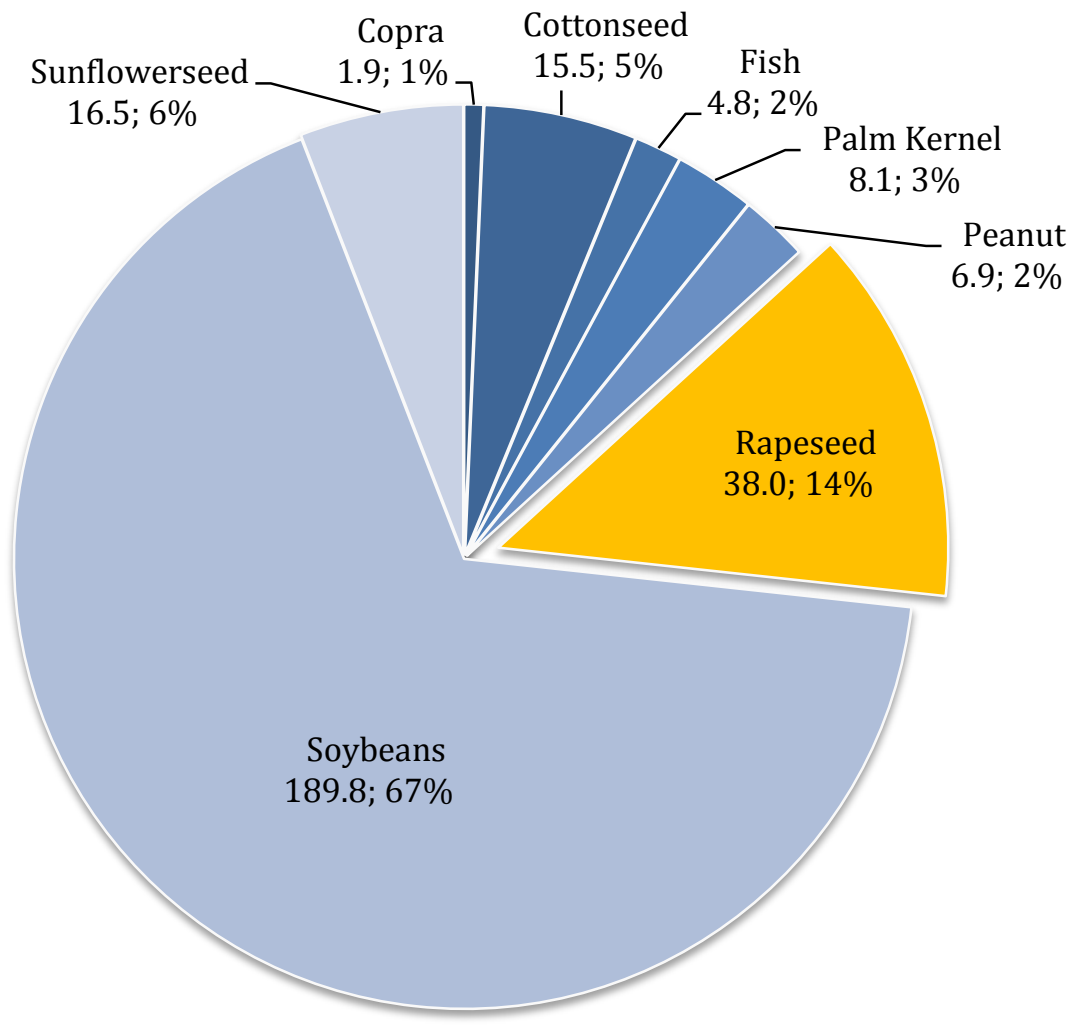

Figure 1.2 World supply major protein meals (in million tons) and distribution (USDA 2014) 
Concerning nutritional values, oilseed rape meal is becoming a potential substitution for soybean meal in livestock feed mixtures due to its high protein content and its excellent balanced composition of essential amino acids (Tan et al. 2011). Protein content of the defatted oilseed rape meal is about 37\% (Table 1.1). Protein plays important role as the main source of energy in the feed and its quality is determined by the amino acid composition. In comparison with soybean meal, oilseed rape meal has higher contents of threonine and of the sulphurcontaining amino acids methionine and cysteine. Methionine is an essential amino acid for animals, particularly for poultry production, and has a significant impact on feather growth and protein synthesis (Bunchasak 2009).

Table 1.1 Chemical composition of oilseed rape and soybean meal

\begin{tabular}{lccc}
\hline Component & Unit & Oilseed rape meal & Soybean meal \\
\hline Crude protein & $\%$ & 36.5 & 45.6 \\
Amino acid & $\%$ & 2.0 & \\
$\quad$ Arginine & $\%$ & 2.0 & 3.2 \\
$\quad$ Lysine & $\%$ & 1.6 & 2.9 \\
$\quad$ Threonine & $\%$ & 0.7 & 1.7 \\
$\quad$ Methionine & $\%$ & 0.9 & 0.6 \\
$\quad$ Cysteine & $\%$ & & 0.7 \\
Dietary fibre fractions & $\%$ & 26.0 & 12.0 \\
$\quad$ Neutral detergent fibre (NDF) & $\%$ & 18.2 & 7.5 \\
$\quad$ Acid detergent fibre (ADF) & $\%$ & 1.0 & 2.6 \\
$\quad$ Lignin and polyphenols & $\mu \mathrm{mol} / \mathrm{g}$ & 5.5 & - \\
Sinapine & $\mathrm{kcal} / \mathrm{kg}$ & 2000 & - \\
Total glucosinolates & & & 2230 \\
Metabolizable energy & & & \\
\hline
\end{tabular}

Source: Khajali and Slominski (2012)

The influence of the level of oilseed rape meal protein included in feed rations is mainly a reflection of the energy costs (Downey and Bell 1990). Many studies have been conducted to evaluate the effect of oilseed rape meal on the performance of ruminant, poultry and monogastric animals. Meta-analysis conducted by Huhtanen et al. (2011) showed that oilseed rape meal can be applied as substitution for soybean meal in lactating dairy cow diets without any effect in milk production. Maupertuis et al. (2011) suggested that regular oilseed rape meal could be fed in all stages of pig production without any effect on performance and carcass quality, if the maximum of $18 \%$ in the feeding diet is not exceeded and its glucosinolate content remains below $5 \mu \mathrm{mol} / \mathrm{g}$. Khajali and Slominski (2012) proposed that the rations for broilers or laying hens could contain $20 \%$ of canola meal without producing any adverse effects. The nutritional value of oilseed rape meal could potentially be increased for feeding purposes when 
limiting factors such as fibre content and antinutritive compounds as sinapine are reduced (Abbadi and Leckband 2011).

\subsection{Antinutritive components in oilseed rape meal}

Despite the excellent balance of amino acids, the presence of antinutritive components in oilseed rape meal is the major obstacle for its use in animal feeding. These antinutritive components are glucosinolates, phenolics, phytic acid and fibre fractions of the seed hull. Glucosinolates are amino acid-derived secondary plant products that contain a sulphate and thioglucose moiety (Halkier and Du 1997). As reviewed by Röbbelen and Thies (1980) glucosinolates are widely distributed among the component parts of Brassica plants and maximum concentration are found in the seed embryo at full maturity. Glucosinolates are recognized by their pungent taste that is primarily due to their isothiocyanate hydrolysis products (Halkier and Gershenzon 2006). In oilseed rape meal, the presence of pungent taste reduces the acceptance of the feed by the animals. Glucosinolates have been found to reduce animal performance and impair thyroid function in growing animals (Bell 1984; Mailer et al. 2008). The identification of low glucosinolate gene(s) in the Polish spring rape variety 'Bronowski' in 1967 (Kondra and Stefansson 1970) provided the basis for international backcrossing program to introduce this polygenic low glucosinolate trait into high yielding erucic acid-free cultivars (Abbadi and Leckband 2011). At present, the glucosinolate content in modern oilseed rape cultivars in Germany ranges between 12.0 - $17.9 \mu \mathrm{mol} / \mathrm{g}$ (Bundessortenamt 2013). The union for the promotion of oil and protein plants in Germany (UFOP 2008) on its background paper stated that the target currently pursued in Germany and also on a European level is a reduction of the generally acceptable maximum glucosinolate content in oilseed rape to less than $8 \mu \mathrm{mol} / \mathrm{g}$ as the quality desired for the future global development.

Phenolic compounds are considered as principal antinutritive components in oilseed rape. The predominant phenolics present in oilseed rape are phenolic acids and condensed tannins (Naczk et al. 1998) which have been correlated with antioxidant capacity (Szydłowska-Czerniak et al. 2010). Phenolic acids are present in the free phenolic, esterified and insoluble-bound forms. These components have been shown to cause a dark colour, a bitter taste and astringency of oilseed rape meal (Zum Felde et al. 2007; Naczk et al. 1998; Shahidi and Naczk 1992). They and their oxidized products may also form complexes with essential amino acids and other proteins thus lowering the nutritional value of oilseed rape meal products (Naczk et al. 1998). The total content of phenolic acids in oilseed rape meal is up to $18.4 \mathrm{~g} / \mathrm{kg}$ (Naczk et al. 
1998). This content is much higher than in other oleaginous seeds and amounts to about 30 times that in soybean meal (Shahidi and Naczk 1992).

Tannins are complex phenolic compounds that can be classified into condensed and hydrolysable types based on their structure and their reactivity towards hydrolytic agents (Kozlowska et al. 1990). Most of the tannins in oilseed rape are condensed tannins known as proanthocyanidins (Rezaeizad et al. 2010), and they accumulate predominantly in the endothelium cell layer between the outer integument and the aleuronic layer of seed hulls (Lipsa et al. 2012; Marles and Gruber 2004). The amount of tannins in oilseed rape meal varies from 0.2 to $3 \%$ depending on the variety, the degree of maturation and the extraction method (Naczk et al. 1998). Tannins can form soluble and insoluble complexes with proteins and this may be the reason for their antinutritional effects for non ruminant and ruminant animals (Naczk et al. 2000).

Phytic acid is another antinutritive component found in oilseed rape meal, existing as $\mathrm{Ca}, \mathrm{K}$ and Mg salts (phytates) (Tan et al. 2011). The level of phytate in oilseed rape meal ranges from 2.9 to $3.2 \%$ (Zhou et al. 1990). The formation of phytic acid-mineral complexes decreases the availability of minerals. Phytic acid also binds to proteins, reducing the protein digestibility and amino acid availability. Non ruminant animals utilize the protein in oilseed rape meal less effectively than that of soybean meal (Yin et al. 1994) and this may also be related to the elevated levels of phytate (Newkirk and Classen 1998).

\subsection{Fibre fractions in oilseed rape meal}

The presence of comparatively high fibre content is one of the limiting factors for the use of oilseed rape meal as protein source for animal feed. Fibre was initially defined as the skeletal remain of plant cells that are resistant to hydrolysis by digestive enzymes (Selvendran 1987). This definition implied that fibre is derived primarily from plant cell walls, including cellulose, hemicellulose and lignin. Fibre is poorly digestible and essentially dilutes the available energy and protein. Consequently, oilseed rape meal has less metabolizable energy (Table 1.1) and reduces the value of the meal relatively to soybean meal.

Cellulose is a key component of plant cell walls. It is comprised of hydrogen-bonded B-1,4linked glucan chains that are synthesized at the plasma membrane by large cellulose synthase (CESA) complexes (Mutwil et al. 2008). The combination of the chair conformation of the glucose and interchain hydgrogen bonding gives cellulose molecules a very stable structure (Weimer 1992). In relation to animal feed, cellulose plays an important role as energy source particularly for ruminant animals. Cellulose can be degraded by cattle and other grazing animals 
with the help of microbial enzymes in the rumen (Weimer 1992). Cellulose can also be turned into feed for non-ruminant animals like poultry and swine with the help of enzymes. In oilseed rape meal, cellulose content ranges between 4.6 and 5.7\% (Slominski et al. 2012; Slominski and Campbell 1990).

Hemicelluloses are polysaccharides synthesized in Golgi membranes that have $ß-(1 \rightarrow 4)$-linked backbones with an equatorial configuration. The polysaccharides include xyloglucans, xylans, mannans and glucomannans, and $ß-(1 \rightarrow 3,1 \rightarrow 4)$-glucans (Scheller and Ulvskov 2010). In the primary cell wall of dicotyledonous species and non graminaceous monocotyledons, the most common hemicellulose is xyloglucan (Albersheim et al. 2010) which have a 'cellulosic' backbone consisting of $\beta$-1,4-linked glucan residues. Hemicelluloses are intimately associated with cellulose by multiple hydrogen bonds between xyloglucans and cellulose (Scheller and Ulvskov 2010). Regarding nutritional availability, hemicelluloses are mostly classified as non-cellulosic polysaccharides and they are partially digested in the ruminant digestive system and poorly digested by non-ruminants (Soest 1967). In oilseed rape meal, the content of hemicellulose is about 13.8 to $14.3 \%$ (Slominski et al. 2012).

Lignin is a complex phenolic polymer which is formed from monolignols derived from the phenylpropanoid pathway (Bonawitz and Chapple 2010). Lignin is deposited in plant cell walls as part of cell maturation after cell elongation has ceased and it confers strength, rigidity and hydrophobicity. It is found mainly as component of the secondary cell wall and impregnates the cellulose and hemicellulose matrix found there. Lignin is considered as a quality reducing component because of its negative impact on nutritional availability of animal feeds. Lignin interferes with the digestion of cell-wall polysaccharides (cellulose and hemicellulose) by acting as a physical barrier to microbial enzymes (Moore and Jung 2001). Lignification level controls the amount of polysaccharides that can be digested (Moore and Jung 2001) and therefore has direct impact on the digestible energy value of the feed (Jung and Allen 1995). Lignin content in oilseed rape meal is about $10.4 \%$, and is mostly coming from seed hull fraction (Slominski et al. 2012).

\subsection{Determination of fibre fraction}

The most common method used for determination of fibre content is the detergent system of feed analysis developed by Van Soest et al. (1991). The concept behind this detergent system is that plant cell walls can be divided into less digestive cell walls comprising hemicellulose, cellulose and lignin, and easy digestible cell contents comprising starch, sugars and protein. The separation of these two components can be done through a digestion process at high 
temperature by using two different detergent solutions: (i) neutral detergent and (ii) acid detergent (Fig. 1.3).

The remaining component of the feed sample after the digestion with neutral detergent solution is called neutral detergent fibre (NDF). Neutral detergent fibre (NDF) represents the total cell wall comprising cellulose, hemicellulose and lignin (Soest 1967). NDF value is important for nutritionist when creating animal feed ration formulations, because this value reflects the amount of feed that animals can consume (Jung et al. 1997; Möller 2008; Saun 2006). As NDF percentage increases, dry matter intake will generally decrease.

Acid detergent fibre (ADF) value is obtained after the digestion of feed sample with acid detergent solution ( $\sim 5 \%$ sulfuric acid). ADF value refers to the proportions of the feed/meal that are made up of cellulose and lignin. The value relate to the ability of an animal to digest the feed. When ADF value increases, digestibility of the feedstuff decreases. Livestock nutritionists have been using ADF and NDF as indicators of dietary energy and intake, particularly for ruminants ration (Möller 2008). ADF and NDF values are used to estimate the amount of forage that can be digested by animals. Other functions of ADF and NDF values are to calculate the total digestible nutrients, to price hay and to assess forage management, harvest and storage skills (Möller 2008).

Acid detergent lignin (ADL) value represents the percentage of indigestible lignin in the feed. The ADL value is determined from ADF samples after the digestion process in strong sulfuric acid (72\% sulfuric acid). As ADL value increases, digestibility and feed intake usually decrease (Jung and Allen 1995). 


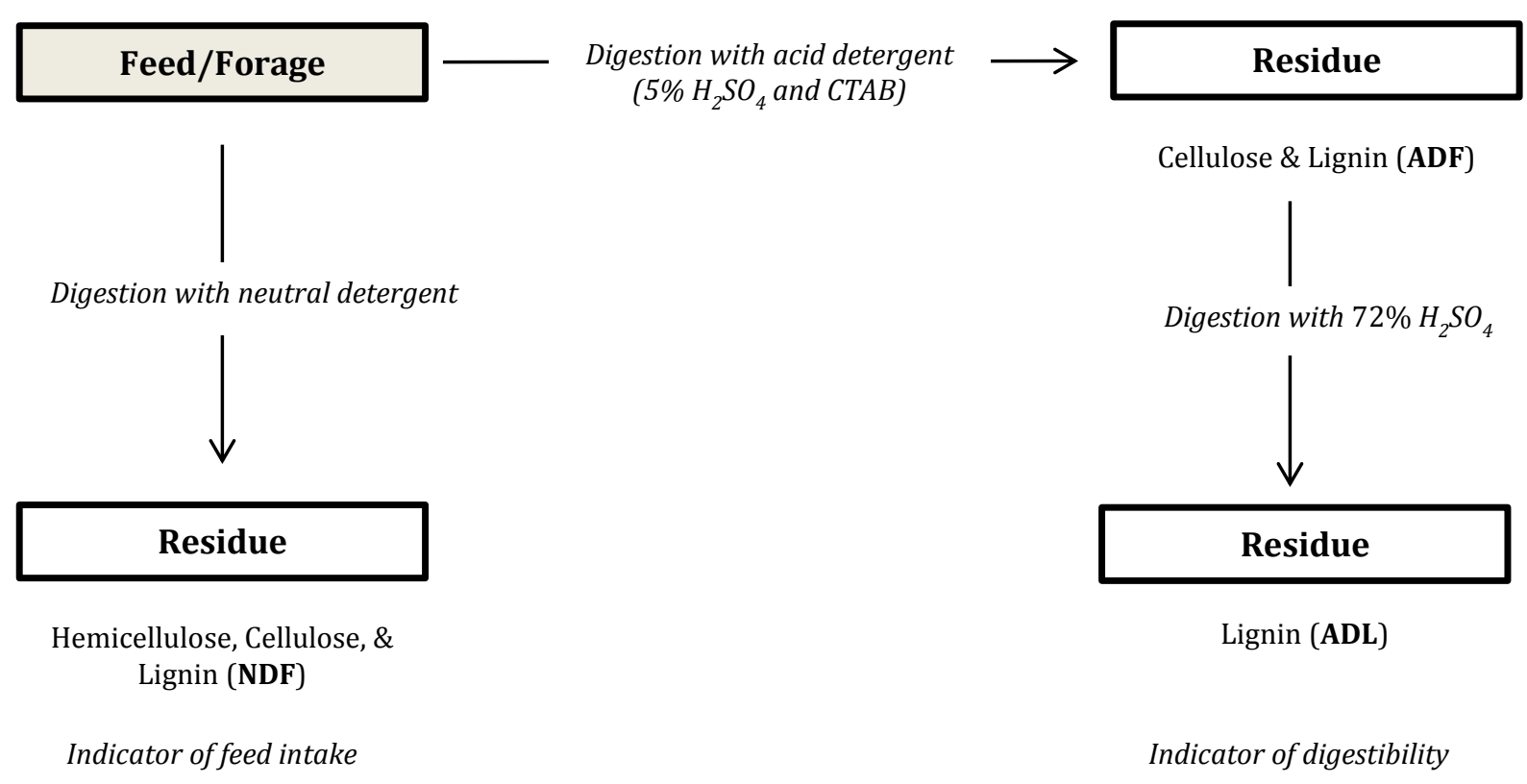

Figure 1.3 The detergent fibre system according to Van Soest et al. (1991) and adapted from ANKOM $^{\mathrm{TM}}$ detergent fibre analysis system with filter bag technology (ANKOM Model 220; ANKOM Technology, Macedon, NY, USA; ANKOM 2013; ANKOM 2011a; ANKOM 2011b)

\subsection{Relevance of seed hull to oilseed rape meal quality}

The seed hull of oilseed rape is derived from the ovule integuments (Jiang and Deyholos 2010) and consists of several layers of specialized maternal cell types that provide an important interface between the embryo and the external environment. This interface is particularly important during embryogenesis, dormancy and germination (Haughn and Chaudhury 2005). The seed coat contains a palisade layer, a single layer of cells which have thick secondary cell walls. In yellow-seeded B. napus, the palisade layer is about two-thirds thinner than in black/brown-seeded lines (Rahman et al. 2001; Stringam et al. 1974).

Seed hull accounts for about $15 \%$ of seed dry matter in winter oilseed rape and for up to $18 \%$ in spring cultivars (Shirzadegan and Röbbelen 1985), and it constitutes to about $28-30 \%$ of the oilseed rape meal. The seed hull proportion in oilseed rape depends on the seed size where larger seeds show a clear tendency towards a lower proportion of seed hulls (Jensen et al. 1995; Minkowski 2002).

Seed hull has an important role in affecting quality of oilseed rape meal because most antinutritive components such as lignin and phenolics are accumulated in seed hull (Bell 1993). The hull of oilseed rape contains high fibre fraction with the composition of $23 \%$ lignin, $20 \%$ cellulose, 20\% protein, 9\% pectin, and 5\% ash (Bell and Shires 1982). In recent results, Kracht et al. (2004) found 14\% crude cellulose, $14.5 \%$ hemicellulose and $25.8 \%$ lignin in seed hulls of 
the black-seeded variety Express. The presence of high lignin and phenolic compounds in the seed coat contributes to the negative value of oilseed rape meal as animal feed. Removal of seed hull from oilseed rape resulted in improved digestibility of the protein by reducing antinutritive factors.

Several studies on the effect of removing the hulls (called "dehulling") on oilseed rape meal quality have been conducted. Dehulling and excluding the hull from oilseed rape seeds prior to oil extraction increases the protein content of the meal from 38.8 to 43.7\% (Minkowski 2002), reduces the fibre content from 11 to $6 \%$ (Ikebudu et al. 2000) as well as decreases the content of condensed tannins (Matthäus 1998). The advantage of dehulling is the decrease of lignin content which amounts to $50 \%$ for black seeded oilseed rape meal (Kracht et al. 2004). However, dehulling leads to an increase of glucosinolates, sinapine and inositol phosphates (Matthäus 1998). In addition, the mechanical separation of hulls from oilseed rape seeds is still inefficient and is not a standard practice in oilseed rape extraction plants (Naczk et al. 1998).

Research conducted by Bell and Shires (1982) and Jensen et al. (1995) showed that there was a highly significant positive correlation between seed hull proportion and lignin content, and a negative correlation between seed hull proportion, and protein and energy digestibility. Other study by Yan et al. (2009) showed that seed hull proportion was negatively correlated with seed oil content. The reduction of seed hull in yellow-seeded oilseed rape is associated with an increase in seed oil and protein content per dry weight because of the proportional increase in the contribution of the embryo to seed volume (Badani et al. 2006). It was suggested that a selection for larger seeds will be nutritionally beneficial due to the impact to lower proportion of seed hull and have indirect effect to the lower fibre content.

\subsection{Oilseed rape breeding for improved meal quality}

Breeding program for oilseed rape quality improvement has been largely driven by consumers and food industry demands. The primary objectives of oilseed rape breeding are to increase seed oil content, to reduce content of undesirable fatty acids, to improve oil stability to diversify application and to improve meal energy value for feed (Nesi et al. 2008). Concerning improvement of meal quality for feed purposes, breeding efforts are undertaken to reduce contents of fibres and other antinutritive components. There are a variety of characters that may indirectly affect the level of fibre content in oilseed rape meal such as seed size, seed hull proportion, seed color and chemical composition of the hull (Bell 1993).

Selection for improvement of meal quality so far mostly focused on yellow-seeded oilseed rape because of their desirable characteristic associated with thinner seed hull and lower fibre 
content (Rahman 2001; Stringam et al. 1974). Yellow-seeded B. napus has been developed from interspecific crosses with related species, because there is no naturally occurring yellow seededness in B. napus (Rahman and McVetty 2011). Different interspecific crosses have been performed to develop yellow-seeded B. napus material, for instance between B. napus x B. carinata and B. napus x B. juncea (Rashid et al. 1994), B. alboglabra x B. rapa and B. carinata $\mathrm{x}$ B. rapa (Rahman et al. 2001), B. napus x B. campestris, and B. campestris $\times$ B. oleracea (Tang et al. 1997).

Evaluation of fibre content in the meal derived from yellow-seeded oilseed rape has been conducted in comparison to brown- and black-seeded types. Yellow- and brown-seeded types exhibited a 3\% reduction in fibre and hull contents as compared to the common black-seeded oilseed rape (Shirzadegan and Röbbelen 1985). Simbaya et al. (1995) reported that dietary fibre in yellow-seeded types averaged 28\%, lower than that of brown-seeded ones (33\%). In addition, Simbaya et al. (1995) also stated that lower dietary fibre in yellow-seeded samples compared to brown-seeded was accompanied by a lower content of lignin and associated polyphenols. Rahman et al. (2001) have identified that the fibre content of yellow-seeded $B$. napus developed from interspecific crosses was 55\% lower than that of black-seeded genotypes from the same genetic background. In the investigation of seed quality of yellow seeded B. napus from diverse genetic backgrounds, Tang et al. (1997) reported that the cellulose content of the yellow-seeded types is $17.7 \%$ higher than that of the brown-seeded. Rakow et al. (2007) in an evaluation of agronomic and quality performance of yellow- and black-seeded B. napus canola found that the lignin content in yellow-seeded types was $4.1 \%$ lower than in the black-seeded. Recent results of the fractionation study from Slominski et al. (2012) concluded that the reduction in fibre content observed in the meal derived from yellow-seeded B. napus is a consequence of bigger seed size, lower contribution of the hull fraction to the total seed mass and lower lignin content of the hull fraction.

Correlation between oil, protein and fibre content is an important factor to be considered in the selection of low fibre genotypes. Rahman et al. (2001) reported that the sum of oil and protein content in yellow-seeded B. napus to be 3\% higher than in black-seeded. Similar results were also obtained by Rakow et al. (2007) who showed that the oil content in yellow-seeded B. napus was $3.3 \%$ higher than in black-seeded, but the protein content was $2.1 \%$ lower. Different results have been described by Tang et al. (1997) who reported that the oil content in embryo does not appear to differ between yellow and brown seeds, and yellow seeds have higher oil content because their embryo to seed ratio has increased as a consequence of larger seeds as well as because of an increase of oil content in the seed coat. This argument was confirmed by Hu et al. (2013) who studied the ultrahigh oil content of B. napus YN171 lines. Hu et al. (2013) found that 
the very high oil content (64.8\%) in this genotype was due to the high ratio of oil bodies to cotyledon cells and due to a higher proportion of oil bodies in aleuronic cells of the seed coat. Hu et al. (2013) have also suggested that to reach high oil content, the seed coat should be thin, but not necessarily needs to be yellow, because they found some black-seeded lines which also had high oil content.

Breeding for yellow-seeded B. napus, however, still encounters difficulties because of strong environmental effects (Burbulis and Kott 2005). The yellowness of the seed in B. napus was affected by the growth temperature, whereby an increase of yellowness was associated with higher temperatures (Burbulis and Kott 2005; Deynze et al. 1993). In addition, efforts to develop true breeding yellow oilseed rape that consistently produces pure and bright yellow seeds under a wide range of environmental conditions have so far not been successful. More recently, Snowdon et al. (2010) reported that the broad-sense heritability for seed colour $\left(h^{2}=\right.$ 0.51) were lower than that for fibre components $\left(h^{2}=0.79\right.$ for ADL), which reflects high environmental influence on seed colour and underlines the comparative benefit of selecting directly for fibre content in breeding for improved oilseed rape meal quality.

Recently, selection for low fibre content has also been conducted in black-seeded B. napus material. Taking advantage of natural genetic variation for fibre content among black-seeded germplasm may complement ongoing approaches to reduce fibre content in oilseed rape meal as well as to increase oil and protein content in the seed. The studies of Wittkop et al. (2012) revealed relatively large genetic variation for NDF, ADF and ADL content among modern blackseeded European winter oilseed rape cultivars and breeding lines. These variations have opened the opportunity to develop material with low fibre content within black-seeded B. napus populations. Until now, little is known about the inheritance of fibre content in doubled-haploid populations of black-seeded winter oilseed rape. Understanding the genetic basis of fibre fractions and their interaction with other seed components in black-seeded B. napus may contribute to breeding improved oilseed rape meal quality.

\subsection{Mapping of QTL associated with fibre components in B. napus}

The selection of specific genotypes with desirable traits is the fundamental basis of plant breeding. It typically involves evaluating a breeding population for one or more traits in greenhouse and field experiments or with chemical test. The goal of plant breeding is to assemble more desirable combinations of genes in new varieties (Collard and Mackill 2008). Markers are required that may assist breeders for doing the selection, either morphological marker or molecular marker (DNA). 
Many important traits in crop, such as yield and yield components, quality and some forms of disease resistance are mostly controlled by many genes and are known as quantitative, polygenic or complex traits (Collard et al. 2005). These quantitative traits are typically affected by environment (Doerge 2002). A region within a genome that contains a gene associated with a particular quantitative trait is called quantitative trait locus (QTL). In the selection of desired quantitative traits which are difficult to assess, environmentally affected, and controlled by many genes, the use of molecular marker is more effective (Rahman and McVetty 2011). Identification of molecular markers tightly linked to traits of interest could facilitate the selection of desired traits at very early stages of plant development.

Detection of QTL or genetic mapping can be carried out through two approaches: (1) linkage analysis by using a purpose-created population, such as a bi-parental mapping population and (2) association analysis by using a collection of individuals derived from wild populations, germplasm collections, cultivars, or subsets of breeding germplasm (Rafalski 2010). In linkage analysis using bi-parental populations, identification of QTL is based on the principle of detecting an association between quantitative trait and markers segregating in the population (Kearsey and Farquhar 1998). Markers are used to partition the mapping population into different genotypic groups based on the presence and absence of a particular marker locus and to determine whether significant differences exist between groups with respect to the trait being measured (Collard et al. 2005). A significant difference between phenotypic means of the groups indicates that the marker locus used to partition the mapping population is linked to a QTL controlling the trait.

Unlike linkage analysis where familiar relationship are used to predict correlations between phenotype and genotype, association analysis method relies on previous, unrecorded sources of linkage disequilibrium to study the relationship between phenotypic variation and genetic polymorphism (Flint-Garcia et al. 2003). Linkage disequilibrium (LD) is the nonrandom combination of alleles at two genetic loci, which in random mating populations is mostly generated by mutation, and genetic drifts and decays by recombination (Breseghello and Sorrells 2006). The individuals of a mapping population in association analysis do not have to be closely related. Detection of QTL in association analysis based on LD between QTL and linked markers is strongly dependent on the extent and structure of LD in the population analysed (Honsdorf et al. 2010).

Research in yellow-seeded B. napus has allowed the identification of quantitative trait loci (QTL) involved in seed quality. Some recent studies in QTL mapping have detected several regions from different B. napus chromosomes associated with fibre components and seed hull content 
through linkage analysis and association mapping. Working with three different mapping populations developed from crossings between yellow-seeded and black-seeded B. napus, Badani et al. (2006) identified a major QTL with large effect on both seed colour and ADF content at the same position on chromosome N18 ( C08). This QTL was detected in all three populations in multiple environments. Combined QTL and segregation data for seed colour and ADF content in the different populations suggested that a partially dominant B. napus gene for seed colour on chromosome N18 contributes to a reduction in fibre content in yellow-seeded genotypes (Badani et al. 2006).

Association analysis of 49 genetically diverse winter-type B. napus inbred lines conducted by Snowdon et al. (2010) has led to the identification of a major QTL influencing seed colour, fibre content and phenolic compounds on chromosome A09. The same QTL was also identified on linkage group A09 in a bi-parental mapping populations derived from black-seeded x yellowseeded B. napus crosses Express 617 x 1012-98 (Snowdon et al. 2010). A comparison of the partial genetic map of B. napus chromosome A09 in the cross Express 617 x 1012-98 with a corresponding genome sequence of $B$. rapa genome revealed potential positional and functional genes for seed colour and fibre (ADL) traits (Snowdon et al. 2010). More recently, the study with recombinant inbred lines (RIL) population derived by single seed descent from $\mathrm{F}_{2}$ offspring of a cross between GH06 (yellow-seeded) and P174 (black-seeded), Liu et al. (2012) detected a significant QTL for ADL content in chromosome A09. Fine mapping in $\mathrm{BC}_{1} \mathrm{~F}_{2}$ plants from a cross of an $\mathrm{F}_{7}$ RIL from above-mentioned population and the parent P174 indicated that a single, dominant, major locus causes substantial reduction in ADL content (Liu et al. 2012). Further, Liu et al. (2012) identified the important lignin biosynthesis gene CINNAMOYL CO-A REDUCTASE 1 (CCR1) - a key enzyme in phenylpropanoid biosynthesis - as a positional candidate with very close physical vicinity to markers that are tightly linked to the major dominant locus for low seed coat ADL content.

Concerning seed hull content, Jin et al. (2007) identified four QTL responsible for seed hull content that individually contributed to phenotypic variation ranging from $4.9 \%$ to $6.8 \%$ in a RIL population of B. napus segregating for yellow-seed colour. Yan et al. (2009) reported twelve QTL associated with seed hull content and four QTL responsible for seed coat colour in the RIL population developed from a cross between yellow-seeded and black-seeded parents. They also found co-localization between QTL for seed hull, seed coat colour and seed oil content on chromosome N08. 


\subsection{The use of Near-Infrared Reflectance Spectroscopy for fibre content determination}

Near-infrared reflectance spectroscopy (NIRS) is a technique that uses the radiation absorbed by a set of samples in the region of electromagnetic spectrum range from $780-2526 \mathrm{~nm}$ (Reich 2005) to develop calibration equation that are related to samples properties (Fig. 1.4). Calibration development is the process in which spectral variation is related to variation in the concentration of organic constituents of the samples as revealed by reference laboratory methods (Stuth et al. 2003). After calibration, the regression equation permits accurate analysis of other samples by prediction of data on the basis of the spectra (Font et al. 2003). NIRS has several advantages when compared to chemical-based analysis because it is non-destructive, rapid, and cost effective, does not require labor intensive sample processing, is environmentally safe and allows the simultaneous estimation of several traits in one sample (Stuth et al. 2003).

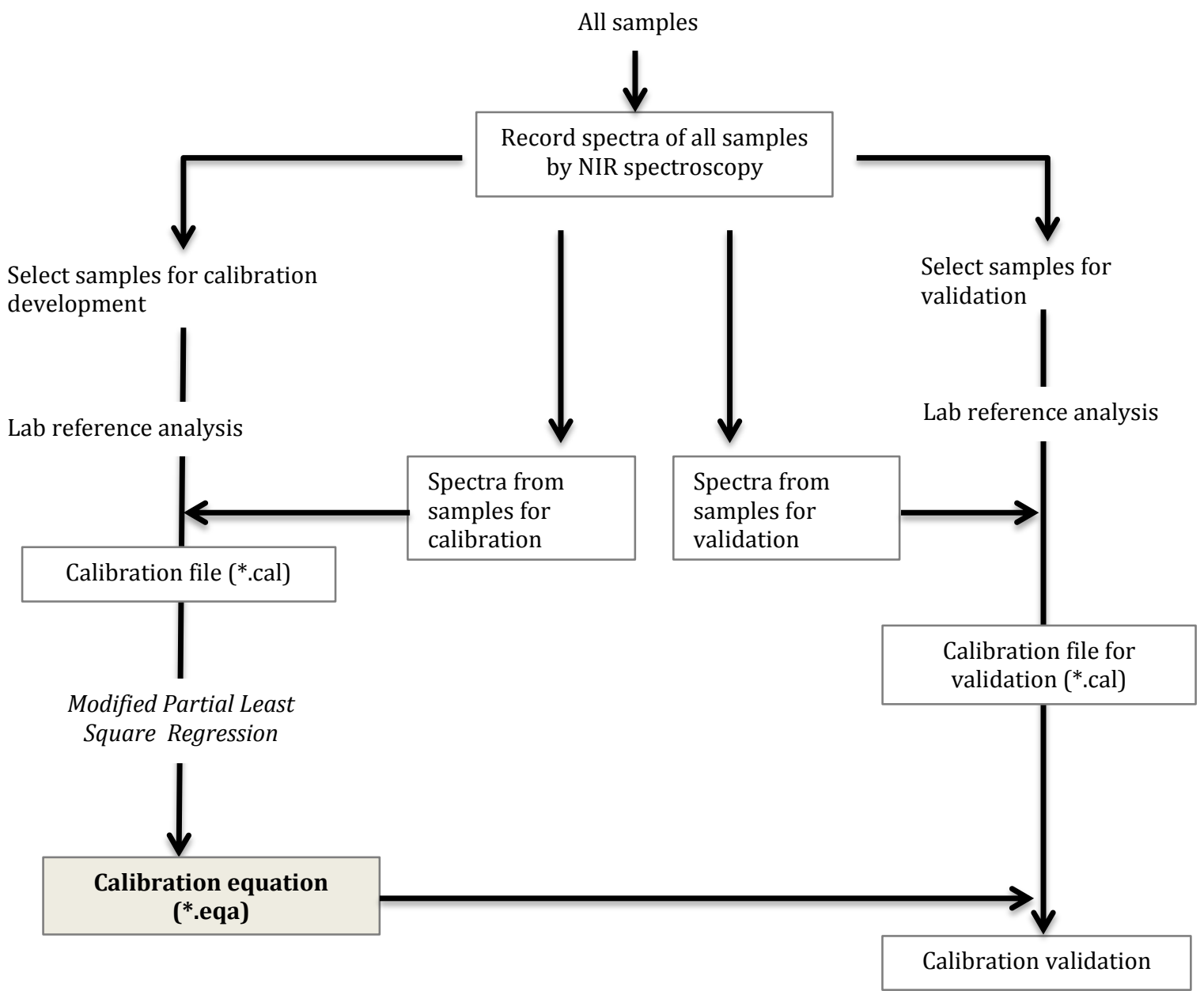

Figure 1.4 Development of NIRS calibration equation 
NIRS have been widely used for the analysis of quality traits from many different crops. In oilseed rape breeding, NIRS has been used to estimate seed weight as well as the content of many important traits such seed oil (Velasco et al. 1999), protein (Velasco and Möllers 2002), glucosinolate (Hom et al. 2007; Velasco and Becker 1998a), fatty acids like oleic, linoleic and linolenic acid (Velasco and Becker 1998b), erucic acid (Sasongko and Möllers 2005), sinapate esters (Zum Felde et al. 2007) and phytosterols (Amar et al. 2009). In forages, NIRS has been used for the analysis of many compounds including protein, moisture and acid detergent fibre content as well as grain hardness, (Batten 1998). Many authors have reported successful results in predicting fibre content by NIRS in different crops, such as maize (Cozzolino et al. 2000), barley (Gous et al. 2012), alfalfa (Brogna et al. 2010), rice stem (Kong et al. 2005) and wheat (Stubbs et al. 2010).

To date only few studies have been done regarding the use of NIRS for determination of fibre content in oilseed rape. Font et al. (2003) have studied the potential of NIRS for determining the acid detergent fibre (ADF) content in seeds of Brassica species, including B. juncea, $B$. carinata and B. napus. They concluded that NIRS can be used to evaluate ADF content in Brassica oilseeds with sufficient accuracy for use as a screening tool in plant breeding program. Wittkop et al. (2012) have developed the NIRS calibration from 338 diverse winter oilseed rape genotypes for the estimation of $\mathrm{NDF}, \mathrm{ADF}$ and $\mathrm{ADL}$, and demonstrated that the developed calibration can be effectively used for selection in both young and advanced breeding materials.

The reliability of the estimation of fibre components or other compounds in routine analysis by NIRS is determined by the quality of calibration equation developed. In developing robust calibration equations, the types and origin of breeding materials used on calibration should be considered, and it requires a comprehensive set of samples representing the entire population (Shenk and Westerhaus 1991). Velasco and Becker (1998b) found that the accurate calibration equations were obtained for oleic, linoleic, linolenic and erucic acid due to the availability of samples covering a wide range of values for these traits. A large variation existing in the calibration data set led to the close relationship between NIRS and GC results. When the variability in the data set is scarce, a poor relationship was obtained, and makes the calibration equation unsuitable to use in routine analysis. The origin of breeding materials, in this term environmental condition during cultivation, was also an important factor that can influence the error level in NIRS analysis. Velasco and Becker (1998b) reported that calibration equations for fatty acids in Ethiopian mustard became more robust as new samples from different environments were added to the calibration set. To evaluate the accuracy of the NIRS calibration, some statistical values could be used including: (i) standard error of performance corrected for bias [SEP(C)], (ii) coefficient of determination $\left(\mathrm{R}^{2}\right)$ of calibration and validation 
which represents the proportion of explained variance of the response in the calibration or validation data set; (iii) ratio performance deviation [RPD, SD/SEP(C)]; and (iv) range-to-error ratio [RER, Range/SEP(C)]. An RPD value between 1.5 - 1.9 indicates the coarse quantitative prediction are possible, but still need some improvement in calibration, a value between $2-2.5$ means that prediction model is sufficient, while RPD value between 2.5 and 3 or above corresponds to good and excellent prediction accuracy, respectively (Fearn 2002). For a good calibration, the minimum value of RER is between 9 to 10 (Williams and Sobering 1996).

\subsection{Aims of the research}

The objectives of this research were:

- to analyse genetic variation and inheritance for seed fibre content and seed hull proportion and to develop NIRS calibrations for fibre content

- to study the importance of genotype, environment, and genotype x environment (GxE) interaction for seed fibre content

- to investigate correlations between fibre content and other important quality traits

- to identify quantitative trait loci (QTL) associated with fibre content by linkage analysis in three doubled haploid populations of black-seeded winter oilseed rape and by association mapping in a set of canola quality winter oilseed rape cultivars

\subsection{References}

Abbadi A, Leckband G (2011) Rapeseed breeding for oil content, quality, and sustainability. Eur J Lipid Sci Technol 113:1198-1206

Albersheim P, Darvill A, Roberts K, Sederoff R, Staehelin A (2010) Plant cell walls: From chemistry to biology. Garland Science, Taylor and Francis Group, LLC

Amar S, Becker HC, Möllers C (2009) Genetic variation in phytosterol content of winter rapeseed (Brassica napus L.) and development of NIRS calibration equations. Plant Breed 128:78-83

ANKOM (2013) Method 8 - Determining acid detergent lignin in beakers. http//www.ankom.com/media/documents/Method_8_Lignin_in_beakers_3_13_13.pdf (Site visited March 9, 2014)

ANKOM (2011a) Method 5 - Acid Detergent Fiber in Feeds Filter Bag Technique. http//www.ankom.com/media/documents/Method_5_ADF_4-13-11_A200,A200I.pdf (Site Visit. March 9, 2014)

ANKOM (2011b) Method 6 - Neutral Detergent Fiber in Feeds Filter Bag Technique. http//www.ankom.com/media/documents/Method_6_NDF_4013011_A200,A200I.pdf (Site visited March 9, 2014) 
Badani AG, Snowdon RJ, Wittkop B, Lipsa FD, Baetzel R, Horn R, Haro A, Font R, Lühs W (2006) Colocalization of a partially dominant gene for yellow seed colour with a major QTL influencing acid detergent fibre (ADF) content in different crosses of oilseed rape (Brassica napus). Genome 49:1499-1509

Batten GD (1998) Plant analysis using near infrared reflectance spectroscopy: The potential and the limitations. Aust J Exp Agric 38:697-706

Bell J (1993) Factors affecting the nutritional value of canola meal: A review. Can J Anim Sci 697:679-697

Bell JM (1984) Nutrients and toxicants in rapeseed meal: A review. J Anim Sci 58:996-1010

Bell JM, Shires A (1982) Composition and digestibility by pigs of hull fractions from rapeseed cultivars with yellow or brown seed coats. Can J Anim Sci 62:557-565

Bonawitz ND, Chapple C (2010) The genetics of lignin biosynthesis: connecting genotype to phenotype. Annu Rev Genet 44:337-363

Breseghello F, Sorrells ME (2006) Association analysis as a strategy for improvement of quantitative traits in plants. Crop Sci 46:1323-1330

Brogna N, Pacchioli MT, Immovilli A, Ruozzi F, Ward R, Formigoni A (2010) The use of nearinfrared reflectance spectroscopy (NIRS) in the prediction of chemical composition and in vitro neutral detergent fiber (NDF) digestibility of Italian alfalfa hay. Ital J Anim Sci 8:271273

Bunchasak C (2009) Role of dietary methionine in poultry production. J Poult Sci 46:169-179

Bundessortenamt (2013) Beschreibende Sortenliste Getreide, Mais, Öl- und Faserpflanzen, Leguminosen, Rüben, Zwischenfrüchte.

http//www.bundessortenamt.de/internet30/fileadmin/Files/PDF/bsl_getreide_2013.pdf (Site visited March 9, 2014)

Burbulis N, Kott LS (2005) A new yellow-seeded canola genotype originating from double low black-seeded Brassica napus cultivars. Can J Plant Sci 85:109-114

Collard BCY, Jahufer MZZ, Brouwer JB, Pang ECK (2005) An introduction to markers, quantitative trait loci (QTL) mapping and marker-assisted selection for crop improvement: The basic concepts. Euphytica 142:169-196

Collard BCY, Mackill DJ (2008) Marker-assisted selection: an approach for precision plant breeding in the twenty-first century. Philos Trans R Soc Lond B Biol Sci 363:557-572

Cozzolino D, Fassio A, Gimenez A (2000) The use of near infrared reflectance spectroscopy (NIRS) to predict the composition of whole maize plants. J Sci Food Agric 81:142-146

Deynze A, Beversdorf W, Pauls K (1993) Temperature effects on seed color in black-and yellowseeded rapeseed. Can J Plant Sci 7:383-388

Doerge RW (2002) Mapping and analysis of quantitative trait loci in experimental populations. Nat Rev Genet 3:43-52 
Downey R, Bell J (1990) New Developments in Canola Research. In: Shahidi F (ed) Canola Rapeseed Prod. Chem. Nutr. Process. Technol. Van Nostrand Reinhold New York, pp 38-45

FAO (2013) Oilseeds and oilseed products. OECD-FAO Agric. Outlook 2013, pp 139-282

Fearn T (2002) Assessing calibrations: SEP, RPD, RER and R2. NIR news 13:12-14

FEDIOL (2013) Meals Production, Imports, Exports and Consumption. http//www.fediol.eu/data/1376905793Stat\%20meals\%202012.pdf (Site visited March 9, 2014)

Flint-Garcia SA, Thornsberry JM, Buckler ES, IV B (2003) Structure of linkage disequilibrium in plants. Annu Rev Plant Biol 54:357-374

Font R, Del Rio M, Fernández JM, De Haro A (2003) Acid detergent fiber analysis in oilseed Brassicas by near-infrared spectroscopy. J Agric Food Chem 51:2917-22

Gous P, Martin A, Lawson W, Kelly A (2012) Correlation between NIRS generated and chemically measured feed quality data in barley (Hordeum vulgare), and potential use in QTL analysis identification. Euphytica 188:325-332

Halkier BA, Du L (1997) The biosynthesis of glucosinolates. Trends Plant Sci 2:425-431

Halkier BA, Gershenzon J (2006) Biology and biochemistry of glucosinolates. Annu Rev Plant Biol 57:303-33

Haughn G, Chaudhury A (2005) Genetic analysis of seed coat development in Arabidopsis. Trends Plant Sci 10:472-477

Hom NH, Becker HC, Möllers C (2007) Non-destructive analysis of rapeseed quality by NIRS of small seed samples and single seeds. Euphytica 153:27-34

Honsdorf N, Becker HC, Ecke W (2010) Association mapping for phenological, morphological, and quality traits in canola quality winter rapeseed (Brassica napus L.). Genome 53:899907

Hu Z, Hua W, Zhang L, Deng L, Wang X (2013) Seed structure characteristics to form ultrahigh oil content in rapeseed. PLoS One 8:e62099

Huhtanen P, Hetta M, Swensson C (2011) Evaluation of canola meal as a protein supplement for dairy cows: A review and a meta-analysis. Can J Anim Sci 91:529-543

Ikebudu J, Sokhansanj S, Tyler R, Milne B, Thakor N (2000) Grain conditioning for dehulling of canola. Can Agric Eng 42:1-13

Jensen SK, Liu YG, Eggum BO (1995) The influence of seed size and hull content on the composition and digestibility of rapeseeds in rats. Anim Feed Sci Technol 54:9-19

Jiang Y, Deyholos MK (2010) Transcriptome analysis of secondary-wall-enriched seed coat tissues of canola (Brassica napus L .) 
Jin M, Li J, Fu F, Zhang Z, Zhang X, Liu L (2007) QTL analysis of oil and hull content in Brassica napus L. Sci Agric Sin 40:677-684

Jung HG, Allen MS (1995) Characteristics of plant cell walls affecting intake and digestibility of forages by ruminants. J Anim Sci 73:2774-2790

Jung HG, Mertens DR, Payne AJ (1997) Correlation of acid detergent lignin and Klason lignin with digestibility of forage dry matter and neutral detergent fiber. J Dairy Sci 80:16221628

Kearsey M, Farquhar A (1998) QTL analysis in plants; where are we now? Heredity 80:137-142

Khajali F, Slominski BA (2012) Factors that affect the nutritive value of canola meal for poultry. Poult Sci 91:2564-2575

Kondra Z, Stefansson B (1970) Inheritance of the major glucosinolates of rapeseed (Brassica napus) meal. Can J Plant Sci 50:643-647

Kong X, Xie J, Wu X, Huang Y, Bao J (2005) Rapid prediction of acid detergent fiber, neutral detergent fiber, and acid detergent lignin of rice materials by near-infrared spectroscopy. J Agric Food Chem 53:2843-2848

Kozlowska H, Naczk M, Shahidi F, Zadernowski R (1990) Phenolic acids and tannins in rapeseed and canola. In: Shahidi F (ed) Canola Rapeseed Prod. Chem. Nutr. Process. Technol. Van Nostrand Reinhold, New York, pp 193-210

Kracht W, Dänicke S, Kluge H, Keller K, Matzke W, Hennig U, Schumann W (2004) Effect of dehulling of rapeseed on feed value and nutrient digestibility of rape products in pigs. Arch Anim Nutr 58:389-404

Lipsa FD, Snowdon R, Friedt W (2012) Quantitative genetic analysis of condensed tannins in oilseed rape meal. Euphytica 184: 195-205

Liu L, Stein A, Wittkop B, Sarvari P, Li J (2012) A knockout mutation in the lignin biosynthesis gene CCR1 explains a major QTL for acid detergent lignin content in Brassica napus seeds. Theor Appl Genet 124:1573-1586

Mailer RJ, McFadden A, Ayton J, Redden B (2008) Anti-Nutritional Components, Fibre, Sinapine and Glucosinolate Content, in Australian Canola (Brassica napus L.) Meal. J Am Oil Chem Soc 85:937-944

Marles MS, Gruber MY (2004) Histochemical characterisation of unextractable seed coat pigments and quantification of extractable lignin in the Brassicaceae. J Sci Food Agric $84: 251-262$

Matthäus B (1998) Effect of dehulling on the composition of antinutritive compounds in various cultivars of rapeseed. Lipid/Fett 92:139-144

Maupertuis F, Quiniou N, Royer E, Quinsac A, Peyronnet C, Rheu L (2011) Effets d ' une utilisation continue et du mode de distribution du tourteau de colza sur les performances des porcs charcutiers. Journees Rech Procine 43:67-72 
Minkowski K (2002) Influence of dehulling of rape seeds on chemical composition of meal. Anim Feed Sci Technol 96:237-244

Möller J (2008) Animal feeding stuff: Global standard for the determination of acid detergent fibre (ADF) and lignin. Focus FOSS Gr J Technol Food, Dairy Agric Anal 32:22-24

Moore KJ, Jung HG (2001) Lignin and fiber digestion. J Range Manag 54:420-430

Mutwil M, Debolt S, Persson S (2008) Cellulose synthesis: a complex complex. Curr Opin Plant Biol 11:252-257

Naczk M, Amarowicz R, Pink D, Shahidi F (2000) Insoluble condensed tannins of canola/rapeseed. J Agric Food Chem 48:1758-1762

Naczk M, Amarowicz R, Sullivan A, Shahidi F (1998) Current research developments on polyphenolics of rapeseed/canola: A review. Food Chem 62:489-502

Nath UK, Goswami G, Clemens R, Becker HC, Möllers C (2008) Inheritance and variation of erucic acid content in a transgenic rapeseed (Brassica napus L.) doubled haploid population. Mol Breed 23:125-138

Nesi N, Delourme R, Brégeon M, Falentin C, Renard M (2008) Genetic and molecular approaches to improve nutritional value of Brassica napus L. seed. C R Biol 331:763-771

Newkirk R., Classen H. (1998) In vitro hydrolysis of phytate in canola meal with purified and crude sources of phytase. Anim Feed Sci Technol 72:315-327.

OVID (2013) Produktion Pflanzenöle Weltweit 2012. http//www.ovidverband.de/index.php?id=318 (Site visited March 9, 2014)

Rafalski JA (2010) Association genetics in crop improvement. Curr Opin Plant Biol 13:174-80

Rahman M (2001) Production of yellow seeded Brassica napus through interspecific crosses. Plant Breed 120:463-472

Rahman M, Joersbo M, Poulsen M (2001) Development of yellow seeded Brassica napus of double low quality. Plant Breed 120:473-478

Rahman M, McVetty PBE (2011) A review of Brassica seed color. Can J Plant Sci 91:437-446

Rakow G, Relf-Eckstein J, Raney J (2007) Rapeseed genetic research to improve its agronomic performance and seed quality. Helia 30:199-206

Rashid A, Rakow G, Downey RK (1994) Development of yellow seeded Brassica napus through interspecific crosses. Plant Breed 112:127-134

Reich G (2005) Near-infrared spectroscopy and imaging: basic principles and pharmaceutical applications. Adv Drug Deliv Rev 57:1109-43

Rezaeizad A, Wittkop B, Snowdon R, Hasan M, Mohammadi V, Zali A, Friedt W (2010) Identification of QTLs for phenolic compounds in oilseed rape (Brassica napus L.) by association mapping using SSR markers. Euphytica 177:335-342 
Röbbelen G, Thies W (1980) Variation in rapeseed glucosinolates and breeding for improved meal quality. In: Tsunoda S, Hinata K, Gomez-Campo C (eds) Brassica Crop Wild allies II. Japan Scientific Societies Press, pp 285-299

Sasongko ND, Möllers C (2005) Toward increasing erucic acid content in oilseed rape (Brassica napus L.) through the combination with genes for high oleic acid. J Am Oil Chem Soc 82:445-449

Saun RJ Van (2006) Determining Forage Quality: Understanding Feed Analysis. Lamalink.com $3: 25-26$

Scheller HV, Ulvskov P (2010) Hemicelluloses. Annu Rev Plant Biol 61:263-89

Selvendran RR (1987) Chemistry of plant cell walls and dietary fibre. Scand J Gastroenterol 22:33-41

Shahidi F, Naczk M (1992) An overview of the phenolics of canola and rapeseed: Chemical, sensory and nutritional significance. J Am Oil Chem Soc 69:917-924

Shenk JS, Westerhaus MO (1991) Population structuring of near infrared spectra and modified partial least squares regression. Crop Sci 474:1548-1555

Shirzadegan M, Röbbelen G (1985) Influence of seed color and hull proportion on quality properties of seeds in Brassica napus L. Fette, Seifen, Anstrichm 87:235-237

Simbaya J, Slominski B, Rakow G, Campbell LD, Downey RK, Bell JM, Bello JM (1995) Quality characteristics of yellow-seeded Brassica seed meals: Protein, carbohydrate, and dietary fiber components. J Agric Food Chem 43:2062-2066

Slominski BA, Campbell LD (1990) Non-starch polysaccharides of canola meal: Quantification, digestibility in poultry and potential benefit of dietary enzyme supplementation. J Sci Food Agric 53:175-184

Slominski BA, Jia W, Rogiewicz A, Nyachoti CM, Hickling D (2012) Low-Fiber Canola. Part 1. Chemical and Nutritive Composition of the Meal. J Agric Food Chem 60:12225-12230

Snowdon R, Wittkop B, Rezaidad A, Hasan MH, Lipsa F, Stein A, Friedt W, Francki M (2010) Regional association analysis delineates a sequenced chromosome region influencing antinutritive seed meal compounds in oilseed rape. Genome 53:917-928

Soest P Van (1967) Development of a comprehensive system of feed analyses and its application to forages. J Anim Sci 119-128

Van Soest PJ, Robertson JB, Lewis BA (1991) Methods for dietary fiber, neutral detergent fiber, and nonstarch polysaccharides in relation to animal nutrition. J Dairy Sci 74:3583-3597

Stringam G, McGregor D, Pawlowski. S (1974) Chemical and morphological characteristics associated with seedcoat color in rapeseed. Proc. 4. Int. Rapskongress, Giessen, West Ger. pp 99-108

Stubbs TL, Kennedy AC, Fortuna A-MM (2010) Using NIRS to predict fiber and nutrient content of dryland cereal cultivars. J Agric Food Chem 58:398-403 
Stuth J, Jama A, Tolleson D (2003) Direct and indirect means of predicting forage quality through near infrared reflectance spectroscopy. F Crop Res 84:45-56

Szydłowska-Czerniak A, Trokowski K, Karlovits G, Szłyk E (2010) Determination of antioxidant capacity, phenolic acids, and fatty acid composition of rapeseed varieties. J Agric Food Chem 58:7502-7509

Tan SH, Mailer RJ, Blanchard CL, Agboola SO (2011) Canola proteins for human consumption: extraction, profile, and functional properties. J Food Sci 76:R16-R28

Tang Z, Li J, Zhang X, Chen L, Wang R (1997) Genetic variation of yellow-seeded rapeseed lines (Brassica napus L.) from different genetic sources. Plant Breed 116:471-474

UFOP (2008) Background paper on quality improvement of rapeseed meal concerning the glucosinolate content. http//www.ufop.de/files/9113/3940/7603/Rapeseed_meal_UFOP_OVID.pdf (Site visited March 9, 2014)

USDA (2014) Oilseeds: World Markets and Trade. http//apps.fas.usda.gov/psdonline/circulars/oilseeds.pdf (Site visited March 9, 2014)

Velasco L, Becker H (1998a) Analysis of total glucosinolate content and individual glucosinolates in Brassica spp. by near-infrared reflectance spectroscopy. Plant Breed 117:97-102

Velasco L, Becker H (1998b) Estimating the fatty acid composition of the oil in intact-seed rapeseed (Brassica napus L.) by near-infrared reflectance spectroscopy. Euphytica 101:221-230

Velasco L, Möllers C (2002) Nondestructive assessment of protein content in single seeds of rapeseed (Brassica napus L.) by near-infrared reflectance spectroscopy. Euphytica 123: 89-93

Velasco L, Möllers C, Becker H (1999) Estimation of seed weight, oil content and fatty acid composition in intact single seeds of rapeseed (Brassica napus L.) by near-infrared reflectance spectroscopy. Euphytica 106:79-85

Weimer PJ (1992) Cellulose degradation by ruminal microorganisms. Crit Rev Biotechnol 12:189-223

Williams PC, Sobering DC (1996) How do we do it: a brief summary of the methods we use in developing near infrared calibrations. In Near Infrared Spectroscopy: The Future Waves. Eds. A M C Davis and P Williams. NIR Publications, Chichester, UK, Montreal, Canada, pp 185-188

Wittkop B, Snowdon RJ, Friedt W (2012) New NIRS calibrations for fiber fractions reveal broad genetic variation in Brassica napus seed quality. J Agric Food Chem 60:2248-2256

Wu J, Muir AD (2008) Comparative structural, emulsifying, and biological properties of 2 major canola proteins, cruciferin and napin. J Food Sci 73:C210-6 
Yan XY, Li JN, Fu FY, Jin MY, Chen L, Liu LZ (2009) Co-location of seed oil content, seed hull content and seed coat color QTL in three different environments in Brassica napus L. Euphytica 170:355-364

Yin Y-L, Chen C-M, Zhong H-Y, Huang R-L, Chen X-S (1994) Apparent digestibilities of energy, cell wall constituents, crude protein and amino acids of Chinese oil seed meals for growing pigs. Anim Feed Sci Technol 45:283-298

Zhou B, He Z, Yu H, Mukherjee KD (1990) Proteins from double-zero rapeseed. J Agric Food Chem 38:690-694

Zum Felde T, Baumert A, Strack D, Becker HC, Möllers C (2007) Genetic variation for sinapate ester content in winter rapeseed (Brassica napus L.) and development of NIRS calibration equations. Plant Breed 126:291-296 
Genetic variation for seed hull and fibre content in a collection of European winter oilseed rape material (Brassica napus L.) and development of NIRS calibrations 


\title{
Genetic variation for seed hull and fibre content in a collection of European winter oilseed rape material (Brassica napus L.) and development of NIRS calibrations
}

\author{
Zoran Dimov ${ }^{1}$, Edy Suprianto ${ }^{2}$, Frank Hermann ${ }^{2}$ and Christian Möllers ${ }^{2,3}$ \\ ${ }^{1}$ Faculty of Agriculture and Food, Bul. Aleksandar Makedonski b.b., P.O. Box 297, 1000 Skopje, Republic of Macedonia; \\ ${ }^{2}$ Department of Crop Sciences, Plant Breeding, Georg-August-Universität Göttingen, Von-Siebold-Str. 8, 37075 Göttingen, \\ Germany; ${ }^{3}$ Corresponding author, E-mail: cmoelle2@gwdg.de \\ With 2 figures and 6 tables
}

Received July 22, 2011/Accepted December 23, 2011

Communicated by A.-M. Chevre

\begin{abstract}
After oil extraction, the meal of oilseed rape provides an important protein-rich animal feedstuff. However, compared with soybean meal, the crude fibre content of oilseed rape meal is too high. The objectives of the present study were to analyse the genetic variation for and the environmental influence on the seed hull, neutral detergent fibre (NDF), acid detergent fibre (ADF) and acid detergent lignin (ADL) content of 28 black-seeded winter oilseed rape cultivars tested in field experiments in Germany and to develop near-infrared reflectance spectroscopic calibrations (NIRS). Significant effects of the genotype and of the location on all traits were found. NIRS calibrations showed in independent validations low standard errors [SEP(C)] of about $1 \%$ for NDF, ADF and ADL contents in the defatted meal and coefficients of determination $\left(R^{2} \mathrm{~V}\right)$ ranging from 0.72 for $\mathrm{NDF}$ to 0.80 for $\mathrm{ADF}$. Results indicate a large genetic variation for NDF, ADF and ADL contents among current black-seeded winter oilseed rape cultivars, which can be used to develop new improved cultivars with reduced crude fibre content.
\end{abstract}

Key words: neutral detergent fibre - acid detergent fibre acid detergent lignin - meal quality - near-infrared reflectance spectroscopy

The meal of canola-type oilseed rape (Brassica napus L.) with a low glucosinolate content in the seed and a low erucic acid content of the seed oil is a valuable feedstuff for animals and a potential protein source for human nutrition (Leckband et al. 2002). However, compared with soybean, fibre content of the oilseed rape meal is high and its energy and protein content is low (Bell 1993). This limits its use in feeding diets. These shortcomings of the oilseed rape meal were mainly attributed to the brown or black fibrous seed hull of oilseed rape, which essentially dilutes the available energy and protein (Clark et al. 2001). Consequently, research has focused on the reduction of the seed hull fraction by breeding yellow-seeded oilseed rape and by mechanical separation of the seed hull of black-seeded types (Clark et al. 2001).

Yellow-seeded oilseed rape cultivars are characterized by proportionately less hull and less fibre within the hull than cultivars with black seed coats (Bell 1993). The recently released yellow-seeded spring oilseed rape line YN01-429 shows a very much reduced fibre content, consisting of neutral detergent fibre (NDF), acid detergent fibre (ADF) and acid detergent lignin (ADL; http://www.canolacouncil.org/uploads/ canola_meal_research/presentation3_relf_eckstein.pdf; site visited January 25, 2012). NDF comprises hemicellulose, cellulose and lignin; ADF comprises cellulose and lignin; and ADL represents the non-digestible lignin fraction (Van Soest et al. 1991), which is mainly located in the seed coat (Matthäus 1998, Wittkop et al. 2009 and references therein). Despite these achievements, the overall fibre content of yellow-seeded types is still high compared with soybean, indicating that the fibre content of the seed embryo is equally important. Apart from studying the fibre content of several yellow-seeded types, little research has been carried out to investigate the quantitative genetic variation for NDF, ADF and ADL contents in blackseeded oilseed rape germplasm. Variation for those traits among black-seeded types may complement the variation existing in the genetically narrow yellow-seeded material. Furthermore, knowledge about the inheritance of seed fibre fractions and possible interactions with other seed constituents may facilitate breeding for increased seed oil and protein contents.

The adoption of near-infrared reflectance spectroscopy (NIRS) in breeding oilseed rape with improved quality traits has proven indispensable during the past decade. Nowadays, NIRS is routinely applied in oilseed rape breeding programmes to determine the moisture, oil, protein and glucosinolate content of the seeds as well as the fatty acid composition of the seed oil. A first calibration for crude fibre content of ground seed samples was developed by Panford et al. (1988). Using intact seeds, Michalski et al. (1992) reported NIRS calibrations for NDF and ADF. More recently, NIRS calibrations for ADF content of intact seeds have been developed by Font et al. (2003, 2005) including yellow- and black-seeded material from different Brassica species.

The aim of the present study was to analyse the genetic variation and the genotype $\times$ environment interactions for seed hull, NDF, ADF and ADL contents of black-seeded modern winter oilseed rape cultivars tested in field experiments in six contrasting environments and to develop NIRS calibrations.

\section{Materials and Methods}

Plant material and field experiments: The seed material consisted of 28 black-seeded canola-type winter oilseed rape cultivars (see Table 3). The material was tested in 2008/2009 in 15 different environments located in different federal states of Germany (Bundes- und EUSortenversuch Winterraps; BSV/EUV1, Gronow et al. 2009). The field experiments were conducted as a randomized complete block design 
with four replicates for each cultivar at each location. Seed samples were taken after combined harvesting of the yield plots. Samples from the four replicates of each cultivar at each location were equally mixed and used for NIRS analysis. On the basis of the mean oil content of the seed samples of the locations, seed samples from locations with a low oil content (Langenstein, Ihinger Hof), an intermediate oil content (Hohenschulen, Futterkamp) and a high oil content (Mollenfelde, Sophienhof) were chosen for the analysis of NDF, ADF and ADL contents. For more details about the cultivars and locations, see the study by Gronow et al. (2009).

For development of NIRS calibrations, the above-mentioned 168 samples were used plus additional 230 seeds samples from a blackseeded doubled haploid (DH) population derived from the cross cultivar 'Express' $\times$ 'R53' (a resynthesized oilseed rape line) cultivated in 2008/2009 at Göttingen and at Thüle in field experiments Furthermore, 60 representative seed samples from the same DH population cultivated in $2009 / 10$ at the same two locations were selected by using the 'Select samples from a spectra file' routine from the WinISI v1.50 programme, and those seed samples were used for independent validation. All seeds samples were derived from open pollinated plants.

Analytical methods: Oil, protein and moisture content, thousand kernel weight $(T K W)$ : Seed samples of about $3 \mathrm{~g}$ were scanned with a NIRS monochromator model 6500 (NIR Systems mod. 6500; NIRSystems Inc., Silversprings, MD, USA). Spectra were recorded between 400 and $2498 \mathrm{~nm}$, registering the absorbance values $\log (1 / \mathrm{R})$ at $2-\mathrm{nm}$ intervals for each sample. Oil, protein and moisture content were determined using the calibration raps2009.eqa provided by VDLUFA Qualitätssicherung NIRS GmbH (Am Versuchsfeld 13, D-34128 Kassel, Germany). Oil and protein content are expressed on a seed dry matter basis. Protein content of the oil-extracted meal was calculated by using the seed oil and protein content data obtained from NIRS prediction. TKW was determined with a seed counter (model Contador; Pfeuffer GmbH, D-97318 Kitzingen, Germany, http:// www.pfeuffer.com)

Analysis of NDF, ADF and ADL content: $10 \mathrm{~g}$ of seeds from each sample were ground in a coffee mill model Krups F203 for $6 \mathrm{~s}$ (three times $2 \mathrm{~s}$ with in between mixing of the meal). Five grams of this meal was defatted for $10 \mathrm{~h}$ with petrolether using a continuous extraction apparatus. The defatted meal was air-dried under a hood and subsequently dried in an oven at $60^{\circ} \mathrm{C}$ for $24 \mathrm{~h}$. Five hundred milligrams of this defatted meal was used to determine its dry matter content after $24 \mathrm{~h}$ incubation at $105^{\circ} \mathrm{C}$. NDF, ADF and ADL contents were determined in 500-mg meal samples according to Van Soest et al (1991) using the ANKOM ${ }^{\text {TM }}$ detergent fibre analysis system with filter bag technology (ANKOM Model 220; ANKOM Technology, Macedon, NY, USA, http://www.ankom.com/default.aspx). With this equipment, 24 filter bags can be analysed at a time. NDF and ADF contents were determined following the ANKOM Technology Method 9 and 8 , respectively, and ADL content was determined according to the method 'ADL', ANKOM Technology 08/05.

Seed hull content: This was determined by drying seeds at $105^{\circ} \mathrm{C}$ for $8 \mathrm{~h}$. Then seeds were imbibed in water for 15-20 h. Afterwards, seed hulls were separated from embryos by using a dissecting needle. Both fractions were dried at $105^{\circ} \mathrm{C}$ over night, before their dry weights were determined. The seed hull proportion (in \%) was determined from 100 seeds (approx. $500 \mathrm{mg}$ ) per sample.

Near-infrared reflectance spectroscopy calibration development: The NDF, ADF and ADL values of the seed samples were imported into the WinISI software and assigned to their corresponding NIRS spectra. The resulting cal file was used to develop calibration equations with spectral absorbance information using WinISI II ProjectManager v1.50 (Infrasoft International LLC, 1362 South Atherton St., State College, PA 16801, USA). GLOBAL calibrations were developed using Modified Partial Least Squares regression analysis (MPLS) and cross-validation techniques. Spectra were first treated with the scatter correction 'SNV and Detrend'. Then, the first derivative was used in combination with a gap of 4 . The first and second smooth were set to 4 and $1 \mathrm{~nm}$, respectively. Other software settings than those did not lead to improved results (data not shown). The maximum number of terms tested by the software was 16 , but the actual number of terms selected to avoid over fitting was 3 for ADL, 11 for ADF and 12 for NDF. For cross-validation, the suggested setting of four groups was used. The results of the calibration were checked by observing $t$ and global $\mathrm{H}$ $(\mathrm{GH})$ outliers. Outliers with $t>2.5$ and $\mathrm{GH}>10$ were not considered for calibration development. The number of outlier elimination passes was 2 . Calibration performance was assessed by standard error of calibration (SEC), coefficient of determination $\left(R^{2} \mathrm{C}\right)$, standard error of cross-validation (SECV) and coefficient of determination in crossvalidation $\left(R^{2} \mathrm{CV}\right)$. The standard deviations $(\mathrm{SD})$ and the means for the calibration sets as well as range of the calibration were taken from the WINISI software. Calibration performance in validation was assessed by standard error of performance corrected for bias [SEP(C)], by the coefficient of determination in validation $\left(R^{2} \mathrm{~V}\right)$, by the ratio performance deviation (RPD) $[\mathrm{SD} / \mathrm{SEP}(\mathrm{C})]$ and the range-to-error ratio (RER) [Range/SEP(C)]; Williams and Sobering 1996).

Statistical analysis: Analysis of variance and calculation of heritabilities were performed by using PLABSTAT software (Utz 2008). For the oilseed rape cultivar experiment, the locations were considered as random and the genotypes as fixed factors. Mean values of the genotypes across the environments were used to calculate Spearman's rank correlation coefficients between traits.

\section{Results}

The analysis of variance showed highly significant effects of the locations and the genotypes on the NDF, ADF and ADL contents of the defatted seed meal of 28 current winter oilseed rape cultivars as determined with the ANKOM technology (Table 1). Highly significant effects of the locations and the genotypes on TKW, seed oil and protein content and protein content of the defatted meal were also found. Comparatively large variance components were detected for the effect of the locations on all traits, except for seed hull content and TKW. For these two traits, the variance components for the genotypic effect were 13 fold and twofold larger than that of

\begin{tabular}{|c|c|c|c|c|c|c|c|c|}
\hline \multirow{2}{*}{$\begin{array}{l}\text { Source of } \\
\text { variance }\end{array}$} & \multicolumn{4}{|c|}{ In $\%$ of defatted meal } & \multirow[b]{2}{*}{ TKW (g) } & \multicolumn{3}{|c|}{ In $\%$ of seed dry matter } \\
\hline & NDF & ADF & ADL & Protein & & Seed hull & Oil & Protein \\
\hline Location & $10.7 * *$ & $7.6 * *$ & $3.6 * *$ & $6.21 * *$ & $0.05 * *$ & $0.03 *$ & $6.9 * *$ & $5.22 * *$ \\
\hline Genotype & $1.4 * *$ & $1.4 * *$ & $0.5^{*}$ & $1.14 * *$ & $0.10 * *$ & $0.39 * *$ & $0.9 * *$ & $0.36^{* *}$ \\
\hline $\mathrm{L} \times \mathrm{G}$ & 2.4 & 2.7 & 4.5 & 0.53 & 0.04 & 0.45 & 0.6 & 0.33 \\
\hline $\mathrm{h}^{2}$ & 0.78 & 0.75 & 0.41 & 0.93 & 0.94 & 0.84 & 0.90 & 0.87 \\
\hline
\end{tabular}

Table 1: Variance components of NDF, ADF and ADL contents and of other seed quality traits in 28 current winter oilseed rape cultivars tested in field experiments in six locations

ADF, acid detergent fibre; ADL, acid detergent lignin; NDF, neutral detergent fibre; TKW thousand kernel weight.

${ }^{*}{ }^{* *}$ Significant at $\mathrm{P}=0.05$ and $\mathrm{P}=0.01$, respectively ( $F$ test, ANOVA)

$h^{2}=$ heritability 
the location, respectively. Variance components for the location $\times$ genotype interactions were in general smaller than effects caused by the locations but larger than the effects caused by the genotypes. Heritabilities were low for ADL, intermediate for NDF and ADF, and high for the other traits.

The selected contrasting locations did not only show large differences for the seed yield per hectare but also for all other traits (Table 2). Locations that gave high oil contents as a mean over all cultivars (Sophienhof and Mollenfelde) gave rather low seed protein contents and vice versa (cf. Ihinger Hof und Langenstein). There was no obvious relationship between seed yield and oil content of the locations. Within the locations, a large variation for NDF, ADF and ADL contents were found among the genotypes. Large differences between the locations were also found for the NDF, ADF and ADL contents, and across the locations, there was a positive relation between fibre content and oil content.

Among the cultivars, the NDF content ranged from $26.1 \%$ to $32.7 \%$ in the dry matter of the defatted seed meal (Table 3 ). Calculated on the basis of dry seeds, the NDF content varied from $12.5 \%$ to $15.9 \%$ (data not shown). ADF content ranged from $20.5 \%$ to $26.8 \%$ in the dry matter of the defatted meal and from $9.8 \%$ to $13.0 \%$ in the seeds. In the defatted meal, the ADL content varied from $8.5 \%$ to $13.2 \%$ and calculated on the basis of seeds it varied from $4.1 \%$ to $6.4 \%$. Lowest NDF, ADF and ADL contents in the defatted meal as well as in the

Table 2: Mean values for seed yield and seed quality traits of 28 winter oilseed rape cultivars tested in field experiments in $2008 / 2009$ at six different locations. The range for NDF, ADF and ADL contents for each location is given in parentheses

\begin{tabular}{|c|c|c|c|c|c|c|c|c|}
\hline \multirow[b]{2}{*}{ Location } & \multirow[b]{2}{*}{ Yield* } & \multicolumn{3}{|c|}{ In $\%$ of seed dry matter } & \multirow[b]{2}{*}{ TKW (g) } & \multicolumn{3}{|c|}{ In $\%$ of defatted meal } \\
\hline & & Oil & Protein & Seed hull & & NDF & $\mathrm{ADF}$ & ADL \\
\hline Sophienhof & 54.7 & 50.9 & 17.1 & $16.3(14.6-18.1)$ & 4.62 & $33.5(28.8-37.3)$ & $27.4(23.5-33.1)$ & $13.5(7.3-18.8)$ \\
\hline Mollenfelde & 55.2 & 50.6 & 18.0 & $15.8(14.6-17.8)$ & 4.70 & $31.9(29.7-36.3)$ & $24.8(21.6-29.2)$ & $10.8(8.6-13.4)$ \\
\hline Futterkamp & 66.0 & 49.7 & 18.1 & $16.2(14.8-17.5)$ & 4.62 & $32.4(24.9-39.0)$ & $26.4(20.6-33.9)$ & $12.2(7.6-16.8)$ \\
\hline Hohenschulen & 59.3 & 49.3 & 18.7 & $16.3(14.5-18.6)$ & 4.96 & $30.1(26.4-32.2)$ & $24.0(20.2-26.9)$ & $10.7(6.3-12.7)$ \\
\hline Ihinger Hof & 47.8 & 46.0 & 22.0 & $16.4(14.5-18.6)$ & 4.44 & $28.3(24.0-31.7)$ & $22.2(19.0-25.0)$ & $8.9(7.1-11.7)$ \\
\hline Langenstein & $43.8 * *$ & 44.5 & 22.6 & $16.4(15.2-18.6)$ & 4.29 & $24.6(19.0-26.9)$ & $19.8(14.6-21.6)$ & $8.4(4.5-13.8)$ \\
\hline
\end{tabular}

ADF, acid detergent fibre; ADL, acid detergent lignin; NDF, neutral detergent fibre; TKW, thousand kernel weight.

*In dt/ha; data taken from Gronow et al. (2009).

**J. Gronow, personal communications.

Table 3: Neutral detergent fibre (NDF), acid detergent fibre (ADF), acid detergent lignin (ADL), seed hull content and other seed quality traits of 20 of 28 European winter oilseed rape cultivars tested at six locations in 2008/2009 (BSV EUV1)

\begin{tabular}{|c|c|c|c|c|c|c|c|c|c|}
\hline \multirow[b]{2}{*}{ Cultivar } & \multirow[b]{2}{*}{ Type } & \multicolumn{4}{|c|}{ In $\%$ of defatted meal } & \multirow[b]{2}{*}{ TKW (g) } & \multicolumn{3}{|c|}{ In $\%$ of seed dry matter } \\
\hline & & $\mathrm{NDF}$ & $\mathrm{ADF}$ & $\mathrm{ADL}$ & Protein & & Seed hull & Oil & Protein \\
\hline ES Alienor & $\mathrm{L}$ & 26.1 & 20.5 & 8.5 & 37.2 & 5.2 & 15.2 & 47.8 & 19.5 \\
\hline Adriana & L & 27.9 & 22.4 & 9.1 & 38.0 & 5.2 & 14.9 & 49.7 & 19.2 \\
\hline Loveli CS & $\mathrm{L}$ & 28.0 & 21.1 & 8.8 & 40.1 & 4.5 & 15.5 & 49.8 & 20.2 \\
\hline DK Secure & Hzk & 28.8 & 23.8 & 10.9 & 37.6 & 4.2 & 16.4 & 46.8 & 20.1 \\
\hline Safran & $\mathrm{H}$ & 29.3 & 23.3 & 9.8 & 37.7 & 4.4 & 15.7 & 47.4 & 19.9 \\
\hline Limone & $\mathrm{H}$ & 29.5 & 23.9 & 10.3 & 37.1 & 4.7 & 15.8 & 48.5 & 19.2 \\
\hline Exotic & $\mathrm{H}$ & 29.5 & 24.0 & 10.8 & 39.0 & 5.1 & 15.9 & 46.6 & 20.9 \\
\hline Lorenz & L & 29.7 & 23.3 & 9.5 & 37.0 & 4.4 & 15.7 & 50.4 & 18.4 \\
\hline Cuillin & $\mathrm{H}$ & 29.8 & 24.3 & 11.4 & 38.6 & 4.5 & 15.5 & 48.6 & 19.9 \\
\hline Monolit & L & 29.8 & 24.0 & 10.8 & 35.7 & 5.0 & 16.4 & 49.5 & 18.1 \\
\hline Katabatic & $\mathrm{L}$ & 29.8 & 24.2 & 11.5 & 38.3 & 4.5 & 15.9 & 50.0 & 19.2 \\
\hline Elektra & $\mathrm{H}$ & 29.9 & 23.7 & 9.6 & 38.0 & 4.9 & 15.9 & 48.0 & 19.4 \\
\hline Tassilo & $\mathrm{H}$ & 30.0 & 23.9 & 10.8 & 38.4 & 4.5 & 16.4 & 47.9 & 20.0 \\
\hline PR44W 18 & $\mathrm{H}$ & 30.0 & 23.2 & 10.5 & 37.4 & 4.7 & 16.2 & 48.3 & 19.3 \\
\hline PR44W22 & $\mathrm{H}$ & 30.3 & 24.1 & 10.7 & 37.6 & 4.5 & 15.7 & 49.1 & 19.2 \\
\hline Bellevue & $\mathrm{L}$ & 30.4 & 24.7 & 12.2 & 38.8 & 5.2 & 16.3 & 48.6 & 19.9 \\
\hline Hybrisurf & $\mathrm{H}$ & 30.4 & 24.0 & 10.5 & 38.8 & 4.4 & 16.1 & 48.8 & 19.9 \\
\hline Iwan & $\mathrm{L}$ & 30.5 & 24.5 & 12.0 & 38.5 & 4.7 & 16.8 & 48.9 & 19.7 \\
\hline Visby & $\mathrm{H}$ & 30.7 & 23.9 & 11.5 & 36.8 & 5.0 & 16.2 & 47.6 & 19.3 \\
\hline Azur & $\mathrm{L}$ & 30.7 & 25.7 & 11.6 & 37.4 & 4.7 & 16.7 & 49.1 & 19.1 \\
\hline NK Pegaz & $\mathrm{L}$ & 30.8 & 25.4 & 11.0 & 35.7 & 4.7 & 17.1 & 48.3 & 18.5 \\
\hline PR 45 DR 01 & Hzk & 30.9 & 23.9 & 9.4 & 36.3 & 4.5 & 17.2 & 47.8 & 19.0 \\
\hline NK Aviator & $\mathrm{H}$ & 31.1 & 24.2 & 10.4 & 37.7 & 4.0 & 16.1 & 47.3 & 19.9 \\
\hline Zeppelin & $\mathrm{H}$ & 31.3 & 25.0 & 10.7 & 38.3 & 4.4 & 16.0 & 49.6 & 19.3 \\
\hline Arcadia & $\mathrm{L}$ & 31.5 & 26.1 & 12.0 & 37.2 & 4.1 & 17.1 & 48.0 & 19.4 \\
\hline NK Caravel & $\mathrm{H}$ & 31.8 & 25.1 & 11.2 & 37.2 & 4.5 & 17.5 & 46.8 & 19.8 \\
\hline DK Cabernet & $\mathrm{L}$ & 32.3 & 26.8 & 12.3 & 36.2 & 4.2 & 17.6 & 48.5 & 18.7 \\
\hline NK Morse & $\mathrm{L}$ & 32.7 & 26.2 & 13.2 & 35.1 & 4.6 & 17.0 & 48.6 & 18.1 \\
\hline Mean & & 30.1 & 24.1 & 10.7 & 37.5 & 4.6 & 16.2 & 48.5 & 19.4 \\
\hline Min & & 26.1 & 20.5 & 8.5 & 35.1 & 4.0 & 14.9 & 46.8 & 18.1 \\
\hline $\operatorname{Max}$ & & 32.7 & 26.8 & 13.2 & 40.1 & 5.2 & 17.6 & 50.4 & 20.9 \\
\hline LSD5 $\%$ & & 1.77 & 1.89 & 2.42 & 0.83 & 0.22 & 0.77 & 0.88 & 0.66 \\
\hline
\end{tabular}

H, Hybrid cultivars; L, Line cultivars; Hzk, semidwarf hybrid cultivars; TKW, thousand kernel weight. LSD $5 \%$ - least significant difference at the level of probability $\mathrm{P}=0.05$. 
seeds were found in cultivar 'ES Alienor', which was also one of the cultivars with the highest TKW. There was no obvious difference in fibre content between line and hybrid cultivars. Seed hull content varied between $14.9 \%$ and $17.6 \%$. The highest protein content in the defatted meal was found in cultivar 'Loveli CS'.

Spearman's rank correlations revealed highly significant positive correlations between NDF, ADF, ADL and seed hull content (Table 4). All correlations between NDF, ADF, ADL, seed hull content and the other seed traits were negative, although most of them were not significant. Among the fibre fractions, closest negative correlations were found for NDF and the other seed quality traits. NDF was more negatively correlated with protein content in the defatted meal than to the oil content and NDF was also negatively correlated with TKW.

The NIRS calibration seed sample set consisted of 397 samples. From those between 368 and 381 were used for NIRS calibration development (Table 5). The seed samples showed a large variation for $\mathrm{NDF}, \mathrm{ADF}$ and $\mathrm{ADL}$ contents in the defatted meal (see also Fig. 1). Standard errors in crossvalidation (SECV) ranged from $0.89 \%$ for ADL to $1.25 \%$ for NDF. The coefficient of determination in cross-validation $\left(R^{2} \mathrm{CV}\right)$ ranged between $0.74 \%$ for $\mathrm{NDF}$ and $0.81 \%$ for ADL. The ratio between the standard deviation (SD) and the SECV ranged from 1.92 for $\mathrm{ADF}$ to 2.25 for ADL. The additional 60 seed samples from a different field year used for independent validation showed for ADF a larger and for NDF and ADL a slightly smaller standard deviation (Table 6 and Fig. 1) compared to the calibration set. The standard error of performance corrected for bias $[\mathrm{SEP}(\mathrm{C})]$ ranged from $1.06 \%$ for $\mathrm{ADL}$ to $1.26 \%$ for NDF. Coefficients of determination in validation ranged from 0.72 for $\mathrm{NDF}$ to 0.80 for $\mathrm{ADF}$. The RPD ranged between 1.78 for NDF and 2.22 for ADF. The RER varied between 8.76 for NDF and 10.03 for ADF. The Modified Partial Least Squares (MPLS) loadings for NDF, ADF and ADL are shown for the first factor in Fig. 2. The loading plots show the regression coefficients of each wavelength for NDF, ADF and ADL contents in the defatted meal. The fraction of explained variance for the first factor was $58 \%, 49 \%$ and $24 \%$ for NDF, ADF and ADL, respectively. For NDF and ADF, the subsequent factors (Factors 2-32) explained 2\% or less of the variance, whereas for ADL the second and the third factor explained $17 \%$ and $10 \%$ of the variance, respectively. The loading plots of NDF and ADF are quite similar to each other. However, the loading plot for ADL shows major differences at wavelengths $466,506,610$ and $626 \mathrm{~nm}$.

\section{Discussion}

In the present study, a significant and large quantitative variation was found for NDF, ADF and ADL contents among 28 black-seeded winter oilseed rape cultivars evaluated in field experiments at six different locations in Germany. The variance components showed a dominant effect of the locations on the NDF, ADF and ADL contents of the defatted meal (Table 1). This was not surprising because the six locations were selected among 15 locations based on large differences in mean seed oil content (Table 2). Seeds harvested from locations with high yield levels and high oil contents tended to have higher fibre contents in the seeds. This could indicate that optimal conditions during plant growth and maturation do not only increase seed oil content but also seed fibre content. On the other hand, suboptimal conditions during maturation or too early swathing may equally affect oil content and seed fibre content. Remarkably, the heritability for ADL content was much lower than for $\mathrm{ADF}$ and NDF content. Analysing a larger sample set of yellow-, brown- and black-seeded lines, a close correlation between seed ADL content and seed colour was found by Wittkop et al. (2009), confirming earlier results that lignin is mainly located in the seed coat. Seed colour and hence ADL content may be influenced by environmental conditions like temperature (Van Deynze et al. 1993, Burbulis and Kott 2005) and the degree of maturity at the time of harvest.

\begin{tabular}{|c|c|c|c|c|c|c|c|c|}
\hline & Oil & Protein & Oil + Prot. ${ }^{1}$ & Prot. idM ${ }^{2}$ & TKW & NDF & $\mathrm{ADF}$ & $\mathrm{ADL}$ \\
\hline Protein & $-0.42 *$ & & & & & & & \\
\hline Oil + Prot. $^{1}$ & $0.80^{* *}$ & 0.14 & & & & & & \\
\hline Prot. idM ${ }^{2}$ & 0.16 & $0.77 * *$ & $0.66 * *$ & & & & & \\
\hline TKW & 0.09 & -0.14 & 0.07 & -0.004 & & & & \\
\hline NDF & -0.13 & -0.33 & -0.38 & -0.35 & -0.30 & & & \\
\hline $\mathrm{ADF}$ & -0.001 & -0.26 & -0.22 & -0.18 & -0.23 & $0.81^{* *}$ & & \\
\hline $\mathrm{ADL}$ & -0.07 & -0.14 & -0.23 & -0.12 & -0.05 & $0.60 * *$ & $0.84 * *$ & \\
\hline Seed hull & -0.35 & -0.24 & $-0.61 * *$ & $-0.44 *$ & -0.16 & $0.77 * *$ & $0.66 * *$ & $0.56^{* *}$ \\
\hline
\end{tabular}

Table 4: Spearman's rank correlations for seed quality traits of 28 modern winter oilseed rape cultivars tested in field experiments at six locations

ADF, acid detergent fibre; ADL, acid detergent lignin; NDF, neutral detergent fibre; TKW, thousand kernel weight.

${ }^{1}$ Sum of oil and protein.

${ }^{2}$ Protein in the defatted meal.

Table 5: NIRS calibration development for NDF, ADF and ADL contents ( $\%$ of defatted meal) using seed samples of black-seeded winter oilseed rape cultivars $(n=168)$ and of the doubled haploid winter oilseed rape population Express $617 \times \mathrm{R} 53(\mathrm{n}=229)$

\begin{tabular}{|c|c|c|c|c|c|c|c|c|c|}
\hline Trait & $\mathrm{N}$ & Mean & SD & Range & SEC & $R^{2} \mathrm{C}$ & SECV & $R^{2} \mathrm{CV}$ & $\mathrm{SD} / \mathrm{SECV}$ \\
\hline NDF & 381 & 30.32 & 2.44 & $20.35-36.32$ & 1.17 & 0.77 & 1.25 & 0.74 & 1.95 \\
\hline $\mathrm{ADF}$ & 375 & 24.34 & 2.15 & $17.62-29.40$ & 1.04 & 0.77 & 1.12 & 0.74 & 1.92 \\
\hline ADL & 368 & 11.69 & 2.00 & $5.36-15.79$ & 0.79 & 0.84 & 0.89 & 0.81 & 2.25 \\
\hline
\end{tabular}

ADF, acid detergent fibre; ADL, acid detergent lignin; NDF, neutral detergent fibre; NIRS, near-infrared reflectance spectroscopic; SEC, standard error of calibration; SECV, standard error of cross-validation. 

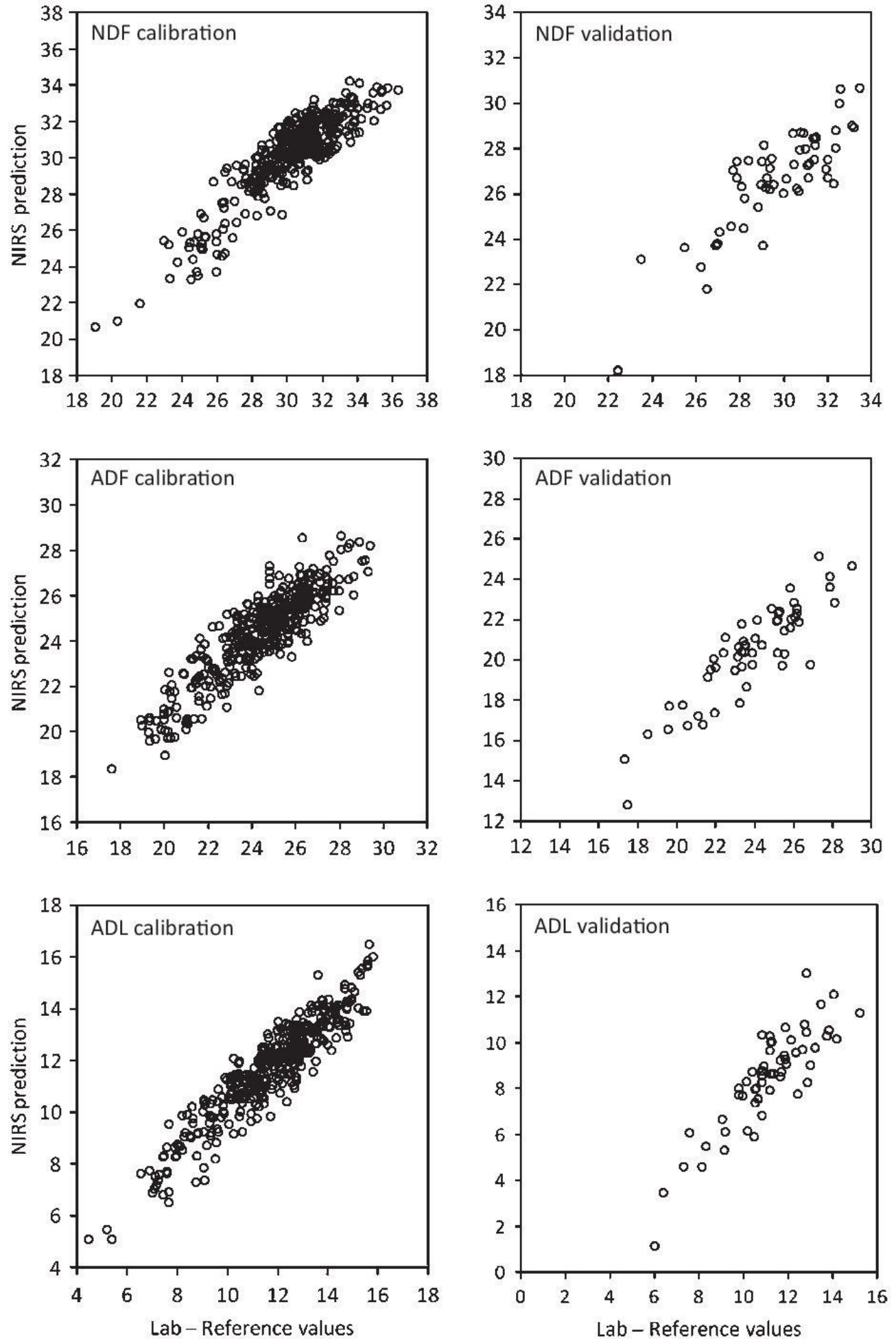

Fig. 1: Calibration and independent validation scatter plots for neutral detergent fibre (NDF), acid detergent fibre (ADF) and acid detergent lignin (ADL). Values are expressed in \% of defatted meal

Among the genotypes, the mean NDF content in the defatted meal ranged from $26.1 \%$ to $32.7 \%$. This is about $4 \%$ lower than the $30.3-37.4 \%$ reported by Mailer et al. (2008) for eight Australian canola spring cultivars tested at different sites in Australia. Because Mailer et al. (2008) used the same $\mathrm{ANKOM}^{\mathrm{TM}}$ system for fibre analysis, the higher NDF contents of the Australian material may be due to the specific genotypes and the environmental conditions. Calculated on the basis of dry seeds, the NDF content in the present winter oilseed rape material ranged from $12.5 \%$ to $15.9 \%$. This compares well with the NDF contents of $14.5 \%$ and $18.0 \%$ in dry seeds reported by Wittkop et al. (2009) for a yellow and a closely related black-seeded oilseed rape DH line, respectively.

In the present study, the ADF content in the defatted meal ranged from $20.5 \%$ to $26.8 \%$ for the 28 cultivars. Compared with this, the ADF contents reported by Mailer et al. (2008) 
Table 6: Independent validation of NIRS calibration equations for NDF, ADF and ADL contents ( $\%$ of defatted meal) with 60 seed samples of the doubled haploid winter oilseed rape population Express $617 \times \mathrm{R} 53$ from the second field year

\begin{tabular}{lccccccr}
\hline Trait & Mean & SD & Range & SEP $(C)$ & $R^{2} V$ & RPD & RER \\
\hline NDF & 29.69 & 2.34 & $22.42-33.46$ & 1.26 & 0.72 & 1.86 & 8.76 \\
ADF & 23.79 & 2.58 & $17.34-28.98$ & 1.16 & 0.80 & 2.22 & 10.03 \\
ADL & 11.08 & 1.89 & $5.97-15.21$ & 1.06 & 0.76 & 1.78 & 8.89
\end{tabular}

ADF, acid detergent fibre; ADL, acid detergent lignin; NDF, neutral detergent fibre; NIRS, near-infrared reflectance spectroscopic. $\mathrm{RPD}=\mathrm{SD} / \mathrm{SEP}(\mathrm{C}), \mathrm{RER}=\mathrm{Range} / \mathrm{SEP}(\mathrm{C})$.

for the above-mentioned plant material were about $5 \%$ lower with contents ranging from $16.4 \%$ to $20.8 \%$ of the defatted meal. Wittkop et al. (2009) reported a seed ADF content of $9.6 \%$ for a yellow-seeded and $12.7 \%$ for a black-seeded oilseed rape line. This compares well with the $9.8-13.0 \%$ ADF content determined in the present set of black-seeded modern oilseed rape cultivars, indicating that yellow-seeded oilseed rape not necessarily need to have a lower ADF content than blackseeded oilseed rape. Similar results were obtained by Font et al. (2003), who reported overlapping ADF contents for yellow-seeded $B$. carinat $a$ and $B$. juncea and black-seeded B. napus accessions. In that work, the ADF contents of 41 B. napus accessions ranged from $8.5 \%$ to $13.4 \%$ of the seed dry weight. In a follow-up study with yellow-, brown- and black-seeded B. napus samples, a slightly larger variation ranging from $6.8 \%$ to $13.5 \%$ of dry seeds were reported by Font et al. (2005).

The ADL content of the defatted meal of the modern cultivars analysed in this study ranged from $8.5 \%$ to $13.2 \%$ which corresponds to $4.1-6.4 \%$ of the seed dry matter. These results compare well with the $9.9-13.9 \%$ variation in the defatted meal reported for Australian canola cultivars (Mailer et al. 2008). Wittkop et al. (2009) reported ADL contents of $3.2 \%$ and $5.9 \%$ of dry seeds of a yellow- and a black-seeded winter oilseed rape DH line.

The seed hull content of seed samples analysed in the present study varied between $14.9 \%$ and $17.6 \%$ (Table 3 ). These
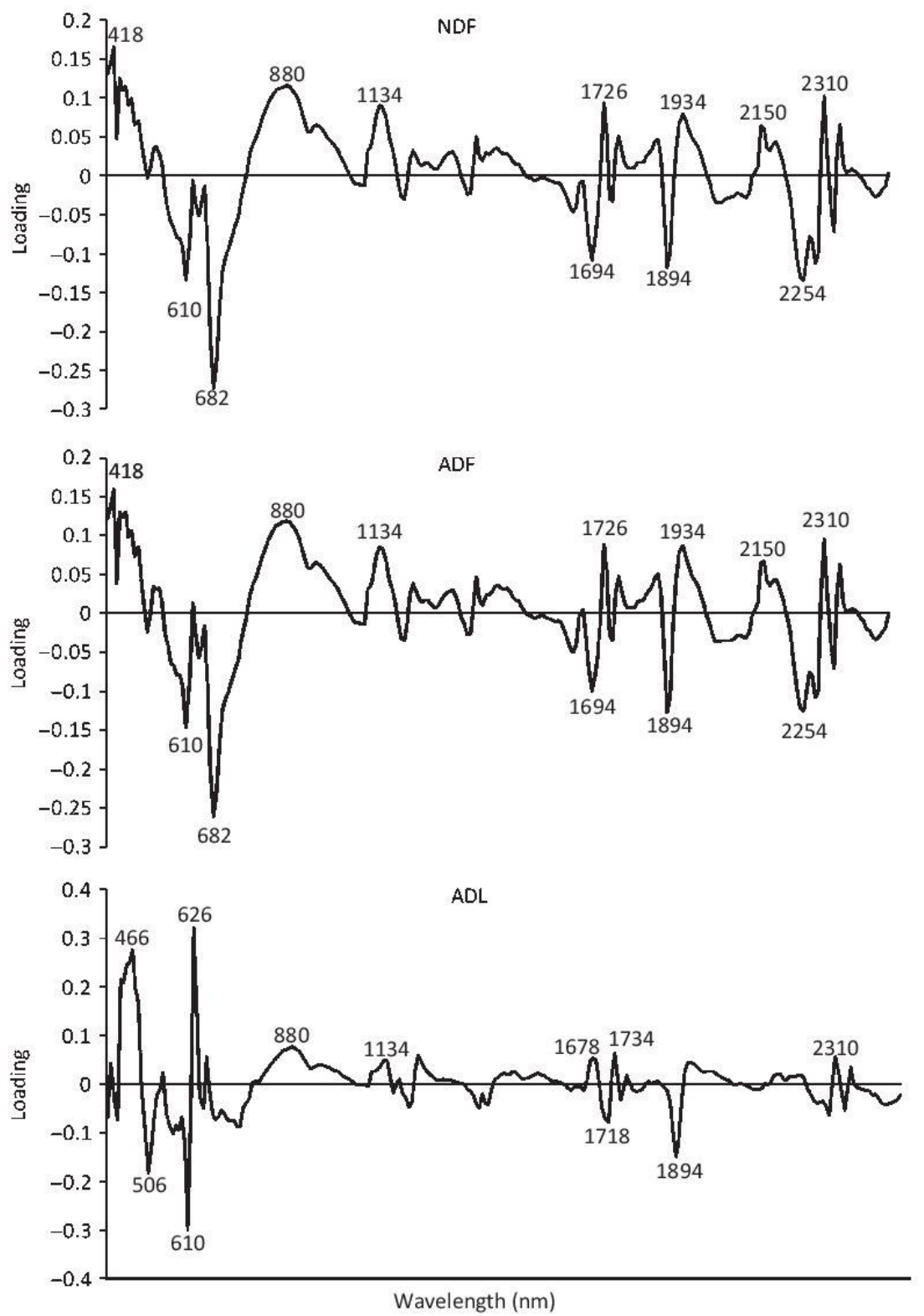

Fig. 2: Modified partial least squares loading spectra for neutral detergent fibre (NDF), acid detergent fibre (ADF) and acid detergent lignin (ADL) contents in the defatted meal of intact seeds of black-seeded Brassica napus in the first derivative $(1,4,4,1)$ transformation 
results compare well with the results of Matthäus (1998) who found a variation of $13-18.5 \%$ seed hull content among seven winter oilseed rape cultivars tested in different environments. Shirzadegan and Röbbelen (1985) described a variation of $14.0-18.6 \%$ in seed lots of black-seeded samples with a similar TKW. Yan et al. (2009) reported for a black-seeded B. napus line tested in three different environments in China seed hull contents ranging from $16.8 \%$ to $21.3 \%$. A simultaneously tested yellow-seeded line had seed hull contents ranging from $12.3 \%$ to $15.8 \%$.

The Spearman rank correlation coefficients showed, as expected, a close correlation between NDF, ADF and ADL contents. Most of the other correlation coefficients were not significant, because of the limited number of genotypes tested. However, the correlations indicate some trends. NDF, ADF and $\mathrm{ADL}$ contents were in descending order negatively correlated with the seed protein content and the protein content of the defatted meal, but they were not at all correlated with seed oil content. These results are in contrast with the results of Wittkop et al. (2009) who observed in a set of 54 dark-seeded winter oilseed rape varieties a negative correlation between NDF content and oil content $\left(r=-0.51^{* *}\right)$. Some earlier studies have also demonstrated reduced fibre content to be negatively correlated with the oil and protein content in the seed (Stringam et al. 1974, Simbaya et al. 1995, Badani et al. 2006). In the study of Yan et al. (2009), reduced seed hull content was found to be negatively correlated with seed oil content and seed coat colour. Considering the large number of different genes involved in the expression of fibre-related traits in oilseed rape and the increasing number of available yellowand brown-seeded germplasm sources, clearly more research is needed to come to conclusive results regarding the genetic interactions between the contents of fibre, oil and protein in the seed.

Regarding the development of NIRS calibrations for fibre fractions developed in the present work, the results indicate that NIRS can be used efficiently to select in segregating blackseeded populations for low NDF, ADF and ADL contents, provided that there is sufficient variation. For the intact seeds, Font et al. (2003) obtained best calibration results for ADF content using the math treatment: derivative 2, gap 5, first smooth 5 and second smooth 2. For ADF, they reported a standard error in cross-validation (SECV) of $0.93 \%$ and a standard error of prediction (SEP) of $0.75 \%$. These results are about comparable with the results of this study, because on a seed basis, we obtained for ADF a SECV of $0.67 \%$ and a $\mathrm{SEP}(\mathrm{C})$ of $0.95 \%$ (data not shown). Wittkop et al. (2009) reported the development of a NIRS calibration for ADL content, but without giving statistical details. The usefulness of NIRS calibrations is frequently estimated by using the SD/ SECV and RPD [SD/SEP(C)] ratio. For good calibrations, these ratios should ideally be at least 3 (Williams and Sobering 1996). In the present study, these ratios were only in the range of 1.8-2.2 (cf. Tables 5 and 6). These low values are partly due to the fact that the majority of the seed samples had intermediate NDF, ADF and ADL contents, and only few samples had very low and very high contents (see Fig. 1). Nevertheless, RER values (Williams and Sobering 1996) in the range of $9-10$ and the trait variations depicted in Fig. 1 indicate that the calibrations should be useful to select genotypes with low fibre fraction contents. The strong similarity between the MPLS loading plots of the first factor for NDF and ADF (Fig. 2) is not surprising because the only difference between the two fractions is hemicellulose (see Introduction). Hemicellulose and cellulose may be quite similar in their NIRS absorption characteristics. On the other hand, the MPLS loading plot for ADL (an extract of ADF) is quite different from the ADF and NDF loading plots. Differences were found mainly in the visible region (400$700 \mathrm{~nm}$ ), indicating that lignin may be located mainly in the seed hull and may be closely correlated with seed colour (Font et al. 2003, Wittkop et al. 2009). MPLS loading plots for ADF were also published by Font et al. (2003), but results are not comparable, because the authors developed the plots following second derivative $(2,5,5,2)$ transformation of the spectra. To our knowledge, there are no other comparable reports about the NIRS calibration development for ADL and NDF contents in the meal of oilseed rape. However, NIRS calibrations for NDF, ADF and ADL have been developed for cereals like wheat and barley (Stubbs et al. 2010, and references therein).

In conclusion, the results of the present study revealed a large genetic variation for NDF, ADF and ADL contents among modern black-seeded European winter oilseed rape cultivars. With medium to high heritabilities and the availability of NIRS calibrations for NDF, ADF and ADL contents, the prospects for reducing fibre content in winter oilseed rape breeding programmes can be considered as good.

\section{Acknowledgements}

The authors express their gratitude to Rolf Jeromin and Uwe Ammermann for their technical assistance and to Sortenförderungsgesellschaft (SFG) in Bonn for providing seed sample material from the Bundes- und EU-Sortenversuch Winterraps 2008/2009 field experiments. Zoran Dimov gratefully acknowledges a fellowship from the DAAD.

\section{References}

Badani, A. G., R. J. Snowdon, R. Baetzel, F. D. Lipsa, B. Wittkop, R. Horn, A. De Haro, R. Font, W. Lühs, and W. Friedt, 2006: A model for the inheritance of seed colour in oilseed rape (Brassica napus L.) based on analyses of segregation data, QTL and associated quality traits in two genetically distinct crosses. Genome 49, $1499-1509$.

Bell, J. M., 1993: Factors affecting the nutritional value of canola meal: a review. Can. J. Anim. Sci. 73, 679-697.

Burbulis, N., and L. S. Kott, 2005: A new yellow-seeded canola genotype originating from double low black-seeded Brassica napus cultivars. Can. J. Plant Sci. 85, 109-114.

Clark, W. D., H. L. Classen, and R. W. Newkirk, 2001: Assessment of tail-end dehulled canola meal for use in broiler diets. Can. J. Anim. Sci. 81, 379-386.

Font, R., M. del Río, J. M. Fernández, and A. de Haro, 2003: Acid detergent fiber analysis in oilseed Brassicas by near-infrared spectroscopy. J. Agric. Food. Chem. 51, 2917-2922.

Font, R., B. Wittkop, A. G. Badani, M. Del Rio-Celestino, W. Friedt, W. Lühs, and A. De Haro-Baillon, 2005: The measurements of acid detergent fibre in rapeseed by visible and nearinfrared spectroscopy. Plant Breed. 124, $410-412$.

Gronow, J., W. Sauermann, and G. Barthelmes, 2009: Sortenversuche 2009 - Mit Winterraps, Futtererbsen und Sonnenblumen. UFOP Schriften, Heft 37/Agrar (E-Book). Available at: http://www.ufop.de/publikationen_schriften.php (last accessed on January 25, 2012).

Leckband, G., M. Frauen, and W. Friedt, 2002: NAPUS 2000. Rapeseed (Brassica napus) breeding for improved human nutrition. Food Res. Int. 35, 273-278. 
Mailer, R. J., A. McFadden, J. Ayton, and B. Redden, 2008: Antinutritional components, fibre, sinapine and glucosinolate content, in Australian canola (Brassica napus L.) meal. J. Am. Oil Chem. Soc. 85, $937-944$.

Matthäus, B., 1998: Effect of dehulling on the composition of antinutritive compounds in various cultivars of rapeseed. Fett/Lipid 100, 295-301.

Michalski, K., P. Ochodzki, and B. Cicha, 1992: Determination of fibre, sulphur amino acids and lysine in oilseed rape by NIT. In: I. Murray, and I. A. Cowe (eds), Making Light Work: Advances in Near Infrared Spectroscopy, 333-335. VCH Weinheim, New York

Panford, A., P. C. Williams, and J. M. Man, 1988: Analysis of oilseeds for protein, oil, fiber and moisture by near-infrared reflectance spectroscopy. J. Am. Oil Chem. Soc. 65, 1627-1634.

Shirzadegan, M., and G. Röbbelen, 1985: Influence of seed colour and hull proportion on quality properties of seeds in Brassica napus L. Fette, Seifen, Anstrichmittel 87, 235-237.

Simbaya, J., B. A. Slominski, A. Bogdan, G. Rakow, L. D. Campbell, R. K. Downey, and J. M. Bell, 1995: Quality characteristics of yellow-seeded Brassica seed meals: protein, carbohydrates, and dietary fiber components. J. Agric. Food. Chem. 43, $2062-2066$.

Stringam, G. D., D. I. McGregor, and S. H. Pawlowski, 1974 Chemical and morphological characteristics associated with seed coat color in rapeseed. In: Organizing Committee of the 4th International Rapeseed Congress (ed.), Proceedings of the 4th International Rapeseed Congress, 99-108. Giessen, Germany.
Stubbs, T. L., A. C. Kennedy, and A. M. Fortuna, 2010: Using NIRS to predict fiber and nutrient content of dryland cereal cultivars. J. Agric. Food. Chem. 58, $398-403$.

Utz, H. F., 2008: PLABSTAT (Version 2N), A Computer Program for the Computation of Variances and Covariances. Institute of Plant Breeding, Seed Science, and Population Genetics, University of Hohenheim, Stuttgart, Germany. Available at: http://www.unihohenheim.de/ipspwww/soft.html (Site visited November 30, 2008).

Van Deynze, A. E., W. D. Beversdorf, and K. P. Pauls, 1993: Temperature effects on seed colour in black- and yellow-seeded rapeseed. Can. J. Plant Sci. 73, 383-387.

Van Soest, P. J., J. B. Robertson, and B. A. Lewis, 1991: Methods for dietary fiber, neutral detergent fiber, and nonstarch polysaccharides in relation to animal nutrition. J. Dairy Sci. 74, 3583-3597.

Williams, P. C., and D. C. Sobering, 1996: How do we do it: a brief summary of the methods we use in developing near-infrared calibrations. In: A. M. C. Davies, and P. C. Williams (eds), Near Infrared Spectroscopy: The Future Waves, 185-188. Nir Publications, Chichester, UK.

Wittkop, B., R. J. Snowdon, and W. Friedt, 2009: Status and perspectives of breeding for enhanced yield and quality of oilseed crops for Europe. Euphytica 170, 131-140.

Yan, X. Y., J. N. Li, F. Y. Fu, M. Y. Jin, L. Chen, and L. Z. Liu, 2009: Co-location of seed oil content, seed hull content and seed coat color QTL in three different environments in Brassica napus L. Euphytica 170, $355-364$. 


\title{
Genetic analysis and QTL mapping of fibre content and seed hull proportion in three doubled haploid populations of black-seeded winter oilseed rape (Brassica napus L.)
}

\begin{abstract}
The meal from oilseed rape is a valuable product and potential protein source for animal diets. For feeding purposes, however, fibre content in oilseed rape meal is relatively high. Taking advantage of natural genetic variation for seed fibre content among black-seeded germplasm may complement ongoing approaches to reduce fibre content in winter oilseed rape. Seeds derived from field experiments of three doubled haploid (DH) populations of black-seeded winter oilseed rape, Sollux x Gaoyou, Express 617 x R53 and SG DH14 x Express 617 have been used to identify the genetic variation and inheritance of seed fibre content, to investigate a possible relationship between fibre content and other important seed quality traits and to determine quantitative trait loci (QTL) responsible for fibre content. Relatively large variation of fibre fractions were observed in those three DH populations. In the population SG DH14 $\mathrm{x}$ Express 617, NDF, ADF, and ADL content of defatted meal were negatively correlated with seed oil content indicating that increase in oil content occurred at the expense of fibre content and not at the expense of protein content. Negative correlation between cellulose and glucosinolate content and common QTL with overlapping confidence intervals indicated that both traits might be co-regulated. Selection for high oil, high protein and low fibre content in black-seeded winter oilseed rape is possible to be conducted in the population SG DH14 x Express 617 which showed positive correlation between seed oil content and protein of defatted meal. Thousand kernel weight is an important trait that should be considered for the selection due to its indirect effect on low fibre content by reducing seed hull proportion.
\end{abstract}

Key words: oilseed rape, Brassica napus, black-seeded, neutral detergent fibre, acid detergent fibre, lignin, cellulose, oil, glucosinolate, seed weight, hull, QTL 


\subsection{Introduction}

Apart from being cultivated for its high oil content for food and fuel industries, the meal of oilseed rape (B. napus L.) is a valuable product and a potential source for animal diets and human nutrition. Oilseed rape meal derived from canola quality with low glucosinolate content has a balanced amino acid (Tan et al. 2011) and high methionine content (Khajali and Slominski 2012). However, the presence of comparatively high fibre content is a limiting factor for its use as animal feed. The fibre is mostly poorly digestible and essentially dilutes the metabolizable energy (Clark et al. 2001). The fibre fraction refers to cellulose, hemicellulose and lignin, as the main components of plant cell wall. The proportion of hemicellulose, cellulose and lignin in the oilseed rape meal can be quantified as neutral detergent fibre (NDF), acid detergent fibre (ADF) and acid detergent lignin (ADL) following the detergent fibre system developed by Van Soest et al. (1991). The NDF fraction consists (predominantly) of hemicellulose, cellulose and lignin content, while the ADF fraction comprises cellulose and lignin. ADL represents the nondigestible lignin fraction. NDF, ADF and ADL are used as indicators for forage quality, whereby NDF is used as indicator for feed intake, and ADF and ADL are used to characterize feed digestibility (Jung et al. 1997; Möller 2008; Saun 2006).

To improve the quality of oilseed rape meal, breeding research has been undertaken to select genetic material with lower fibre content. Selection for improved meal quality mostly focused on yellow-seeded B. napus which is characterized by a thinner seed coat (Bell 1993), less fibre (Simbaya et al. 1995), and higher oil content (Rahman 2001; Rakow et al. 2007). The higher seed oil content in yellow-seeded B. napus is partially attributed to the lower seed hull content (Yan et al. 2009), which led to an increase of the proportion of embryo. Stringam et al. (1974) reported that the palisade layer in yellow-seeded B. napus is reduced to half to two third of its thickness compared to that in brown-seeded types. In addition, Stringam et al. (1974) also reported that the oil and protein content of the seed coat of yellow-seeded oilseed rape was higher than those of brown seeded, while the oil and protein content of their embryos was not significantly different. However, selection for low fibre content based on the yellow-seeded phenotype still encountered difficulties because of strong environmental effects (Burbulis and Kott 2005; Deynze et al. 1993). Furthermore, Snowdon et al. (2010) reported that the broadsense heritability for seed colour $\left(h^{2}=0.51\right)$ was lower than that for fibre components $\left(h^{2}=0.79\right.$ for ADL), which reflects high environmental influence on seed colour and underlines the comparative benefit of selecting directly for fibre content in breeding for improved oilseed rape meal quality.

Taking advantage of natural genetic variation for NDF, ADF and ADL as well as seed hull proportion among black-seeded germplasm may complement ongoing approaches to reduce 
fibre content in winter oilseed rape meal. Bell (1993) suggested that there are variety of characters that may indirectly affect the level of the fibre content in oilseed rape meal such as seed size, seed hull proportion and composition of seed hull. Previous research by Dimov et al. (2012) revealed a relative large genetic variation for NDF, ADF, ADL content and seed hull proportion among modern black-seeded European winter oilseed rape cultivars and breeding lines. However, to date there is limited knowledge about the inheritance of fibre content and seed hull proportion in doubled haploid (DH) populations derived from black-seeded winter oilseed rape. The objectives of the present study were to analyze the genetic variation and inheritance of seed fibre fractions and seed hull proportion, to study their correlation with other seed quality traits and to identify quantitative trait loci (QTL) responsible for fibre content and seed hull proportion in three DH populations of black-seeded winter oilseed rape. Understanding the genetic basis of fibre fractions and their interaction with other seed components in oilseed rape may contribute to a more efficient breeding for higher protein content and a lower fibre content of the meal as well as to higher seed oil content.

\subsection{Materials and Methods}

\section{Plant material}

Seeds obtained from three DH populations of black-seeded winter oilseed rape grown in different environments over a period of several years were used for this study. Population I was derived from a cross between the old German winter oilseed rape cultivar Sollux and the Chinese cultivar Gaoyou (Zhao et al. 2005). Both genotypes, Sollux and Gaoyou, have high erucic acid and glucosinolate content ('++' quality) as well as high oil content. The population consisting of 282 DH lines was tested in 2000/2001 at the two locations Reinshof and Weende (both close to Göttingen in north-western Germany). The field experiments were performed as randomized block design with two replicates.

Population II consisted of 229 DH lines derived from a cross between inbred line no. 617 of the German winter oilseed rape cultivar Express and the resynthesized line R53. Cultivar Express is of canola-quality ('00'-quality; low erucic acid and low glucosinolate content). R53 was developed through interspecific hybridization between Brassica oleracea var. sabellica and Brassica rapa ssp. pekinensis, and it has '++' quality (high erucic acid and high glucosinolate content; Radoev et al. 2008, Schatzki et al. 2013). The DH lines were tested in two consecutive growing seasons 2008/2009 and 2009/2010 at two locations, Göttingen-Reinshof and Thüle, both in north western Germany. The field experiments were performed as a randomized block design with two replicates. 
Population III was composed of $228 \mathrm{DH}$ lines derived from a cross between doubled haploid line SG DH14 ('++' quality) and inbred line Express 617. The SG DH14 line has high oil content and is derived from above mentioned DH population Sollux x Gaoyou (Zhao et al. 2005). The DH lines were evaluated in unreplicated field experiments at six locations: 2009/2010 in GöttingenReinshof, Salzkotten-Thüle, and Einbeck and in 2010/2011 in Göttingen-Reinshof, Bad Salzuflen-Biemsen, and Schaumburg-Nienstädt.

From above mentioned field experiments seeds were harvested at maturity from 10 open pollinated plants per genotype and seeds were bulked for further analysis.

\section{Determination of fibre content by NIRS}

About $3 \mathrm{~g}$ of seeds from bulked seed samples were scanned with a NIRS monochromator model 6500 (NIR Systems mod. 6500, NIRSystems, Inc., Silversprings, MD, USA). Spectra were recorded between $400 \mathrm{~nm}$ and $2498 \mathrm{~nm}$, registering the absorbance values log (1/R) at $2 \mathrm{~nm}$ intervals for each sample. The content of neutral detergent fibre (NDF), acid detergent fibre (ADF) and acid detergent lignin (ADL) were extrapolated from NIR spectra using the calibrations developed specifically for measurement of fibre content in black-seeded B. napus (Dimov et al. 2012). Hemicellulose (HC) content was determined by subtracting ADF from NDF, and cellulose $(\mathrm{C})$ content was determined by subtracting ADL from ADF.

The calibration equation developed by Dimov et al. (2012) that contained already spectra data from 289 DH lines of Express 617 x R53 and 28 European winter oilseed rape cultivars was used. For predicting the fibre content in Sollux x Gaoyou and SG DH14 x Express 617 populations, 53 and 60 representative seed samples of Sollux x Gaoyou and of SG DH14 x Express 617 were selected and used to extend the calibration. After determination of NDF, ADF and ADL content on those 113 samples by reference methods (Van Soest et al. 1991), a new extended calibration was developed. The representative seed samples from each population was used for determining standard error of performance corrected for bias [SEP(C)] of the extended calibration. The SEP(C) of extended calibration in predicting NDF, ADF and ADL content in defatted meal of the subset of Express 617 x R53 were 1.27\%, 1.10\% and 1.95\%, of the subset of Sollux x Gaoyou were $4.1 \%, 1.1 \%$ and $0.72 \%$, and of the subset of SG DH14 x Express 617 were $2.92 \%, 1.58 \%$ and $1.21 \%$. The extended calibration was used to predict the NDF, ADF and ADL contents of all seed samples of the three DH populations. All fibre content values are given as percentage of fibre in the defatted meal, while percentage of fibre content in the seed $(\% \mathrm{DM})$ was calculated as:

$\%$ Fibre in the seed $(\% \mathrm{DM})=(\%$ Fibre $/ 100) *(100-\%$ Oil content $)$ 


\section{Seed hull proportion and thousand kernel weight}

The seed hull proportion (in \%) was determined from 100 seeds (approx. $500 \mathrm{mg}$ ) per sample. Seeds were dried at $105^{\circ} \mathrm{C}$ for 8 hours, and then imbibed in water for 15 to $20 \mathrm{hrs}$. Afterwards seed hulls were carefully separated from embryos by using a dissecting needle. Both fractions were dried at $105{ }^{\circ} \mathrm{C}$ overnight, and dry weights were determined. Thousand kernel weight (TKW) in grams was measured from 500 seeds using a seed counter (model Contador, Pfeuffer GmbH, D-97318 Kitzingen, http://www.pfeuffer.com). For Sollux x Gaoyou and Express 617 x R53 populations, seed hull proportion and TKW measurement were conducted only on the samples from the first replicate of each location.

\section{Measurement of other seed quality traits}

Seed oil, protein and glucosinolate content were determined from NIR spectra using the commercial calibration raps2012.eqa provided by VDLUFA Qualitätssicherung NIRS GmbH (Teichstr. 35, D-34130 Kassel, http://h1976726.stratoserver.net/cms, accessed February 24, 2014). Oil and protein are expressed on a seed basis at 91\% dry matter content. Protein content of the defatted meal (PodM) was calculated as:

$\%$ Protein of the defatted meal $($ PodM $)=[\%$ Seed protein $/(100-\%$ Oil $)] * 100$

\section{Statistical analysis}

Analysis of variance was performed by using PLABSTAT software (Utz 2011). In the analysis, for the populations with two replicates in the field experiment, location and replicates were considered as random variables. General model for analysis of variance was as follows:

$$
Y_{i j k}=\mu+g_{i}+e_{j}+r_{j k}+g_{e i j}+e_{i j k}
$$

Where $Y_{i j k}$ is observation of genotype $i$ in environment $j ; \mu$ is general mean; $g_{i}$ and $e_{j}$ are effects of genotype and environment $\mathrm{j}$; $g e_{i j}$ is genotype $\mathrm{x}$ environment interaction of genotype $i$ with environment $j$. Heritability $\left(h^{2}\right)$ of mean values over environment was calculated from components of variance following Hill et al. (1998):

$$
h^{2}=\sigma_{\mathrm{g}}^{2} /\left(\sigma_{\mathrm{g}}^{2}+\sigma_{\mathrm{ge}}^{2} / E+\sigma_{\varepsilon}^{2} / E R\right)
$$

Where $\sigma_{g}^{2}$ and $\sigma_{g e}^{2}$ are variance components for $g$ and $g e$; $E$ and $R$ is number of environment and replicates. Mean values of the genotypes across the environments were used to calculate Spearman's rank correlation coefficients between traits.

\section{Linkage maps and QTL mapping}

The linkage map for Sollux x Gaoyou population was taken from Zhao et al. (2012) which comprised 193 SSR markers, 175 STS, 84 SSCP, 10 CAPS, 17 SRAP and 2 SCAR markers. The 
Sollux x Gaoyou linkage map covers $1948.6 \mathrm{cM}$ genome length with average marker distance of $4.05 \mathrm{cM}$ (Zhao et al. 2012). Genetic map for population of Express 617 x R53 was developed by Radoev et al. (2008), and then extended by Schatzki et al. (2013). Final map consisted of 229 markers including 80 SSR and 149 AFLP markers, with a total map size of 2283 cM covering 21 linkage groups. For the population of SG DH14 x Express 617, a framework map developed by Behnke et al. (2014) was used. It consisted of 395 SNP markers, 22 AFLP markers and 53 DArT markers, with a total map size $2867.2 \mathrm{cM}$ covering 19 linkage groups and with an average marker distance of $6.4 \mathrm{cM}$.

QTL mapping was performed using the software QTL Network 2.1 (Yang et al. 2008) based on a novel QTL mapping method developed by Yang et al. (2007). As described by Yang et al. (2008), the method in detecting QTL begins with marker interval analysis to select candidate marker intervals that might be linked with QTL. These selected markers intervals are subsequently used as cofactors in a genome scan for putative QTL and then significant marker-interval interactions are detected. A 2D genome scan procedure is performed to search for epistasis on the detected QTL with additive main effects. The QTL analyses are implemented in mixed linear model framework with Henderson method III to construct the $F$-statistic, and with a permutation test to calculate the critical $F$-value to control genome-wise type error I (Yang et al. 2008). Permutation test is performed by 1000 permutations to determine the critical $F$ value threshold for each trait.

\subsection{Results}

\section{Analysis of variance and heritability}

Analysis of variance revealed significant effects of the genotypes on fibre content of defatted meal and seed hull proportion in all three DH populations (Table 3.1). The effect of the environments were mostly lower than the effect of the genotypes, except for NDF content in population III and hemicellulose (HC) content in population II and population III. In all populations, variance components for the genotype $x$ environment interactions (GxE) were generally smaller than the effects caused by genotypes, but larger than the effects caused by the locations. Only for NDF content in population III and seed hull proportion in population I, the GxE interaction effects were larger than the effect of the genotypes. Moderate to high heritabilities ranging from 0.56 to 0.97 were found for all traits in all three DH populations. Population I showed lowest heritabilities for seed hull proportion as well as for most of the fibre content related traits. 
Table 3.1 Components of variance and heritabilities for NDF, ADF, ADL, hemicelluloses (HC), and cellulose content (C) (\% of defatted meal), seed hull proportion (\%) and thousand kernel weight (TKW in g) in three DH populations of winter oilseed rape

\begin{tabular}{|c|c|c|c|c|c|c|}
\hline \multirow[t]{2}{*}{ Traits } & \multirow[t]{2}{*}{ Population } & \multicolumn{4}{|c|}{ Variance components } & \multirow{2}{*}{$\begin{array}{c}\text { Heritability } \\
h^{2}\end{array}$} \\
\hline & & $\sigma_{\mathrm{g}}^{2}$ & $\sigma^{2} \mathrm{e}$ & $\sigma^{2}$ ge & $\sigma_{\varepsilon}^{2}$ & \\
\hline \multirow[t]{3}{*}{$\mathrm{NDF}$} & I & $1.09^{* *}$ & $0.13^{* *}$ & $0.23^{* *}$ & 0.97 & 0.75 \\
\hline & II & $1.44^{* *}$ & $0.08^{* *}$ & $0.56^{* *}$ & 0.87 & 0.86 \\
\hline & III & $1.34^{* *}$ & $2.28^{* *}$ & 1.79 & - & 0.82 \\
\hline \multirow[t]{3}{*}{$\mathrm{ADF}$} & I & $0.53^{* *}$ & $0.11+$ & $0.10^{* *}$ & 0.40 & 0.78 \\
\hline & II & $1.91^{* *}$ & $0.97^{* *}$ & $0.35^{* *}$ & 0.64 & 0.93 \\
\hline & III & $3.39 * *$ & $1.83^{* *}$ & 0.93 & - & 0.96 \\
\hline \multirow[t]{3}{*}{ ADL } & I & $0.25^{* *}$ & 0.01 & $0.03^{* *}$ & 0.18 & 0.81 \\
\hline & II & $1.31^{* *}$ & $1.38^{* *}$ & $0.26^{* *}$ & 0.39 & 0.93 \\
\hline & III & $4.51^{* *}$ & $0.78^{* *}$ & 0.77 & - & 0.97 \\
\hline \multirow{3}{*}{$\begin{array}{l}\text { Hemicellulose } \\
(\mathrm{HC})\end{array}$} & I & $0.74^{* *}$ & 0.00 & $0.04^{*}$ & 0.39 & 0.86 \\
\hline & II & $0.50^{* *}$ & $5.67^{* *}$ & $0.24^{* *}$ & 0.43 & 0.84 \\
\hline & III & $0.73^{* *}$ & $0.85^{* *}$ & 0.84 & - & 0.84 \\
\hline \multirow{3}{*}{$\begin{array}{l}\text { Cellulose } \\
\text { (C) }\end{array}$} & I & $0.12^{* *}$ & $0.04^{*}$ & $0.01 *$ & 0.11 & 0.77 \\
\hline & II & $0.32^{* *}$ & $0.28^{* *}$ & $0.05^{* *}$ & 0.10 & 0.94 \\
\hline & III & $0.21^{* *}$ & $0.25^{* *}$ & 0.15 & - & 0.89 \\
\hline \multirow[t]{3}{*}{ Seed hull } & I & $0.73^{* *}$ & 0.09 & 1.17 & - & 0.56 \\
\hline & II & $0.93^{* *}$ & 0.01 & 0.60 & - & 0.76 \\
\hline & III & $1.60^{* *}$ & $0.16^{* *}$ & 1.12 & - & 0.81 \\
\hline \multirow[t]{3}{*}{ TKW } & I & $0.23^{* *}$ & 0.01 & 0.01 & - & 0.82 \\
\hline & II & 0.18 & 0.00 & 0.00 & - & 0.86 \\
\hline & III & $0.02^{* *}$ & $0.14^{* *}$ & 0.18 & - & 0.71 \\
\hline
\end{tabular}

Population I = Sollux x Gaoyou; II = Express 617 x R53; III = SG DH14 x Express 617. $\sigma^{2} \mathrm{~g}=$ genetic variance; $\sigma^{2} \mathrm{e}=$ environmental variance; $\sigma^{2}$ ge $=$ variance of genotype $\mathrm{x}$ environment interaction; $\sigma_{\varepsilon}^{2}=$ residual error; $*^{* *}$ denotes significance at $P<5 \%$ and $1 \%$

\section{Variation and segregation of traits}

Large and highly significant genetic variation among genotypes in all populations was observed for fibre content of defatted meal, seed hull proportion and TKW (Table 3.2). For the three populations the content of NDF ranged from 25.9 to $37.6 \%$, of ADF from 17.2 to $28.6 \%$ and of ADL from 6.1 to $15.9 \%$. The mean values of NDF and hemicellulose content of population I and III were higher than those of population II. On the contrary, the mean of ADF, ADL and cellulose content in population II were higher than those of population I and III.

The largest variation for fibre fractions and seed hull proportion among genotypes within the populations was found in population III (Table 3.2 and 3.3). The frequency distribution of NDF, ADF and ADL content showed a normal distribution for population I and II, while frequency 
distributions of ADF and ADL content showed a bimodal distribution in population III (Fig 3.1 3.3). Transgressive segregations for NDF, ADF and ADL content in defatted meal were observed in Population II and III (Fig. 3.2 and 3.3). There were genotypes having lower NDF, ADF and ADL contents compared to the ADL content of the lower parental line. In Population II, 207 genotypes had ADL contents lower than that of the parent Express 617 ( $<13.9 \%)$, while in population III 106 genotypes had ADL contents lower than the parent SG DH14 $(<8.3 \%)$.

Table 3.2 Minimum, maximum and mean values for NDF, ADF, ADL, hemicellulose (HC) and cellulose (C) content (\% of defatted meal) in three DH populations of winter oilseed rape

\begin{tabular}{|c|c|c|c|c|c|c|c|c|}
\hline \multirow[t]{2}{*}{ Traits } & \multirow[t]{2}{*}{ Population } & \multirow[t]{2}{*}{ Min } & \multirow[t]{2}{*}{ Max } & \multirow[t]{2}{*}{ Mean } & \multirow[t]{2}{*}{$F_{\text {value }}$} & \multirow[t]{2}{*}{ LSD 5\% } & \multicolumn{2}{|c|}{ Parents } \\
\hline & & & & & & & P1 & $\mathrm{P} 2$ \\
\hline \multirow[t]{3}{*}{$\mathrm{NDF}$} & $I$ & 28.6 & 37.6 & 34.8 & $4.1^{* *}$ & 1.7 & 32.4 & 35.2 \\
\hline & II & 25.9 & 34.7 & 31.6 & $8.0^{* *}$ & 1.3 & 35.5 & 34.7 \\
\hline & III & 30.2 & 37.2 & 33.6 & $5.5^{* *}$ & 1.5 & 35.4 & 36.1 \\
\hline \multirow[t]{3}{*}{$\mathrm{ADF}$} & I & 17.4 & 22.0 & 19.8 & $4.6^{* *}$ & 1.1 & 17.9 & 21.4 \\
\hline & II & 19.1 & 28.6 & 24.4 & $13.8^{* *}$ & 1.1 & 27.9 & 27.8 \\
\hline & III & 17.2 & 25.1 & 20.4 & $22.8^{* *}$ & 1.1 & 20.2 & 23.4 \\
\hline \multirow[t]{3}{*}{ ADL } & I & 6.3 & 9.7 & 7.9 & $5.3^{* *}$ & 0.7 & 7.4 & 11.1 \\
\hline & II & 7.9 & 15.9 & 12.4 & $14.6^{* *}$ & 0.9 & 13.9 & 15.0 \\
\hline & III & 6.1 & 14.0 & 9.4 & $36.1^{* *}$ & 1.0 & 8.3 & 12.0 \\
\hline \multirow[t]{3}{*}{$\mathrm{HC}$} & I & 10.6 & 17.2 & 14.9 & $7.1^{* *}$ & 1.0 & 14.5 & 13.8 \\
\hline & II & 4.7 & 9.1 & 7.2 & $6.3^{* *}$ & 0.9 & 7.5 & 6.9 \\
\hline & III & 11.0 & 15.1 & 13.2 & $6.2^{* *}$ & 1.0 & 15.2 & 12.4 \\
\hline \multirow[t]{3}{*}{$\mathrm{C}$} & I & 10.6 & 13.1 & 11.9 & $4.4^{* *}$ & 0.5 & 10.5 & 10.3 \\
\hline & II & 10.5 & 13.7 & 12.1 & $16.3^{* *}$ & 0.4 & 14.1 & 12.8 \\
\hline & III & 9.9 & 12.5 & 11.1 & $9.3^{* *}$ & 0.4 & 11.9 & 11.8 \\
\hline
\end{tabular}

LSD 5\% = least significant difference at $P<5 \%$; P1 and P2 refer to Parent 1 and Parent 2 for each cross. Population I = Sollux x Gaoyou; II = Express 617 x R53; III = SG DH14 x Express 617.*,** denotes significance at $P<5 \%$ and $1 \%$ 
Table 3.3 Minimum, maximum and mean values for NDF, ADF, ADL, hemicellulose (HC) and cellulose (C) content (\% of seed basis), seed hull proportion (\%), thousand kernel weight (TKW in g), seed oil (\%), seed protein (\%), protein of defatted meal (\%), glucosinolate (GSL in $\mu \mathrm{mol} / \mathrm{g}$ ) and erucic acid (\%) content in seeds of three DH populations of winter oilseed rape

\begin{tabular}{|c|c|c|c|c|c|c|c|c|}
\hline \multirow[t]{2}{*}{ Traits } & \multirow[t]{2}{*}{ Population } & \multirow[t]{2}{*}{ Min } & \multirow[t]{2}{*}{ Max } & \multirow[t]{2}{*}{ Mean } & \multirow[t]{2}{*}{$F_{\text {value }}$} & \multirow{2}{*}{$\begin{array}{l}\text { LSD } \\
5 \%\end{array}$} & \multicolumn{2}{|c|}{ Parents } \\
\hline & & & & & & & P1 & P2 \\
\hline \multirow[t]{3}{*}{$\overline{\mathrm{NDF}}$} & I & 16.3 & 18.5 & 17.3 & $3.5^{* *}$ & 0.5 & 12.1 & 16.3 \\
\hline & II & 14.8 & 19.7 & 17.7 & $9.3^{* *}$ & 0.7 & 15.5 & 16.3 \\
\hline & III & 15.8 & 21.1 & 18.4 & $21.0^{* *}$ & 0.7 & 12.3 & 15.5 \\
\hline \multirow[t]{3}{*}{$\mathrm{ADF}$} & I & 8.8 & 10.9 & 9.9 & $8.0^{* *}$ & 0.4 & 6.7 & 11.7 \\
\hline & II & 10.9 & 16.3 & 13.6 & $15.5^{* *}$ & 0.6 & 13.0 & 14.7 \\
\hline & III & 9.3 & 14.2 & 11.2 & $47.8^{* *}$ & 0.5 & 7.1 & 13.0 \\
\hline \multirow[t]{3}{*}{$\mathrm{ADL}$} & I & 3.3 & 4.8 & 3.9 & $7.2^{* *}$ & 0.3 & 4.1 & 6.4 \\
\hline & II & 4.5 & 9.1 & 6.9 & $14.8^{* *}$ & 0.5 & 6.7 & 8.0 \\
\hline & III & 3.4 & 7.9 & 5.1 & $46.7^{* *}$ & 0.5 & 4.6 & 6.7 \\
\hline \multirow[t]{3}{*}{$\mathrm{HC}$} & I & 6.2 & 8.3 & 7.4 & $5.8^{* *}$ & 0.4 & 5.4 & 4.6 \\
\hline & II & 2.6 & 5.4 & 4.0 & $5.6^{* *}$ & 0.5 & 2.6 & 1.8 \\
\hline & III & 5.9 & 8.5 & 7.2 & $6.2^{* *}$ & 0.6 & 5.2 & 2.6 \\
\hline \multirow[t]{3}{*}{$\mathrm{C}$} & I & 5.3 & 6.5 & 5.9 & $6.7^{* *}$ & 0.2 & 2.6 & 5.3 \\
\hline & II & 5.8 & 7.5 & 6.7 & $11.8^{* *}$ & 0.2 & 6.3 & 6.7 \\
\hline & III & 5.4 & 7.1 & 6.1 & $16.1^{* *}$ & 0.2 & 2.5 & 6.3 \\
\hline \multirow[t]{3}{*}{ Hull } & I & 9.0 & 17.9 & 14.6 & $2.2^{* *}$ & 2.1 & 13.2 & 15.9 \\
\hline & II & 11.3 & 19.4 & 15.9 & $4.1^{* *}$ & 1.5 & 16.3 & 17.8 \\
\hline & III & 11.3 & 17.7 & 14.8 & $5.3^{* *}$ & 1.7 & 12.1 & 16.3 \\
\hline \multirow[t]{3}{*}{ TKW } & I & 2.9 & 5.9 & 4.4 & $5.7^{* *}$ & 0.6 & 4.5 & 3.8 \\
\hline & II & 3.8 & 6.4 & 4.9 & $3.3^{* *}$ & 0.5 & 5.4 & 4.7 \\
\hline & III & 3.8 & 6.3 & 4.7 & $3.4^{* *}$ & 0.7 & 5.0 & 5.4 \\
\hline \multirow[t]{3}{*}{ Oil } & $\mathrm{I}^{\mathrm{a}}$ & 42.9 & 55.4 & 50.2 & $5.0^{* *}$ & 2.3 & 48.0 & 47.2 \\
\hline & II b & 39.7 & 48.3 & 44.1 & $12.7^{* *}$ & 1.4 & 45.7 & 42.6 \\
\hline & III & 38.7 & 50.4 & 45.1 & $12.5^{* *}$ & 1.9 & 52.9 & 45.7 \\
\hline \multirow[t]{3}{*}{ Protein } & I a & 15.1 & 22.3 & 18.1 & $4.3^{* *}$ & 1.7 & 20.1 & 20.8 \\
\hline & $\mathrm{II}^{\mathrm{b}}$ & 18.1 & 24.3 & 21.1 & $5.9^{* *}$ & 1.1 & 18.0 & 20.6 \\
\hline & III & 17.0 & 23.4 & 19.1 & $3.3^{* *}$ & 1.5 & 15.6 & 18.0 \\
\hline \multirow{3}{*}{$\begin{array}{l}\text { Protein of } \\
\text { defatted meal }\end{array}$} & I a & 32.3 & 40.4 & 36.3 & $4.2^{* *}$ & 1.9 & 36.9 & 38.8 \\
\hline & $\mathrm{II}^{\mathrm{b}}$ & 34.2 & 41.6 & 37.8 & $7.9^{* *}$ & 1.3 & 33.1 & 35.9 \\
\hline & III & 30.3 & 40.1 & 34.7 & $8.3^{* *}$ & 1.9 & 33.2 & 33.1 \\
\hline \multirow[t]{3}{*}{ GSL } & I a & 49.2 & 97.4 & 73.1 & $5.5^{* *}$ & 10.3 & 87.3 & 66.7 \\
\hline & $\mathrm{II}^{\mathrm{b}}$ & 16.8 & 81.5 & 42.6 & $43.6^{* *}$ & 6.6 & 16.7 & 41.8 \\
\hline & III & 14.2 & 84.3 & 56.1 & $25.3^{* *}$ & 8.7 & 72.1 & 28.6 \\
\hline \multirow[t]{3}{*}{ C22:1 } & I a & 36.3 & 50.3 & 43.7 & $3.6^{* *}$ & 4.0 & 39.4 & 21.4 \\
\hline & $\mathrm{II}^{\mathrm{b}}$ & 1.3 & 36.7 & 17.9 & $37.1^{* *}$ & 4.2 & 0.0 & 15.9 \\
\hline & III & 0.00 & 49.4 & 23.3 & $110.8^{* *}$ & 4.5 & 45.5 & 0.0 \\
\hline
\end{tabular}

LSD 5\% = least significant difference at $P<5 \%$; aData taken from Zhao (2002); bData taken from Schatzki et al. (2013); P1 and P2 refer to Parent 1 and Parent 2 for each cross. Population I = Sollux x Gaoyou; II = Express 617 x R53; III = SG DH14 $x$ Express 617. *, ** denotes significance at $P<5 \%$ and $1 \%$ 

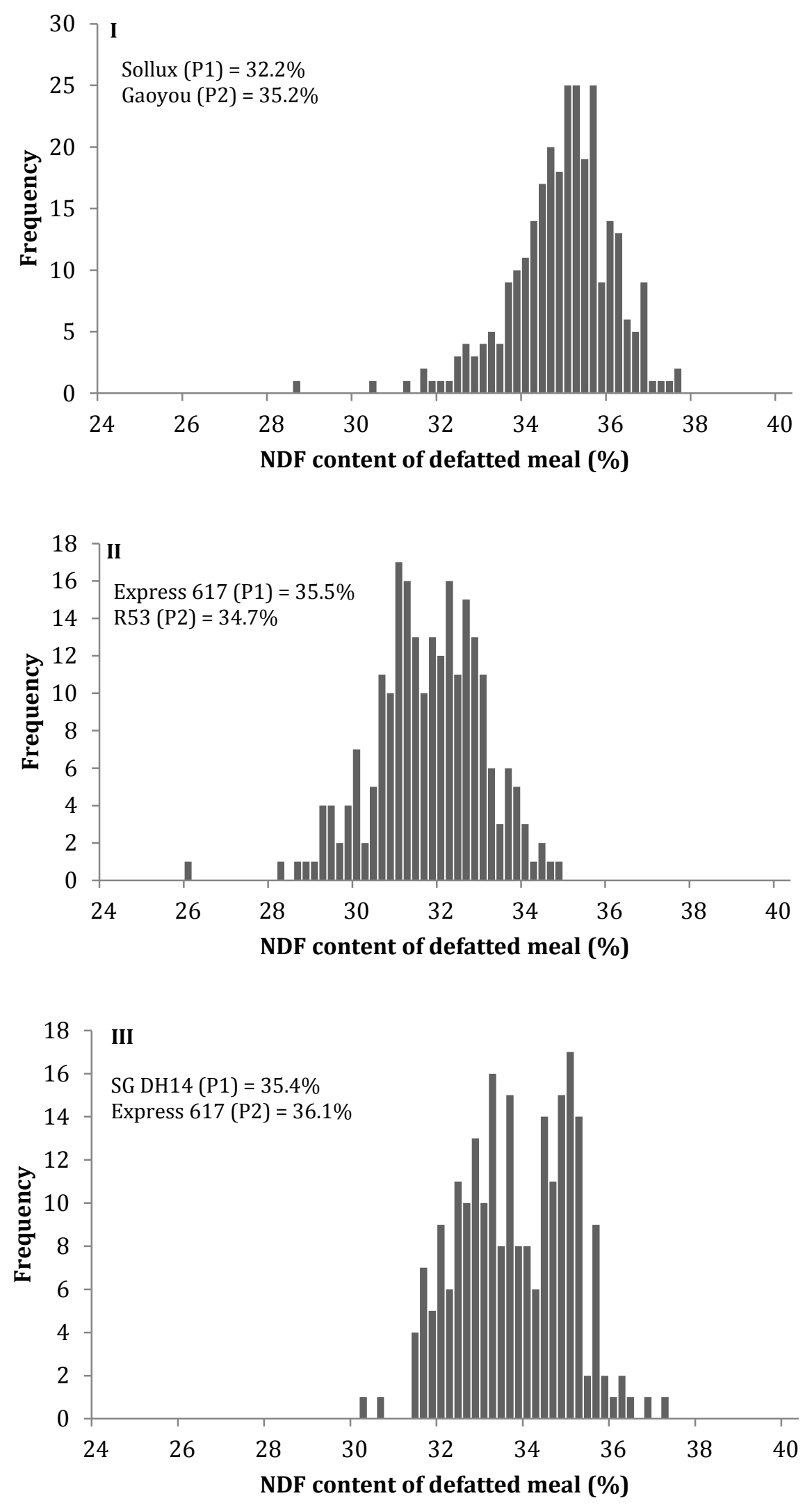

Figure 3.1 Frequency distribution of neutral detergent fibre (NDF) content of defatted meal in DH populations of winter oilseed rape: (I) Sollux x Gaoyou; (II) Express 617 x R53; (III) SG DH14 x Express617 

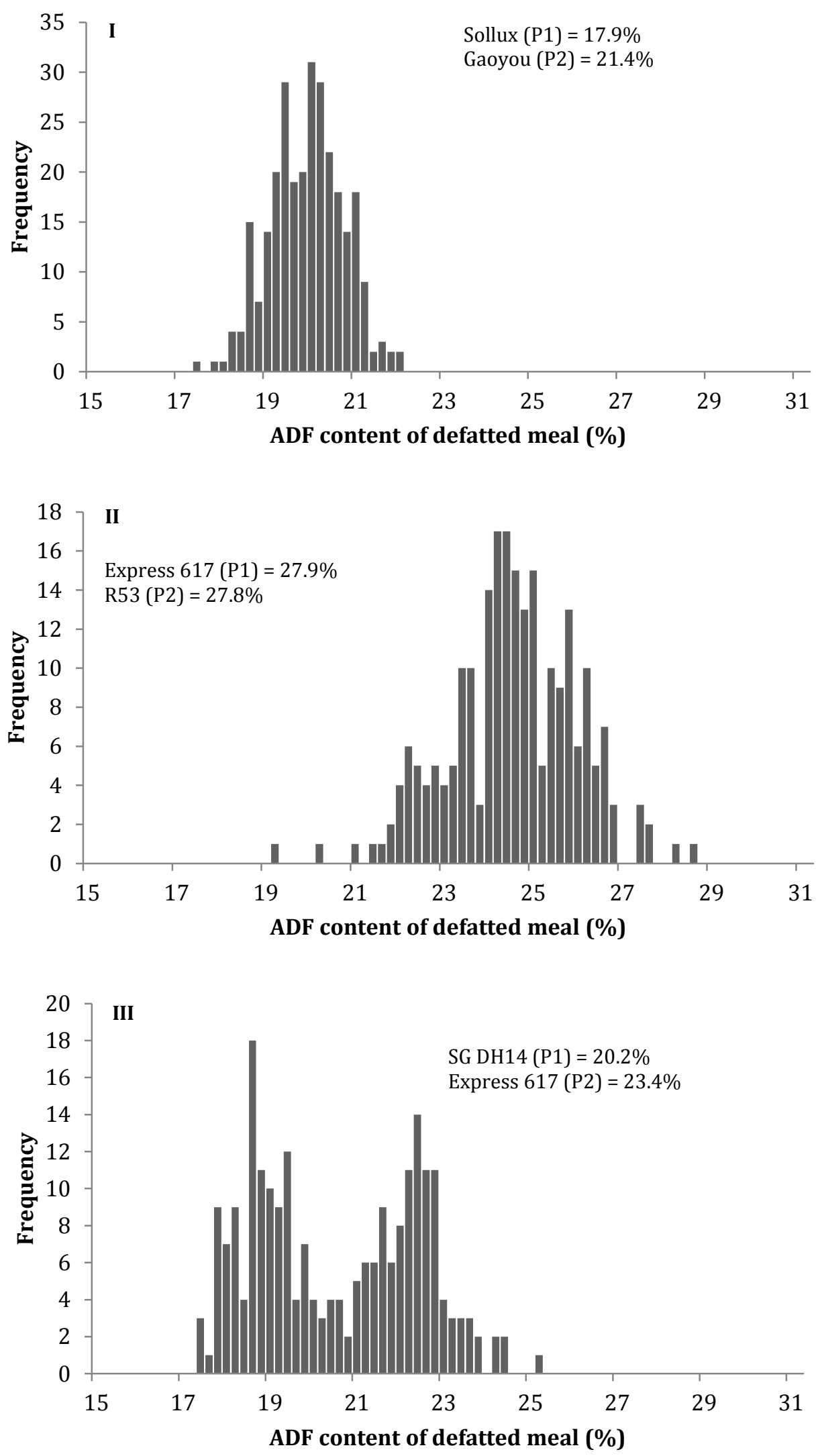

Figure 3.2 Frequency distribution of acid detergent fibre (ADF) content of defatted meal in DH populations of winter oilseed rape: (I) Sollux x Gaoyou; (II) Express 617 x R53; (III) SG DH14 x Express617 

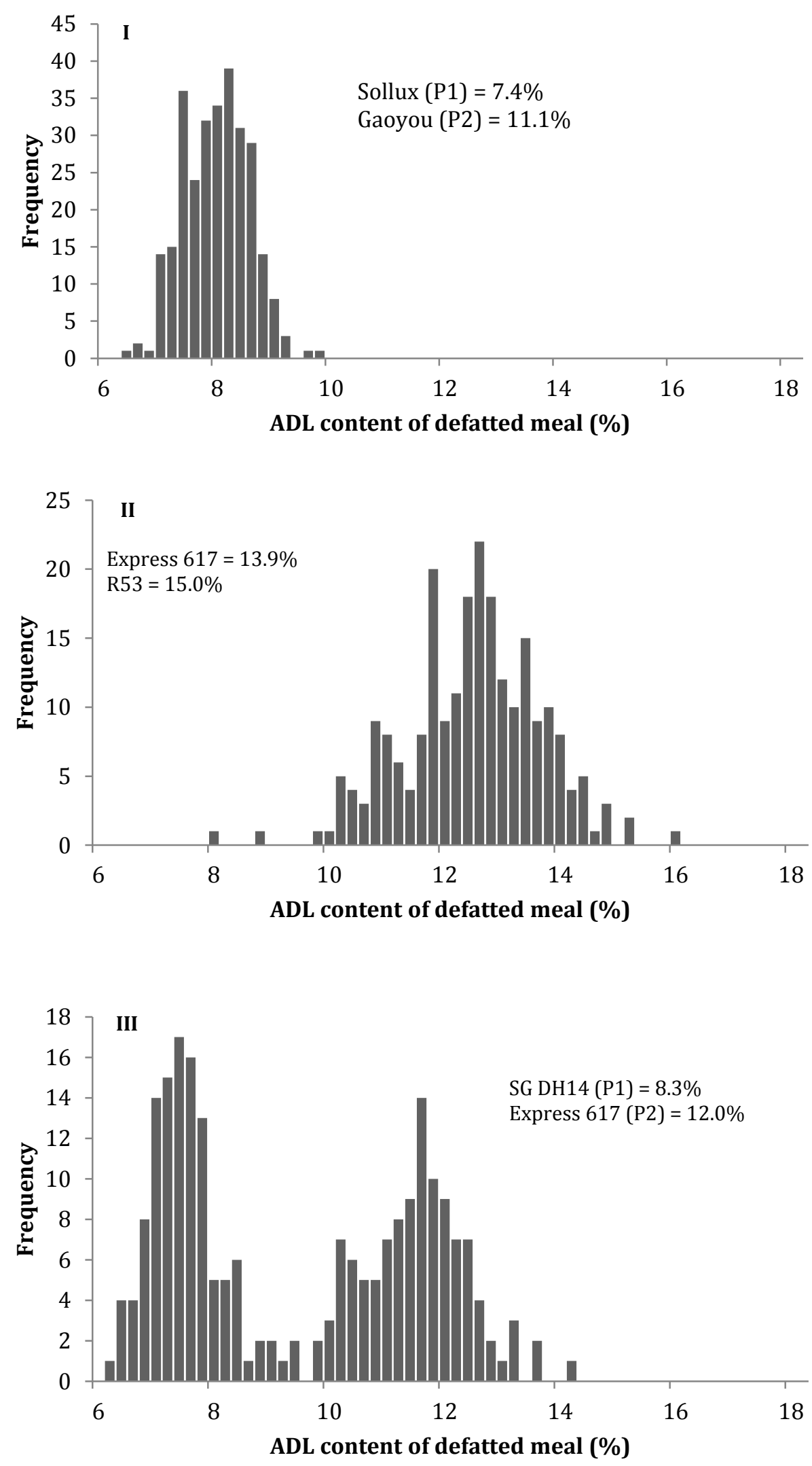

Figure 3.3 Frequency distribution of acid detergent lignin (ADL) content of defatted meal in DH populations of winter oilseed rape: (I) Sollux x Gaoyou; (II) Express 617 x R53; (III) SG DH14 x Express617 


\section{Correlation between traits}

Correlation analysis was performed between fibre fractions and other quality traits based on defatted meal values as well as on seed basis. Based on defatted meal values, close positive correlations were found between NDF, ADF and ADL content (Table 3.4). Hemicellulose was positively correlated to NDF in population I and II, but negatively correlated in population III. Additionally, hemicellulose was negatively correlated to ADF and ADL content in all populations. Cellulose content was positively correlated with NDF, ADF and ADL content in population I and II but negatively correlated in population III. Positive correlation between hemicellulose and cellulose was only detected in population III. NDF, ADF and ADL contents were positively correlated to oil content in population I and II, but were negatively correlated in population III. All fibre fractions showed negative correlations to the protein content of defatted meal with the exception of hemicellulose content in population II and III.

Table 3.4 Spearman's rank correlation of fibre fractions of defatted meal (suffix m), seed oil, protein content of defatted meal (PodM), seed hull proportion and thousand kernel weight (TKW)

\begin{tabular}{|c|c|c|c|c|c|c|c|c|c|}
\hline Traits & Population & Oil & PodM & NDFm & ADFm & ADLm & $\mathrm{HCm}$ & $\mathrm{Cm}$ & Hull \\
\hline Protein of & I & $-0.53^{* *}$ & & & & & & & \\
\hline defatted meal & II & -0.04 & & & & & & & \\
\hline (PodM) & III & $0.51^{* *}$ & & & & & & & \\
\hline \multirow[t]{3}{*}{ NDFm } & I & $0.80^{* *}$ & $-0.76^{* *}$ & & & & & & \\
\hline & II & $0.37 * *$ & $-0.52^{* *}$ & & & & & & \\
\hline & III & $-0.27^{* *}$ & $-0.48^{* *}$ & & & & & & \\
\hline \multirow[t]{3}{*}{$\mathrm{ADFm}$} & I & $0.42^{* *}$ & $-0.67^{* *}$ & $0.60^{* *}$ & & & & & \\
\hline & II & $0.37^{* *}$ & $-0.50^{* *}$ & $0.80^{* *}$ & & & & & \\
\hline & III & $-0.29^{* *}$ & $-0.41^{* *}$ & $0.90^{* *}$ & & & & & \\
\hline \multirow[t]{3}{*}{ ADLm } & I & $0.30 * *$ & $-0.48^{* *}$ & $0.48^{* *}$ & $0.90^{* *}$ & & & & \\
\hline & II & $0.17^{* *}$ & $-0.42^{* *}$ & $0.64^{* *}$ & $0.89^{* *}$ & & & & \\
\hline & III & $-0.29 * *$ & $-0.30^{* *}$ & $0.86^{* *}$ & $0.98^{* *}$ & & & & \\
\hline \multirow[t]{3}{*}{$\mathrm{HCm}$} & I & $0.61^{* *}$ & $-0.30^{* *}$ & $0.66^{* *}$ & $-0.15^{*}$ & $-0.21^{* *}$ & & & \\
\hline & II & -0.07 & 0.03 & $0.11^{* *}$ & $-0.45^{* *}$ & $-0.51^{* *}$ & & & \\
\hline & III & $0.31^{* *}$ & $0.16^{*}$ & $-0.46^{* *}$ & $-0.78^{* *}$ & $-0.78^{* *}$ & & & \\
\hline \multirow[t]{3}{*}{$\mathrm{Cm}$} & I & $0.44^{* *}$ & $-0.71^{* *}$ & $0.55^{* *}$ & $0.77^{* *}$ & $0.43^{* *}$ & -0.01 & & \\
\hline & II & $0.50 * *$ & $-0.37 * *$ & $0.62^{* *}$ & $0.59 * *$ & $0.19 * *$ & -0.08 & & \\
\hline & III & $0.28^{* *}$ & $-0.16^{*}$ & $-0.31^{* *}$ & $-0.45^{* *}$ & $-0.58^{* *}$ & $0.57^{* *}$ & & \\
\hline \multirow[t]{3}{*}{ Hull } & I & $-0.15^{*}$ & $-0.19 *$ & 0.01 & 0.09 & 0.08 & -0.09 & 0.07 & \\
\hline & II & $-0.16^{*}$ & $-0.32^{* *}$ & $0.49 * *$ & $0.51^{* *}$ & $0.57 * *$ & -0.11 & $0.13^{*}$ & \\
\hline & III & $-0.53^{* *}$ & $-0.35^{* *}$ & $0.66^{* *}$ & $0.77^{* *}$ & $0.78^{* *}$ & $-0.67^{* *}$ & $-0.56^{* *}$ & \\
\hline \multirow[t]{3}{*}{ TKW } & I & -0.06 & 0.05 & -0.12 & -0.04 & -0.05 & -0.05 & 0.00 & $-0.25^{* *}$ \\
\hline & II & $0.13 *$ & -0.11 & $-0.13 *$ & -0.10 & $-0.19 *$ & 0.01 & 0.08 & $-0.28^{* *}$ \\
\hline & III & -0.07 & 0.11 & -0.12 & -0.12 & $-0.13^{*}$ & 0.09 & -0.03 & $-0.26^{* *}$ \\
\hline
\end{tabular}

Population I = Sollux x Gaoyou; II = Express 617 x R53; III = SG DH14 x Express 617; *, ** denotes significance at $P<$ $5 \%$ and $1 \%$ 
Different results were observed when the correlation analysis was performed based on seeds. Most fibre fractions were negatively correlated to seed oil content (Table 3.5). Additionally, fibre fractions were less correlated to seed protein content with the exception of ADF, ADL and cellulose content in population II which showed negative correlation. Seed hull proportion was negatively correlated to seed oil content, but positively correlated to NDF, ADF, ADL and cellulose content in all populations. Furthermore, seed hull proportion was negatively correlated to hemicellulose content. Thousand kernel weight (TKW) was negatively correlated with seed hull proportion in all populations as well as with NDF, ADF and ADL content, although less stringent. In population II and III which segregated for erucic acid content, close positive correlations of erucic acid content to oil content and negative correlations to cellulose content were observed (Table 3.5). Negative correlations were detected between glucosinolate content and cellulose content in all three DH populations, which were particularly strong in population II (Fig 3.4). 
Table 3.5 Spearman's rank correlation for seed fibre content (suffix s) and other quality traits

\begin{tabular}{|c|c|c|c|c|c|c|c|c|c|c|c|}
\hline Traits & Population & Oil & Protein & NDFs & ADFs & ADLs & HCs & Cs & Hull & TKW & GSL \\
\hline \multirow[t]{3}{*}{ Protein } & I & $-0.85^{* *}$ & & & & & & & & & \\
\hline & II & $-0.66^{* *}$ & & & & & & & & & \\
\hline & III & $-0.32^{* *}$ & & & & & & & & & \\
\hline \multirow[t]{3}{*}{ NDFs } & I & $-0.38^{* *}$ & 0.03 & & & & & & & & \\
\hline & II & $-0.37^{* *}$ & -0.12 & & & & & & & & \\
\hline & III & $-0.81^{* *}$ & 0.02 & & & & & & & & \\
\hline \multirow[t]{3}{*}{ ADFs } & I & $-0.38^{* *}$ & 0.08 & $0.58^{* *}$ & & & & & & & \\
\hline & II & $-0.15^{*}$ & $-0.27^{* *}$ & $0.76^{* *}$ & & & & & & & \\
\hline & III & $-0.66^{* *}$ & -0.02 & $0.93^{* *}$ & & & & & & & \\
\hline \multirow[t]{3}{*}{ ADLs } & I & $-0.16^{* *}$ & -0.05 & $0.48^{* *}$ & $0.87^{* *}$ & & & & & & \\
\hline & II & $-0.11 *$ & $-0.21^{* *}$ & $0.64^{* *}$ & $0.91^{* *}$ & & & & & & \\
\hline & III & $-0.47^{* *}$ & -0.03 & $0.83^{* *}$ & $0.95^{* *}$ & & & & & & \\
\hline \multirow[t]{3}{*}{$\mathrm{HCs}$} & I & 0.08 & -0.03 & $0.66^{* *}$ & $0.27^{* *}$ & $-0.58^{* *}$ & & & & & \\
\hline & II & $-0.35^{* *}$ & $0.27^{* *}$ & $0.25^{* *}$ & $-0.37^{* *}$ & $-0.42^{* *}$ & & & & & \\
\hline & III & $-0.29 * *$ & 0.09 & -0.01 & $-0.34^{* *}$ & $-0.48^{* *}$ & & & & & \\
\hline \multirow[t]{3}{*}{ Cs } & I & $-0.52^{* *}$ & $0.20^{* *}$ & $0.49^{* *}$ & $0.75^{* *}$ & $-0.36^{* *}$ & $-0.41^{* *}$ & & & & \\
\hline & II & $-0.14^{*}$ & $-0.22^{* *}$ & $0.53^{* *}$ & $0.49^{* *}$ & 0.12 & 0.01 & & & & \\
\hline & III & $-0.61^{* *}$ & $-0.10^{* *}$ & $0.38^{* *}$ & $0.20^{* *}$ & -0.05 & $0.53^{* *}$ & & & & \\
\hline \multirow[t]{3}{*}{ Hull } & I & $-0.15^{*}$ & -0.04 & $0.27^{* *}$ & $0.20^{* *}$ & $0.15^{*}$ & -0.03 & $0.24^{* *}$ & & & \\
\hline & II & $-0.16^{*}$ & -0.12 & $0.63^{* *}$ & $0.65^{* *}$ & $0.63^{* *}$ & -0.05 & $0.29^{* *}$ & & & \\
\hline & III & $-0.53^{* *}$ & 0.08 & $0.76^{* *}$ & $0.84^{* *}$ & $0.84^{* *}$ & $-0.34^{* *}$ & 0.04 & & & \\
\hline \multirow[t]{3}{*}{ TKW } & I & -0.06 & 0.07 & -0.03 & 0.04 & -0.02 & -0.08 & 0.09 & $-0.25^{* *}$ & & \\
\hline & II & $0.13^{*}$ & 0.01 & -0.05 & -0.06 & $-0.16^{*}$ & 0.05 & $0.17^{* *}$ & $-0.28^{* *}$ & & \\
\hline & III & -0.07 & $0.16^{*}$ & -0.03 & -0.08 & -0.13 & 0.10 & 0.10 & $-0.26^{* *}$ & & \\
\hline \multirow[t]{3}{*}{ GSL } & I & -0.08 & 0.11 & -0.05 & -0.11 & -0.02 & 0.05 & $-0.19^{* *}$ & 0.05 & $0.19^{* *}$ & \\
\hline & II & $-0.40^{* *}$ & $0.37^{* *}$ & -0.04 & $-0.17^{*}$ & 0.06 & $0.28^{* *}$ & $-0.57^{* *}$ & -0.05 & $0.15^{*}$ & \\
\hline & III & -0.08 & 0.04 & -0.07 & $-0.17^{*}$ & $-0.15^{*}$ & $0.24^{* *}$ & $-0.15^{* *}$ & -0.08 & $-0.14^{*}$ & \\
\hline \multirow[t]{4}{*}{$\mathrm{C} 22: 1$} & I & $0.22^{* *}$ & -0.09 & $-0.16^{*}$ & -0.08 & 0.02 & -0.09 & $-0.17^{* *}$ & $-0.23^{* *}$ & $-0.12^{*}$ & -0.12 \\
\hline & II & $0.65^{* *}$ & $-0.13^{*}$ & $-0.30 * *$ & $-0.17^{*}$ & -0.11 & $-0.20^{* *}$ & $-0.14^{*}$ & -0.06 & $-0.17^{*}$ & -0.10 \\
\hline & III & $0.75^{* *}$ & $0.17^{* *}$ & $-0.62^{* *}$ & $-0.43^{* *}$ & -0.23 & $-0.47^{* *}$ & $-0.75^{* *}$ & $-0.28^{* *}$ & -0.03 & -0.06 \\
\hline & & Oil & Protein & NDFs & ADFs & ADLs & HCs & Cs & Hull & TKW & GSL \\
\hline
\end{tabular}

Population I = Sollux x Gaoyou; II = Express 617 x R53; III = SG DH14 x Express 617; *, ** denotes significance at $P<$ $5 \%$ and $1 \%$ 


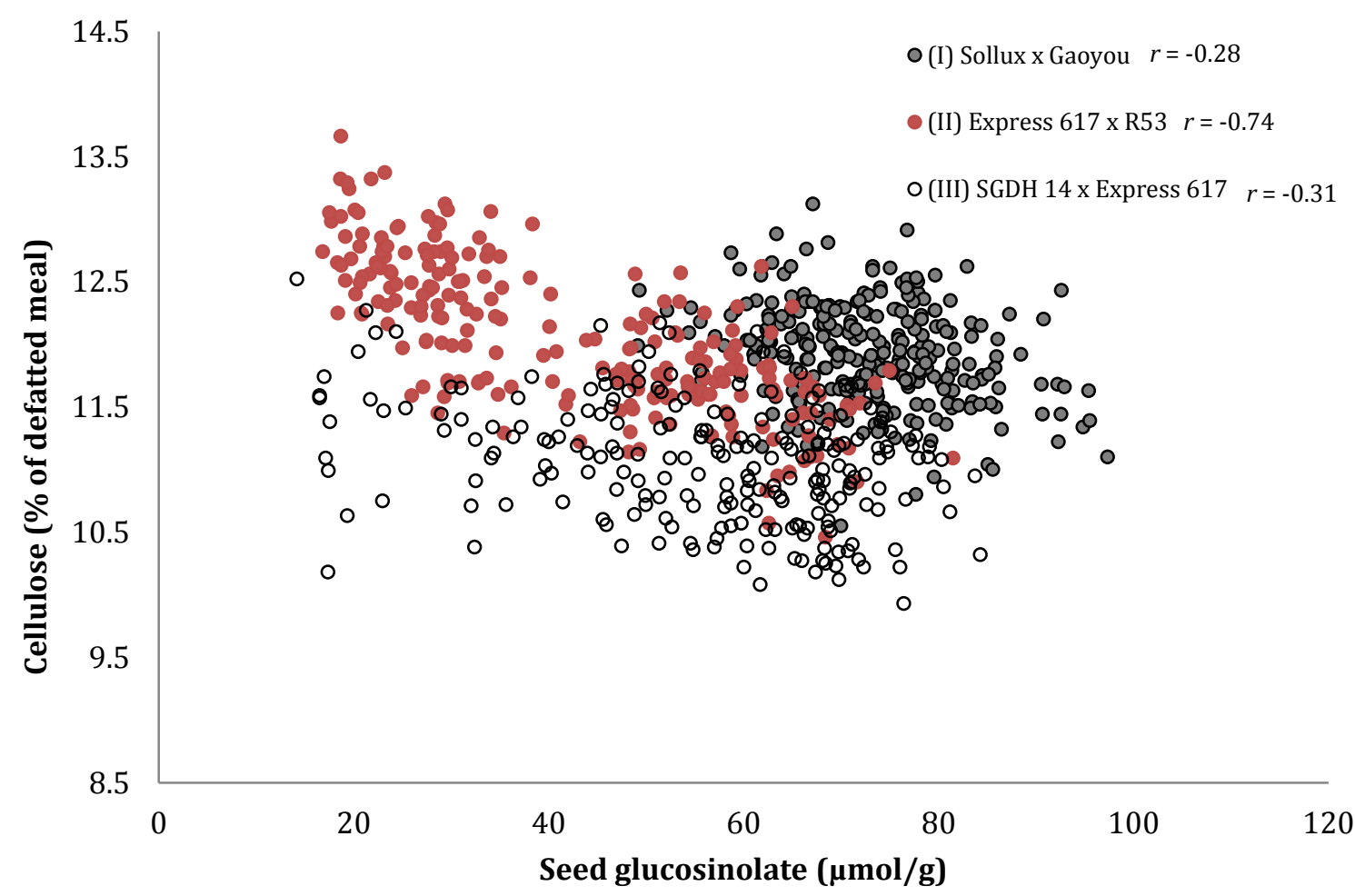

Figure 3.4 Correlation between seed glucosinolate and cellulose content of defatted meal in three DH populations. The $r$ values represent Spearman's rank correlation between seed glucosinolate and cellulose content for each population

\section{QTL for fibre content and seed hull proportion}

\section{Population I: Sollux x Gaoyou}

QTL mapping in population I led to the identification of two to four QTL for different fibre fractions in defatted meal (Table 3.6). For NDF content, three QTL were found and their effects explained $16 \%$ of the phenotypic variance observed in the population. One QTL for NDF content on linkage group C06 at position $59.7 \mathrm{cM}$ was located at the same position as a QTL for ADF content and within the marker interval of a QTL for cellulose content. The QTL for NDF content with the largest additive main effect of $0.31 \%$ on linkage group A08 at position $65.1 \mathrm{cM}$ showed an overlapping confidence interval with a QTL for hemicellulose content. Overlapping confidence intervals were also found for QTL for ADF and ADL contents on linkage group A03 and A06. No QTL was detected for seed hull proportion in population I.

Most of the QTL for fibre fractions calculated on seed basis were detected at different locations than those QTL for fibre content in defatted meal. On seed basis, only QTL ADFs-4 and ADLs-4 located on linkage group A03 and QTL ADFs-5 and ADLs-5 on linkage group A06 showed overlapping confidence intervals with their corresponding QTL in defatted meal (ADFm-1, ADLm-1, ADFm-2 and ADLm-2). 
Table 3.6 Mapped QTL and their most likely positions for NDF, ADF, ADL, hemicellulose (HC) and cellulose (C) content (\%) on the basis of defatted meal (suffix m) and seeds (suffix s) in the Sollux x Gaoyou population

\begin{tabular}{|c|c|c|c|c|c|c|c|c|}
\hline QTL & Markers & $\begin{array}{c}\text { Position } \\
\text { (cM) }\end{array}$ & Range(cM) & A & $\mathrm{h}^{2}(\mathrm{a})$ & $\mathrm{V}(\mathrm{A}) / \mathrm{V}(\mathrm{P})$ & $\mathrm{V}(\mathrm{I}) / \mathrm{V}(\mathrm{P})$ & $V(G) / V(P)$ \\
\hline NDFm-1 & A08 Ra2E12-CB10364 & 65.1 & $56.3-74.8$ & 0.31 & 0.07 & \multirow{3}{*}{0.16} & \multirow{3}{*}{0.06} & \multirow{3}{*}{0.22} \\
\hline NDFm-2 & C02 ZAAS940-CB10530 & 55.5 & $48.8-67.1$ & 0.26 & 0.05 & & & \\
\hline NDFm-3 & C06 KEMP-ZAAS819b & 59.7 & $55.6-61.3$ & 0.21 & 0.03 & & & \\
\hline NDFs-1 & A01 ZAAASA1-21-ZAAS165 & 80.2 & $74.0-83.7$ & -0.11 & 0.10 & \multirow[t]{2}{*}{0.19} & \multirow[t]{2}{*}{-} & \multirow[t]{2}{*}{0.19} \\
\hline NDFs-2 & C08 ZAAS197-BRAS031a & 92.4 & $84.4-100.4$ & 0.11 & 0.09 & & & \\
\hline ADFm-1 & A03 HMR085-ZAAS157 & 137.6 & 128.0-140.9 & -0.20 & 0.06 & \multirow{4}{*}{0.23} & \multirow{4}{*}{-} & \multirow{4}{*}{0.23} \\
\hline ADFm-2 & A06 Na12A08-CB10385 & 78.0 & $60.4-81.7$ & -0.20 & 0.06 & & & \\
\hline ADFm-3 & C02 ZAAS671-CN15 & 65.1 & $57.4-80.6$ & 0.22 & 0.07 & & & \\
\hline ADFm-4 & C06 KEMP4-ZAAS819b & 59.7 & $54.6-63.3$ & 0.17 & 0.05 & & & \\
\hline ADFs-1 & A01 ZAAS165-Ra3H09b & 83.7 & $77.2-91.7$ & -0.09 & 0.05 & \multirow{6}{*}{0.39} & \multirow{6}{*}{0.05} & \multirow{6}{*}{0.44} \\
\hline ADFs-2 & A02 ZAAS408b-Na10B10a & 34.4 & $24.1-58.7$ & -0.08 & 0.04 & & & \\
\hline ADFs-3 & A03 RCA-CN40 & 63.4 & $61.3-66.4$ & -0.12 & 0.08 & & & \\
\hline ADFs-4 & A03 ZAAS157-ZAAS766 & 138.1 & 135.6-140.9 & -0.10 & 0.05 & & & \\
\hline ADFs-5 & A06 ZAAS5-ZAAS969 & 63.4 & $48.6-72.4$ & -0.15 & 0.12 & & & \\
\hline ADFs-6 & C08 ZAAS197-BRAS031a & 91.4 & $78.6-100.4$ & 0.09 & 0.04 & & & \\
\hline ADLm-1 & A03 HMR085-ZAAS157 & 136.6 & 132.7-138.9 & -0.16 & 0.08 & \multirow{2}{*}{0.16} & \multirow{2}{*}{0.11} & \multirow{2}{*}{0.27} \\
\hline ADLm-2 & A06 VHSD-E7M5d & 75.8 & $60.4-80.7$ & -0.16 & 0.08 & & & \\
\hline ADLs-1 & A01 ZAAS165-Ra3H09b & 86.7 & $78.2-96.1$ & -0.06 & 0.04 & \multirow{5}{*}{0.35} & \multirow{5}{*}{-} & \multirow{5}{*}{0.35} \\
\hline ADLs-2 & A02 ZAAS548b-ZAAS425 & 47.9 & $27.4-60.6$ & -0.07 & 0.07 & & & \\
\hline ADLs-3 & A03 Ra2E11-E4M8d & 42.6 & $28.1-66.4$ & -0.07 & 0.06 & & & \\
\hline ADLs-4 & A03 HMR085-ZAAS157 & 137.6 & $134.5-139.9$ & -0.08 & 0.08 & & & \\
\hline ADLs-5 & A06 ZAAS5-ZAAS969 & 67.4 & $58.4-79.0$ & -0.09 & 0.10 & & & \\
\hline $\mathrm{HCm}-1$ & A03 RCA-CN40 & 63.4 & $44.9-67.2$ & 0.21 & 0.06 & \multirow{3}{*}{0.19} & \multirow{3}{*}{-} & \multirow{3}{*}{0.19} \\
\hline $\mathrm{HCm}-2$ & A03 ZAAS661-CAS1 & 113.3 & 105.1-114.3 & 0.20 & 0.05 & & & \\
\hline $\mathrm{HCm}-3$ & A08 Ra2E12-CB10364 & 60.1 & $53.3-68.1$ & 0.25 & 0.08 & & & \\
\hline HCs-1 & A03 ZAAS613-Ra2E11 & 33.1 & $22.4-53.0$ & 0.07 & 0.04 & \multirow{5}{*}{0.33} & \multirow{5}{*}{-} & \multirow{5}{*}{0.33} \\
\hline HCs-2 & A03 CAS1-E4M8c & 122.4 & $116.4-128.0$ & 0.11 & 0.10 & & & \\
\hline HCs-3 & A04 ZAAS185-MR153 & 28.1 & $21.0-37.1$ & 0.07 & 0.04 & & & \\
\hline $\mathrm{HCs}-4$ & A06 ZAAS5-ZAAS969 & 57.4 & $50.6-69.4$ & 0.07 & 0.05 & & & \\
\hline HCs-5 & A08 CB10364-yCS & 81.8 & $71.8-86.8$ & 0.10 & 0.10 & & & \\
\hline $\mathrm{Cm}-1$ & A04 ZAAS1050-ZAAS185 & 24.7 & $20.0-29.1$ & -0.12 & 0.09 & \multirow{4}{*}{0.22} & & \\
\hline $\mathrm{Cm}-2$ & A07 CNU331-ZAAS945b & 72.0 & $62.2-78.5$ & -0.09 & 0.05 & & ר 0 & O 31 \\
\hline $\mathrm{Cm}-3$ & C06 Na12A02a-ZAASA7-47a & 57.6 & $46.6-62.3$ & 0.07 & 0.03 & & 0.09 & 0.31 \\
\hline $\mathrm{Cm}-4$ & C09 ZAAS326-DGD2_1 & 36.8 & $23.5-63.6$ & 0.08 & 0.04 & & & \\
\hline Cs-1 & A03 ZAAS85-Na10B01 & 70.3 & $62.3-75.7$ & -0.06 & 0.07 & & & \\
\hline Cs-2 & C05 ZAAS502/503-SOUL & 22.7 & $6.2-40.3$ & 0.03 & 0.02 & 0.26 & 0.05 & 0.31 \\
\hline Cs-3 & C08 ZAAS197-BRAS031a & 90.4 & $83.4-100.4$ & 0.07 & 0.12 & & & \\
\hline Cs-4 & C09 ANL2-CB10199b & 42.6 & $30.5-49.0$ & 0.05 & 0.05 & & & \\
\hline
\end{tabular}

QTL = main QTL; LG = linkage group, $\mathrm{cM}=$ centimorgan

$\mathrm{A}=$ additive effect. Additive effect of traits is positive when alleles increasing trait value originated from P1 (Sollux) and is negative when alleles increasing trait value originated from P2 (Gaoyou)

$\mathrm{h}^{2}(\mathrm{a})=$ contribution of additive effect QTL

$\mathrm{V}(\mathrm{A}) / \mathrm{V}(\mathrm{P})=$ variance of additive effects/phenotypic variance - total contribution of additive effect QTL

$\mathrm{V}(\mathrm{I}) / \mathrm{V}(\mathrm{P})$ = variance of epistatic effects/phenotypic variance

$\mathrm{V}(\mathrm{G}) / \mathrm{V}(\mathrm{P})=$ variance of genetic main effects/phenotypic variance 


\section{Population II: Express 617 x R53}

In population II, three QTL for NDF content of defatted meal were identified which explained $18 \%$ of the phenotypic variance (Table 3.7). For ADF and ADL content, five and three QTL were identified which together explained $33 \%$ and $18 \%$ of the phenotypic variance, respectively. One of the QTL for cellulose content with the largest additive effect of $0.36 \%$ on linkage group C09 at position $33.5 \mathrm{cM}$ was exactly at the same position as a QTL for glucosinolate content. This QTL was also within the marker interval of QTL for NDF, ADF, oil, and seed protein content. QTL for seed hull proportion was detected in three linkage groups. Of those three, two QTL for seed hull proportion were in association with QTL for NDF, ADF and ADL content in linkage group A05 and C03 (Fig. 3.4). A QTL for thousand kernel weight (TKW) was also mapped on linkage group A05 which showed overlapping confidence intervals with the QTL for seed hull proportion and ADL content, but with opposite direction of the additive effect. QTL mapping performed for fibre fractions in seeds revealed QTL at different positions compared to those QTL for fibre fraction contents in defatted meal. However, some QTL were also detected at identical or adjacent positions both for fibre in defatted meal and in seeds, e.g. QTL for ADF and ADL content on linkage group C01 and C03, for hemicellulose content on linkage group SLG1 and A09, and for cellulose content on linkage group C09.

Table 3.7 Mapped QTL and their most likely positions for NDF, ADF, ADL, hemicellulose (HC) and cellulose (C) content (\%) on the basis of defatted meal (suffix m) and seeds (suffix s) and other quality traits in Express 617 x R53 population

\begin{tabular}{|c|c|c|c|c|c|c|c|c|}
\hline QTL & Markers & $\begin{array}{c}\text { Position } \\
\text { (cM) }\end{array}$ & Range (cM) & A & $\mathrm{h}^{2}(\mathrm{a})$ & $\mathrm{V}(\mathrm{A}) / \mathrm{V}(\mathrm{P})$ & $\mathrm{V}(\mathrm{I}) / \mathrm{V}(\mathrm{P})$ & $\mathrm{V}(\mathrm{G}) / \mathrm{V}(\mathrm{P})$ \\
\hline NDFm-1 & A07 CB10349-CB10439 & 33.7 & $13.0-49.7$ & 0.50 & 0.08 & \multirow{3}{*}{0.18} & & \multirow{3}{*}{0.18} \\
\hline NDFm-2 & C03 E32M47V-R3247212 & 158.7 & $129.5-173.6$ & -0.36 & 0.06 & & & \\
\hline NDFm-3 & C09 E3260396-OL10D08 & 32.0 & $21.0-40.5$ & 0.30 & 0.05 & & & \\
\hline NDFs-1 & A05 E35M62M-R4259343 & 116.0 & $87.3-134.0$ & -0.21 & 0.05 & \multirow{4}{*}{0.37} & \multirow{4}{*}{0.02} & \multirow{4}{*}{0.39} \\
\hline NDFs-2 & A06 CB10204-R4450275 & 76.2 & $68.1-84.2$ & -0.22 & 0.05 & & & \\
\hline NDFs-3 & C03 CB10003-BRAS039 & 24.7 & $19.8-32.3$ & 0.35 & 0.12 & & & \\
\hline NDFs-4 & C03 R3447166-E32M47V & 136.4 & $131.5-143.4$ & -0.29 & 0.09 & & & \\
\hline ADFm-1 & A07 R3447234-R3554057 & 69.5 & $51.5-82.1$ & 0.34 & 0.07 & \multirow{5}{*}{0.33} & \multirow{5}{*}{ - } & \multirow{5}{*}{0.33} \\
\hline ADFm-2 & C01 E3447249-СB10536 & 101.5 & $91.5-102.5$ & 0.35 & 0.06 & & & \\
\hline ADFm-3 & C02 E3860137-E3447120 & 26.4 & $16.7-38.8$ & 0.37 & 0.06 & & & \\
\hline ADFm- 4 & C03 R3447166-E32M47V & 140.4 & $123.3-163.7$ & -0.39 & 0.06 & & & \\
\hline ADFm-5 & C09 E3260396-OL10D08 & 27.0 & $14.1-36.5$ & 0.47 & 0.10 & & & \\
\hline ADFs-1 & A05 E35M62M-R4259343 & 120.0 & $107.0-144.0$ & -0.19 & 0.03 & \multirow{5}{*}{0.38} & \multirow{5}{*}{0.02} & \multirow{5}{*}{0.40} \\
\hline ADFs-2 & A06 R3447079-CB10204 & 74.1 & $64.1-86.2$ & -0.21 & 0.05 & & & \\
\hline ADFs-3 & C01 E3447249-СB10536 & 101.5 & $92.5-102.5$ & 0.23 & 0.07 & & & \\
\hline ADFs- 4 & C03 E4260145-R3554076 & 48.8 & $44.2-55.8$ & 0.27 & 0.07 & & & \\
\hline ADFs-5 & C03 R3447166-E32M47V & 139.4 & $112.4-147.7$ & -0.27 & 0.10 & & & \\
\hline
\end{tabular}


Table 3.7 (continued)

\begin{tabular}{|c|c|c|c|c|c|c|c|c|}
\hline QTL & Markers & $\begin{array}{l}\text { Position } \\
\text { (cM) }\end{array}$ & Range (cM) & A & $h^{2}(a)$ & $\mathrm{V}(\mathrm{A}) / \mathrm{V}(\mathrm{P})$ & $\mathrm{V}(\mathrm{I}) / \mathrm{V}(\mathrm{P})$ & $\mathrm{V}(\mathrm{G}) / \mathrm{V}(\mathrm{P})$ \\
\hline ADLm-1 & A05 R4559278-R3347235 & 94.3 & $79.7-104.7$ & -0.30 & 0.06 & \multirow{3}{*}{0.18} & \multirow{3}{*}{-} & \multirow{3}{*}{0.18} \\
\hline ADLm-2 & A09 BRAS010B-R3347446 & 37.1 & $29.0-45.1$ & -0.26 & 0.06 & & & \\
\hline ADLm-3 & C03 R4559103-R3447166 & 134.5 & $127.3-147.4$ & -0.32 & 0.07 & & & \\
\hline ADLs-1 & A05 R4559278-R3347235 & 96.3 & $88.3-105.7$ & -0.21 & 0.07 & \multirow{5}{*}{0.38} & \multirow{5}{*}{-} & \multirow{5}{*}{0.38} \\
\hline ADLs-2 & A06 R3447079-CB10204 & 75.1 & $66.1-86.2$ & -0.19 & 0.06 & & & \\
\hline ADLs-3 & C01 E3447249-CB10536 & 102.5 & $94.5-102.5$ & 0.18 & 0.05 & & & \\
\hline ADLs-4 & C03 E4260145-R3554076 & 50.8 & $44.2-63.0$ & 0.19 & 0.05 & & & \\
\hline ADLs-5 & C03 R4559103-R3447166 & 133.5 & 128.3-143.4 & -0.24 & 0.09 & & & \\
\hline $\mathrm{HCm}-1$ & SLG1E3750127-CB10211A & 5.0 & $0.0-10.2$ & -0.20 & 0.08 & \multirow{4}{*}{0.30} & \multirow{4}{*}{-} & \multirow{4}{*}{0.30} \\
\hline $\mathrm{HCm}-2$ & A02 E4454277-E4559145 & 101.0 & $80.9-135.5$ & 0.19 & 0.05 & & & \\
\hline $\mathrm{HCm}-3$ & A06 R3754093-NA12D08 & 12.6 & $0.0-35.7$ & 0.18 & 0.06 & & & \\
\hline $\mathrm{HCm}-4$ & A09 R3354222-BRAS010B & 35.8 & $29.0-47.1$ & 0.27 & 0.14 & & & \\
\hline HCs-1 & SLG1E3750127-CB10211A & 4.0 & $0.0-10.2$ & -0.13 & 0.07 & \multirow{7}{*}{0.45} & \multirow{7}{*}{0.04} & \multirow{7}{*}{0.49} \\
\hline HCs-2 & A06 E3347068-R3754093 & 1.0 & $0.0-16.6$ & 0.10 & 0.05 & & & \\
\hline HCs-3 & A09 R3354222-BRAS010B & 35.8 & $30.0-45.1$ & 0.15 & 0.13 & & & \\
\hline HCs-4 & A09 E3447249-CB10536 & 102.5 & $95.5-102.5$ & -0.07 & 0.02 & & & \\
\hline $\mathrm{HCs}-5$ & C02 E4454221-CB10022C & 53.4 & $44.4-53.4$ & -0.09 & 0.03 & & & \\
\hline HCs-6 & C03 CB10003-BRAS039 & 23.7 & $13.4-30.3$ & 0.14 & 0.07 & & & \\
\hline HCs-7 & C09 E3260396-OL10D08 & 27.0 & $12.1-43.0$ & -0.15 & 0.08 & & & \\
\hline $\mathrm{Cm}-1$ & C09 OL10D08-OL10C10 & 33.5 & $30.0-35.5$ & 0.36 & 0.40 & \multirow{2}{*}{0.44} & \multirow{2}{*}{-} & \multirow{2}{*}{0.44} \\
\hline $\mathrm{Cm}-2$ & SLG2 R3347103-R3950075 & 7.9 & $1.0-8.9$ & 0.12 & 0.07 & & & \\
\hline Cs-1 & C03 CB10003-BRAS039 & 21.7 & $16.8-26.7$ & 0.09 & 0.08 & \multirow{4}{*}{0.39} & \multirow{4}{*}{-} & \multirow{4}{*}{0.39} \\
\hline Cs-2 & C03 R4559103-R3447166 & 131.5 & $116.3-142.4$ & -0.04 & 0.05 & & & \\
\hline Cs-3 & C03 E32M47V-R3247212 & 167.7 & $155.7-181.6$ & -0.05 & 0.05 & & & \\
\hline Cs-4 & C09 OL10D08-OL10C10 & 33.5 & $30.0-36.5$ & 0.14 & 0.25 & & & \\
\hline Hull-1 & A05 R4559278-R3347235 & 91.3 & $86.7-120.0$ & -0.30 & 0.06 & \multirow{3}{*}{0.22} & \multirow{3}{*}{ - } & \multirow{3}{*}{0.22} \\
\hline Hull-2 & C01 R3247173-E32M49N & 67.3 & $57.3-80.3$ & 0.29 & 0.08 & & & \\
\hline Hull-3 & C03 R4559103-R3447166 & 133.5 & $126.3-141.4$ & -0.35 & 0.10 & & & \\
\hline TKW-1 & A05 R4559278-R3347235 & 92.3 & $76.7-97.7$ & 0.21 & 0.11 & \multirow{2}{*}{0.18} & \multirow{2}{*}{0.03} & \multirow{2}{*}{0.21} \\
\hline TKW-2 & C02 E4560137-E3860137 & 17.7 & $9.5-27.4$ & -0.14 & 0.04 & & & \\
\hline Oil-1 & C02 E4251130-NA12A01B & 0.0 & $0.0-5.0$ & 0.51 & 0.07 & & & \\
\hline Oil-2 & C03 CB10003-BRAS039 & 23.7 & $19.8-26.7$ & -1.03 & 0.28 & 0.43 & - & 0.43 \\
\hline Oil-3 & C09 OL10D08-OL10C10 & 34.5 & $25.9-41.5$ & 0.46 & 0.08 & & & \\
\hline Prot-1 & A07 CB10349-CB10439 & 36.7 & $22.7-60.5$ & -0.47 & 0.11 & 016 & & 016 \\
\hline Prot-2 & C09 E3260396-OL10D08 & 32.0 & $22.0-39.5$ & -0.26 & 0.06 & 0.16 & - & 0.16 \\
\hline PodM-1 & A07 CB10349-CB10439 & 36.7 & $21.7-59.5$ & -0.50 & 0.07 & & & \\
\hline PodM-2 & C01 R3247173-E32M49N & 79.3 & $71.3-89.5$ & -0.54 & 0.14 & 0.32 & - & 0.32 \\
\hline PodM-3 & C03 BRAS039-E3554162 & 32.3 & 19.8-38.2 & -0.52 & 0.12 & & & \\
\hline GSL-1 & A06 CB10204-R4450275 & 81.2 & $70.1-92.2$ & 2.50 & 0.02 & 074 & - & 074 \\
\hline GSL-2 & C09 OL10D08-OL10C10 & 33.5 & $32.0-35.5$ & -14.35 & 0.72 & 0.14 & - & 0.14 \\
\hline C22:1-1 & C03 CB10003-BRAS039 & 23.7 & $22.7-25.7$ & -9.37 & 0.79 & 0.79 & - & 0.79 \\
\hline
\end{tabular}

QTL = main QTL; LG = linkage group

$\mathrm{A}=$ additive effect. Additive effect of traits is positive when alleles increasing trait value originated from P1 (Express 617) and is negative when alleles increasing trait value originated from P2 (R53)

$\mathrm{h}^{2}(\mathrm{a})=$ contribution of additive effect QTL

$\mathrm{V}(\mathrm{A}) / \mathrm{V}(\mathrm{P})=$ variance of additive effects/phenotypic variance - total contribution of additive effect QTL

$\mathrm{V}(\mathrm{I}) / \mathrm{V}(\mathrm{P})=$ variance of epistatic effects/phenotypic variance

$\mathrm{V}(\mathrm{G}) / \mathrm{V}(\mathrm{P})=$ variance of genetic main effects $/$ phenotypic variance 


\section{Population III: SG DH14 x Express 617}

QTL analysis in population III revealed a large QTL on linkage group C03 associated with NDF, $\mathrm{ADF}, \mathrm{ADL}$, hemicellulose, cellulose content and seed hull proportion as well as protein content of defatted meal with an opposite additive effect (Table 3.8, Fig. 3.5). QTL located on linkage group C05 at the position of $36 \mathrm{cM}$ equally affected NDF, ADF and ADL content. Likewise, as in population II, QTL for cellulose content on linkage group C02 showed overlapping confidence intervals with QTL for glucosinolate content.

QTL for fibre fraction contents on seed basis in population III were mostly detected at the same or adjacent positions with those QTL for fibre content in defatted meal. QTL for fibre contents of seeds on linkage group A08 collocated with QTL for oil and erucic acid content. Other QTL for fibre fraction contents of seeds also showed overlapping confidence intervals with a QTL for seed hull proportion on linkage group C05 (Fig. 3.4).

Table 3.8 Mapped QTL and their most likely positions for NDF, ADF, ADL, hemicellulose (HC) and cellulose (C) content (\%) on the basis of defatted meal (suffix m) and seeds (suffix s) and other quality traits in SG DH14 x Express 617 population

\begin{tabular}{|c|c|c|c|c|c|c|c|c|c|}
\hline QTL & LG & Markers & $\begin{array}{l}\text { Pos. } \\
\text { (cM) }\end{array}$ & Range (cM) & A & $h^{2}(\mathrm{a})$ & $\mathrm{V}(\mathrm{A}) / \mathrm{V}(\mathrm{P})$ & $\mathrm{V}(\mathrm{I}) / \mathrm{V}(\mathrm{P})$ & $V(G) / V(P)$ \\
\hline NDFm-1 & A08 & brPb-663528-p372048 & 5.3 & $1.0-8.3$ & -0.31 & 0.09 & \multirow{3}{*}{0.54} & \multirow{3}{*}{0.01} & \multirow{3}{*}{0.55} \\
\hline NDFm-2 & $\mathrm{C} 03$ & p623390-p571357 & 1.0 & $0.0-17.2$ & 0.26 & 0.09 & & & \\
\hline NDFm-3 & $\mathrm{C} 05$ & p28950-p22111286 & 35.0 & $34.6-38.0$ & -0.74 & 0.43 & & & \\
\hline NDFs-1 & A02 & p17156661-p22433753 & 92.9 & $85.2-103.4$ & 0.16 & 0.01 & \multirow{6}{*}{0.83} & \multirow{6}{*}{0.01} & \multirow{6}{*}{0.84} \\
\hline NDFs-2 & A08 & p2922263-p3964840 & 20.0 & $17.0-20.7$ & -0.53 & 0.30 & & & \\
\hline NDFs-3 & $\mathrm{C} 03$ & E35M47-107E-p2737190 & 23.0 & $16.2-24.3$ & 0.21 & 0.00 & & & \\
\hline NDFs-4 & $\mathrm{C} 03$ & p310593-p386456 & 227.5 & 220.4-233.5 & -0.33 & 0.17 & & & \\
\hline NDFs-5 & $\mathrm{C} 05$ & p28950-p22111286 & 36.0 & $34.6-39.0$ & -0.74 & 0.50 & & & \\
\hline NDFs-6 & $\mathrm{C} 07$ & p2288017-p1268741 & 37.4 & $23.0-44.6$ & 0.17 & 0.03 & & & \\
\hline ADFm-1 & A04 & p9808875-p11420466 & 73.6 & $55.4-79.8$ & 0.20 & 0.02 & \multirow{6}{*}{0.79} & \multirow{6}{*}{0.01} & \multirow{6}{*}{0.80} \\
\hline ADFm-2 & $\mathrm{A} 07$ & p20894218-brPb-657676 & 138.5 & $106.5-138.5$ & 0.23 & 0.00 & & & \\
\hline ADFm-3 & $\mathrm{C} 03$ & p623390-p571357 & 2.0 & $0.0-12.2$ & 0.23 & 0.07 & & & \\
\hline ADFm-4 & $\mathrm{C} 05$ & p28950-p22111286 & 35.0 & $33.6-38.0$ & -1.57 & 0.71 & & & \\
\hline ADFm-5 & $\mathrm{C} 07$ & p379677-p995878 & 111.4 & $100.5-122.1$ & -0.22 & 0.02 & & & \\
\hline ADFm-6 & $\mathrm{C} 08$ & p2125574-p135491 & 43.8 & $38.1-52.7$ & 0.18 & 0.04 & & & \\
\hline ADFs-1 & A02 & p17156661-p22433753 & 89.9 & $85.2-99.4$ & 0.09 & 0.01 & \multirow{7}{*}{0.85} & \multirow{7}{*}{0.01} & \multirow{7}{*}{0.86} \\
\hline ADFs-2 & A04 & p9309213-p9808875 & 64.9 & 43.3-73.6 & 0.08 & 0.01 & & & \\
\hline ADFs-3 & $\mathrm{A} 07$ & p20894218-brPb-657676 & 138.5 & $114.0-138.5$ & 0.11 & 0.00 & & & \\
\hline ADFs-4 & A08 & p2922263-p3964840 & 20.0 & $16.0-20.7$ & -0.35 & 0.16 & & & \\
\hline ADFs-5 & $\mathrm{C} 03$ & p623390-p571357 & 1.0 & $0.0-10.2$ & 0.17 & 0.05 & & & \\
\hline ADFs- 6 & $\mathrm{C} 05$ & p28950-p22111286 & 36.0 & $33.6-38.0$ & -1.02 & 0.73 & & & \\
\hline ADFs-7 & $\mathrm{C} 07$ & p3882959-p3392606 & 24.2 & $20.0-52.9$ & 0.11 & 0.00 & & & \\
\hline
\end{tabular}


Table 3.8 (continued)

\begin{tabular}{|c|c|c|c|c|c|c|c|c|c|}
\hline QTL & LG & Markers & $\begin{array}{l}\text { Pos. } \\
\text { (cM) }\end{array}$ & Range (cM) & A & $h^{2}(\mathrm{a})$ & $\mathrm{V}(\mathrm{A}) / \mathrm{V}(\mathrm{P})$ & $\mathrm{V}(\mathrm{I}) / \mathrm{V}(\mathrm{P})$ & $V(G) / V(P)$ \\
\hline$\overline{\text { ADLm-1 }}$ & A02 & p17156661-p22433753 & 88.9 & $83.2-95.9$ & 0.20 & 0.01 & \multirow{7}{*}{0.84} & \multirow{7}{*}{0.01} & \multirow{7}{*}{0.85} \\
\hline ADLm-2 & A04 & p9808875-p11420466 & 72.6 & 62.9-79.8 & 0.24 & 0.01 & & & \\
\hline ADLm-3 & $\mathrm{A} 07$ & p19118066-p19795126 & 119.2 & $104.5-128.3$ & 0.17 & 0.00 & & & \\
\hline ADLm-4 & $\mathrm{C} 02$ & brPb-841932-p44052 & 74.1 & 71.4-79.1 & -0.24 & 0.03 & & & \\
\hline ADLm-5 & $\mathrm{C} 03$ & p623390-p571357 & 3.0 & $0.0-14.2$ & 0.17 & 0.06 & & & \\
\hline ADLm-6 & $\mathrm{C} 05$ & p28950-p22111286 & 35.0 & $34.6-37.0$ & -1.59 & 0.77 & & & \\
\hline ADLm-7 & $\mathrm{C} 05$ & p269557-p406725 & 52.4 & $50.4-55.4$ & -0.40 & 0.63 & & & \\
\hline ADLs-1 & A02 & p17156661-p22433753 & 89.9 & $84.2-96.9$ & 0.14 & 0.01 & \multirow{6}{*}{0.85} & \multirow{6}{*}{0.01} & \multirow{6}{*}{0.86} \\
\hline ADLs-2 & A04 & p9808875-p11420466 & 71.6 & $59.9-76.6$ & 0.11 & 0.00 & & & \\
\hline ADLs-3 & $\mathrm{A} 07$ & brPb-842247-p178437 & 0.0 & $0.0-4.0$ & 0.12 & 0.03 & & & \\
\hline ADLs-4 & $\mathrm{A} 07$ & p19118066-p19795126 & 119.2 & $106.5-138.5$ & 0.10 & 0.00 & & & \\
\hline ADLs-5 & $\mathrm{C} 03$ & p623390-p571357 & 2.0 & $0.0-12.2$ & 0.13 & 0.06 & & & \\
\hline ADLs-6 & $\mathrm{C} 05$ & p28950-p22111286 & 36.0 & $34.6-38.0$ & -1.11 & 0.80 & & & \\
\hline $\mathrm{HCm}-1$ & $\mathrm{~A} 03$ & p1046864-p1755651 & 10.8 & $6.5-16.8$ & -0.08 & 0.01 & \multirow{4}{*}{0.69} & \multirow{4}{*}{0.01} & \multirow{4}{*}{0.70} \\
\hline $\mathrm{HCm}-2$ & $\mathrm{~A} 07$ & p18106750-p19118066 & 115.0 & $97.2-119.2$ & -0.12 & 0.01 & & & \\
\hline $\mathrm{HCm}-3$ & $\mathrm{C} 03$ & p386456-p249628 & 233.5 & $213.6-251.0$ & -0.15 & 0.02 & & & \\
\hline $\mathrm{HCm}-4$ & $\mathrm{C} 05$ & p28950-p22111286 & 35.0 & $33.6-37.0$ & 0.75 & 0.63 & & & \\
\hline HCs-1 & $\mathrm{A} 04$ & p12087644-p13140266 & 93.2 & $72.6-99.8$ & -0.09 & 0.03 & \multirow{4}{*}{0.56} & \multirow{4}{*}{0.01} & \multirow{4}{*}{0.57} \\
\hline HCs-2 & A10 & brPb-670588-p16190708 & 30.3 & 25.1-39.1 & 0.09 & 0.02 & & & \\
\hline HCs-3 & $\mathrm{C03}$ & brPb-660636-p418599 & 217.6 & $212.6-231.5$ & -0.26 & 0.22 & & & \\
\hline $\mathrm{HCs}-4$ & $\mathrm{C} 05$ & p28950-p22111286 & 35.0 & $33.6-37.0$ & 0.26 & 0.26 & & & \\
\hline $\mathrm{Cm}-1$ & $\mathrm{~A} 07$ & brPb-842247-p178437 & 0.0 & $0.0-10.2$ & -0.09 & 0.08 & \multirow{4}{*}{0.56} & \multirow{4}{*}{-} & \multirow{4}{*}{0.56} \\
\hline $\mathrm{Cm}-2$ & $\mathrm{C} 02$ & brPb-670980-p1337221 & 0.0 & $0.0-5.0$ & -0.11 & 0.03 & & & \\
\hline $\mathrm{Cm}-3$ & $\mathrm{C} 05$ & p28950-p22111286 & 36.0 & $33.6-39.0$ & 0.33 & 0.42 & & & \\
\hline $\mathrm{Cm}-4$ & C09 & E44M62-167E-p750450 & 79.3 & 75.7-84.3 & -0.10 & 0.05 & & & \\
\hline Cs-1 & $\mathrm{A} 03$ & p14962288-p15351982 & 99.0 & $94.8-104.0$ & -0.06 & 0.02 & \multirow{5}{*}{0.64} & \multirow{5}{*}{0.04} & \multirow{5}{*}{0.69} \\
\hline Cs-2 & A08 & p3964840-p12699181 & 25.7 & $21.7-32.4$ & -0.19 & 0.32 & & & \\
\hline Cs-3 & A09 & p9004629-brPb-661324 & 58.1 & $55.4-63.1$ & -0.08 & 0.02 & & & \\
\hline Cs-4 & $\mathrm{C} 03$ & p180246-brPb-660636 & 210.2 & 205.6-219.6 & -0.13 & 0.27 & & & \\
\hline Cs-5 & $\mathrm{C} 05$ & p97796-p317634 & 67.1 & $57.5-71.3$ & 0.09 & 0.07 & & & \\
\hline Hull-1 & A08 & p2922263-p3964840 & 20.0 & $13.9-20.7$ & -0.35 & 0.11 & \multirow{3}{*}{0.62} & \multirow{3}{*}{0.01} & \multirow{3}{*}{0.63} \\
\hline Hull-2 & $\mathrm{C} 05$ & p28950-p22111286 & 36.0 & $33.6-38.0$ & -0.65 & 0.55 & & & \\
\hline Hull-3 & $\mathrm{C} 05$ & p269557-p406725 & 54.4 & $51.4-57.4$ & -0.40 & 0.47 & & & \\
\hline TKW-1 & A09 & p17342092-p23552530 & 115.2 & $110.8-121.2$ & -0.11 & 0.08 & \multirow{2}{*}{0.19} & \multirow{2}{*}{-} & 019 \\
\hline TKW-2 & $\mathrm{C} 01$ & p832198-p817715 & 54.3 & $42.1-61.4$ & 0.19 & 0.13 & & & 0.19 \\
\hline Oil-1 & A06 & p22605217-p22268128 & 26.4 & $23.3-29.4$ & 0.36 & 0.03 & & & \\
\hline Oil-2 & A08 & p12699181-p13616733 & 27.4 & $24.7-30.4$ & 0.85 & 0.43 & & & \\
\hline Oil-3 & A08 & p13932634-p14759185 & 39.8 & $33.6-43.9$ & 0.44 & 0.41 & & & \\
\hline Oil-4 & $\mathrm{C} 03$ & p1431681-p392 & 191.6 & 190.7-195.3 & 0.59 & 0.16 & 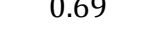 & 0.02 & 0.71 \\
\hline Oil-5 & $\mathrm{C} 05$ & p28950-p22111286 & 39.0 & $35.0-43.2$ & 0.88 & 0.26 & & & \\
\hline Oil-6 & $\mathrm{C} 07$ & p1268741-p556940 & 41.6 & $32.8-55.9$ & -0.32 & 0.07 & & & \\
\hline
\end{tabular}


Table 3.8 (continued)

\begin{tabular}{|c|c|c|c|c|c|c|c|c|c|}
\hline QTL & LG & Markers & $\begin{array}{l}\text { Pos. } \\
\text { (cM) }\end{array}$ & Range (cM) & A & $\mathrm{h}^{2}(\mathrm{a})$ & $\mathrm{V}(\mathrm{A}) / \mathrm{V}(\mathrm{P})$ & $\mathrm{V}(\mathrm{I}) / \mathrm{V}(\mathrm{P})$ & $\mathrm{V}(\mathrm{G}) / \mathrm{V}(\mathrm{P})$ \\
\hline Prot-1 & A10 & p15442975-p15948040 & 22.4 & $14.2-26.1$ & 0.20 & 0.07 & \multirow{3}{*}{0.22} & \multirow{3}{*}{-} & \multirow{3}{*}{0.22} \\
\hline Prot-2 & $\mathrm{C} 04$ & p1301583-p1089867 & 38.5 & $34.4-56.0$ & -0.29 & 0.11 & & & \\
\hline Prot-3 & $\mathrm{C} 06$ & p134193-p16406072 & 96.4 & $89.3-104.5$ & -0.24 & 0.09 & & & \\
\hline PodM-1 & A07 & p1443503-p3266570 & 20.5 & $10.2-23.8$ & 0.41 & 0.05 & \multirow{4}{*}{0.62} & \multirow{4}{*}{-} & \multirow{4}{*}{0.62} \\
\hline PodM-2 & A08 & p2922263-p3964840 & 18.0 & $12.9-20.7$ & 0.99 & 0.40 & & & \\
\hline PodM-3 & $\mathrm{C} 03$ & brPb-660636-p418599 & 213.6 & 208.2-218.6 & 0.80 & 0.27 & & & \\
\hline PodM-4 & $\mathrm{C} 06$ & p134193-p16406072 & 93.4 & $89.3-104.0$ & -0.37 & 0.04 & & & \\
\hline GSL-1 & A09 & p2711315-p3047090 & 36.7 & $35.0-46.8$ & 4.87 & 0.20 & \multirow{4}{*}{0.77} & \multirow{4}{*}{0.07} & \multirow{4}{*}{0.84} \\
\hline GSL-2 & $\mathrm{C} 02$ & brPb-670980-p1337221 & 0.0 & $0.0-2.0$ & 4.14 & 0.09 & & & \\
\hline GSL-3 & $\mathrm{C} 07$ & p556940-p2504173 & 51.3 & $47.3-56.9$ & 3.48 & 0.05 & & & \\
\hline GSL-4 & $\mathrm{C} 09$ & brPb-671034-p2730673 & 125.4 & $122.4-125.4$ & 12.17 & 0.54 & & & \\
\hline C22:1-1 & A08 & p2922263-p3964840 & 20.0 & $18.0-20.7$ & 4.97 & 0.50 & \multirow{3}{*}{0.87} & \multirow{3}{*}{0.02} & \multirow{3}{*}{0.89} \\
\hline C22:1-2 & A08 & p13616733-p13932634 & 37.6 & $32.6-37.8$ & 7.14 & 0.56 & & & \\
\hline C22:1-3 & $\mathrm{C} 03$ & p310593-p386456 & 227.5 & 224.4-229.5 & 8.81 & 0.50 & & & \\
\hline
\end{tabular}

QTL = main QTL; LG = linkage group; $\mathrm{cM}=$ centimorgan

$\mathrm{A}=$ additive effect. Additive effect of traits is positive when alleles increasing trait value originated from P1 (SG DH14) and is negative when alleles increasing trait value originated from P2 (Express 617)

$\mathrm{h}^{2}(\mathrm{a})=$ contribution of additive effect $\mathrm{QTL}$

$\mathrm{V}(\mathrm{A}) / \mathrm{V}(\mathrm{P})=$ variance of additive effects/phenotypic variance - total contribution of additive effect QTL

$\mathrm{V}(\mathrm{I}) / \mathrm{V}(\mathrm{P})=$ variance of epistatic effects/phenotypic variance

$\mathrm{V}(\mathrm{G}) / \mathrm{V}(\mathrm{P})=$ variance of genetic main effects/phenotypic variance 


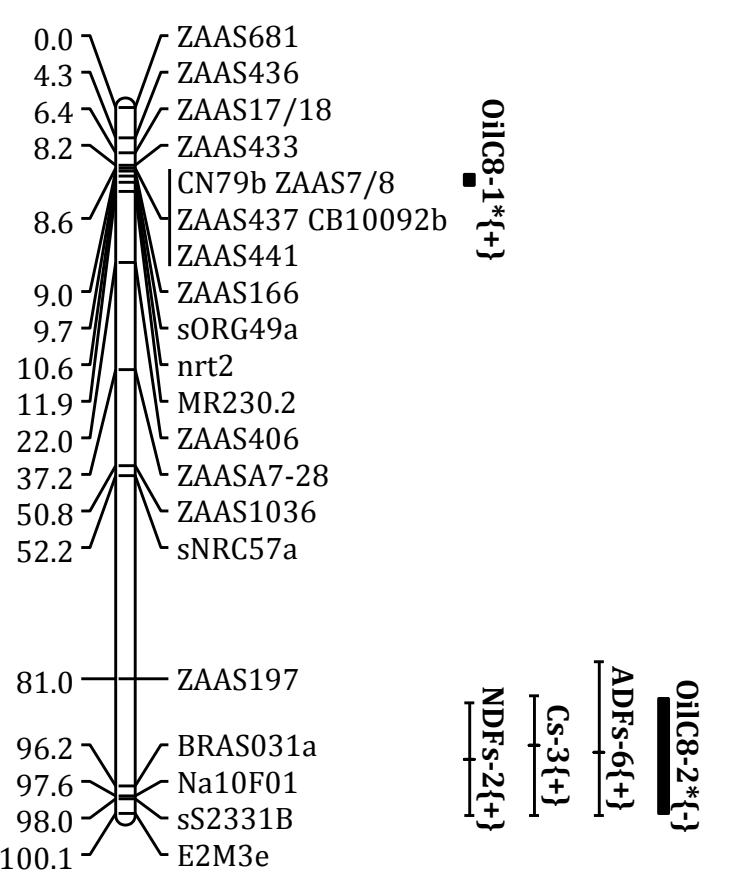

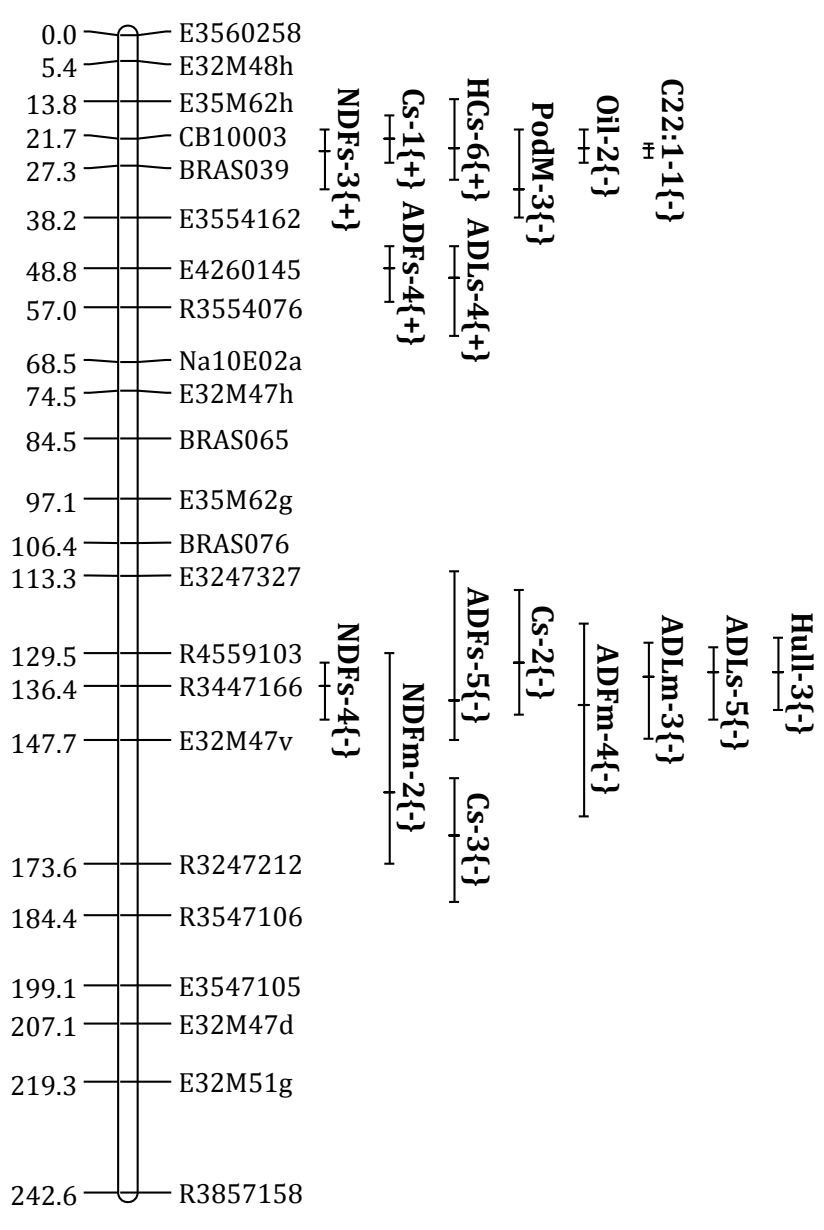

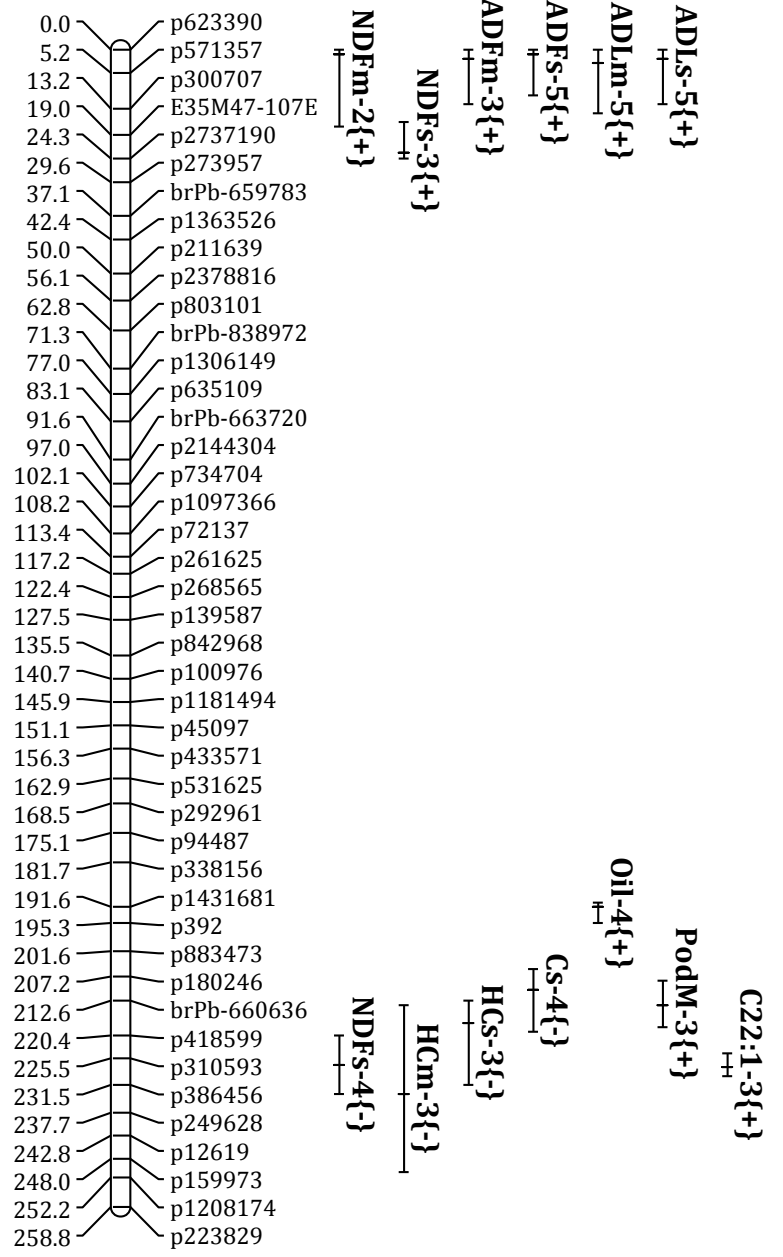

Figure 3.5 QTL associated to fibre content showed overlapping confidence interval with QTL involved in other quality traits on linkage groups C08 of Sollux x Gaoyou, linkage group C03 of Express 617 x R53, and linkage group C03 of SG DH14 x Express 617. The $\{+\}$ and $\{-\}$ describe direction of estimated additive effect. QTL OilC8-1* and OilC8-2* were taken from Zhao et al. (2012) 


\subsection{Discussion}

\section{Genetic variation for fibre content}

Reducing fibre content for improving meal quality and increasing oil content is an important objective in oilseed rape breeding. Results of the present study show relatively large variation of fibre fractions in three different DH populations of black-seeded winter oilseed rape. Among the DH populations, fibre fraction contents of defatted meal ranged from $25.9 \%$ to $37.6 \%$ for NDF, from $19.1 \%$ to $28.6 \%$ for ADF and from $6.1 \%$ to $15.9 \%$ for ADL. On a seed basis, fibre contents ranged from $14.8 \%$ to $18.5 \%$ for $\mathrm{NDF}$, from $9.3 \%$ to 16.3 for $\mathrm{ADF}$, and from $3.4 \%$ to $9.1 \%$ for ADL. The variation of fibre content in the three $\mathrm{DH}$ population were about the same range as found for modern black-seeded European winter oilseed rape cultivars as reported by Dimov et al. (2012). The present results also compare well with the variation found in the black-seeded DH population ExV8 reported by Wittkop et al. (2012), where NDF content ranged from 11.9 to 19.3\%, ADF content ranged from 7.3 to $15.0 \%$ and ADL content ranged from 3.2 to $8.4 \%$, based on seed dry matter.

The variance components showed a predominant effect of the genotypes on NDF, ADF and ADL contents of the defatted meal (Table 3.1). The heritability for NDF, ADF and ADL content ranged from $0.75-0.97$ for the three populations. These heritabilities are higher than those reported before for a set of 28 black seeded European winter oilseed rape cultivars (Dimov et al. 2012), and they are in the same range as heritabilities reported for fibre content in two DH populations derived from yellow-seeded and dark-seeded B. napus (Wittkop et al. 2012). High heritabilities for fibre fractions found in this study underline the comparative benefit for selecting directly for fibre content in breeding for improved meal quality rather than using seed colour as a selection marker (Snowdon et al. 2010).

Transgressive segregation in the $\mathrm{DH}$ population can be explained by the recombination of parental alleles that increase or reduce the fibre content. Transgressive segregation for NDF and ADL content of defatted meal was found in population II and III. The parents of DH population II (Express 617 and R53) and of DH population III (SG DH14 x Express 617) are quite similar in their NDF content (Table 3.2), but since the parents carry different alleles reducing NDF content at different QTL, transgressive segregation was observed in both populations. As shown in Table 3.7 and 3.8, alleles reducing NDF content of defatted meal are coming from both parents as indicated by the different sign of additive effects of detected QTL. In population II, the alleles reducing NDF are mainly derived from the parent R53, while alleles reducing NDF in population III are derived from the parent SG DH14, confirming that in both populations, alleles increasing NDF content are coming from parent Express 617 (Table 3.2). Transgressive segregation was 
also observed for ADL content. In this case, alleles reducing ADL content in population II were mainly coming from parent Express 617, while in population III alleles reducing ADL were mainly from SG DH14.

\section{Correlation between traits}

Correlation analyses revealed close correlations between NDF, ADF and ADL contents in all three populations (Table 3.4 and 3.5). Negative correlations were observed between seed fibre fractions and seed oil content while correlations between seed fibre and seed protein content were mostly not significant (Table 3.5). On seed basis, increasing oil content leads to a simultaneous reduction of seed protein and seed fibre content. Oil content in Brassica species constitute up to $50 \%$ of seed dry weight and the remaining parts of the seed are fibre, protein and other metabolites. Oil content per seed is genetically determined by the seed development and the flow of metabolites into and between seed tissues as well as between cellular compartments (Abbadi and Leckband 2011). Negative correlations between seed oil content, seed fibre and seed protein reflect the competition between carbon signaling pathways involved in oil biosynthesis, the synthesis of cellulose and hemicellulose as the main components of fibre, and the synthesis of protein.

When fibre and protein content were expressed as proportion of defatted meal, correlation between seed oil and fibre fractions mostly revealed positive values except for population III (cf. Table 3.4), while the correlations between seed oil and protein content of defatted meal varied between the populations. The positive correlation between seed oil content and protein content of defatted meal in population III (Table 3.4) indicates that increasing of oil content in the seed simultaneously enhances protein content of the defatted meal, but it leads to a reduction in fibre content which is reflected by strong negative correlation between NDF and oil content $(r=-$ $0.81^{* *}$, Table 3.5 , population III). Positive correlation between oil and protein of defatted meal in population III might be related to erucic acid content, since positive correlation between oil and erucic content ( $\mathrm{r}=0.75^{* *}$, Table 3.5), and between erucic acid content and protein content of defatted meal ( $r=0.78^{* *}$, data not shown) has been observed. Also on defatted meal basis there are negative correlations between fibre fractions and seed oil content in this population (Table 3.4). Our results are in accordance with results of $\mathrm{Si}$ et al. (2003) who suggested that a simultaneous increase in seed oil (probably erucic acid) and meal protein content occurs at the expense of seed residue, in this case, fibre content. Increasing oil content without a concomitant decrease in protein content is possible if there are QTL that influence oil content independently from protein content (Zhao et al. 2006). 
Negative correlations were observed between NDF, ADF, ADL, cellulose and protein content of defatted meal (Tab. 3.4), but only weak negative correlations were observed to seed protein content (Tab. 3.5). These results are in accordance with Dimov et al. (2012) who reported a weak negative correlation between fibre fractions and seed protein content and protein content of defatted meal in a set of 28 black-seeded winter oilseed rape cultivars. On contrary, Wittkop et al. (2012) reported positive correlations between seed NDF and protein content in population ExV8-DH derived from a cross between dark-seeded B. napus. However, weak but significant negative correlation was found between seed ADL and seed protein content. Liu et al. (2012) also observed weak negative correlation between seed ADL and seed protein content in RIL population derived from the cross yellow-seeded and black-seeded B. napus, but relative strong negative correlation was observed in $\mathrm{BC}_{1} \mathrm{~F}_{2}$ population derived from the same cross. A possible biochemical explanation for negative correlation of seed protein and lignin content has been proposed by Snowdon et al. (2010) based on the results of Shen et al. (2002) who described the role of an $S$-adenosyl-L-methionine synthase 3 gene (SAMS3) in the regulation of methionine content in Arabidopsis. The mutant of SAMS3 gene exhibited elevated methionine levels and a simultaneous reduction in lignin accumulation. Since lignification consumes relatively large amounts of $S$-adenosyl methionine, reduced lignification can lead to an increase in free methionine, and that free methionine might be rechanneled into methionine-rich storage proteins (Snowdon et al. 2010). In a study about the seed storage protein in the DH population Express 617 x R53, a weak but significant negative correlation $\left(r=-0.15^{*}, P<0.05\right)$ between napin (a methionine-rich storage protein) content and ADL content of defatted meal was observed (data taken from Schatzki et al. 2014).

Cellulose and glucosinolate content were negatively correlated in all populations (Tab. 3.5, Fig 3.4). These findings are possibly related to the function of brassinosteroids (BRs), the plant hormones that play pivotal roles in regulating plant growth and height via promoting cell elongation and or cell division (Gonzalez et al. 2009). The role of BRs in regulating cellulose synthesis in Arabidopsis has been proposed by Xie et al. (2011). In their experiments, Xie et al. (2011) have demonstrated that BR signaling regulated all CESA genes for primary and secondary cell wall accumulation in order to provide adequate cellulose to sustain the architecture of enlarged cells. More recently, Guo et al. (2013) investigated the role of BR in glucosinolate biosynthesis in Arabidopsis. As results, Guo et al. (2013) reported that BR inhibited the biosynthesis of glucosinolates, and the endogenous content of BR affected the accumulation of glucosinolates in A. thaliana. The results from Xie et al. (2011) and Guo et al. (2013) confirmed that biosynthesis of cellulose and glucosinolate are co-regulated by the same precursor with an opposite effect. In this study, the negative correlation between cellulose and glucosinolate content are also reflected by QTL mapping results of the populations segregating 
for glucosinolate content (population II and III), in which QTL for cellulose content collocated with QTL for glucosinolate content (linkage group C09 in population II, and linkage group C02 in population III). The direction of the additive effects were opposite, with the marker alleles from R53 and SG DH14 increasing glucosinolate content and reducing cellulose content.

Significant variations for seed hull proportion and thousand kernel weight were found in all populations (Tab. 3.1). There were positive correlations between seed hull proportion with NDF, ADF and ADL content in all populations as expected (Tab. 3.4 and 3.5), but no significant correlations observed between TKW and fibre fractions. The significant positive correlation between seed hull content and fibre fractions have also been reported in previous studies (Bell and Shires 1982; Dimov et al. 2012; Jensen et al. 1995; Shirzadegan and Röbbelen 1985). Thousand kernel weight (TKW) was negatively correlated to seed hull proportion in all populations. These results are in accordance with Shirzadegan and Röbbelen (1985) who reported a negative correlation between TKW and seed hull content in brown- and black-seeded B. napus. Jensen et al. (1995) also observed negative correlation between seed weight and hull content in ten oilseed rape cultivars with different seed sizes and hull fractions. The negative correlation between TKW and seed hull proportion was also reported by Tang et al. (1997) in diverse dark- and yellow-seeded B. napus, B. juncea and B. campestris materials. In addition, Tanska et al. (2008) reported that oilseed rape with small seed size has higher seed coat content (19.8\%) compared to genotypes with larger seed sizes (16.5\%). Evidence for this negative association is a QTL for TKW on linkage group A05 in population II that mapped within the confidence interval of a QTL for seed hull proportion (Table 3.7) with an opposite effect. Jensen et al. (1995) suggested that selection for larger seeds will be nutritionally beneficial. More recently, comparing the meals derived from three different types of oilseed rape (black-seeded B. napus, yellow-seeded B. napus and B. juncea), Slominski et al. (2012) reported that reduction of fibre content in the meal derived from yellow-seeded B. napus canola is a consequence of a bigger seed size, lower contribution of the hull fraction to the total seed mass, and lower lignin content of the hull fraction. Reducing the seed hull proportion of the seed will also give positive impact to the reduction of anti-nutritional components which are mostly accumulated in seed hull. Results from this research confirmed TKW as an important trait that should be considered in the selection for low fibre content due to its indirect effect on fibre content by affecting seed hull proportion.

\section{QTL mapping for fibre content and seed hull proportion}

In previous research, Badani et al. (2006) identified a major QTL with large effect on both seed colour and ADF content at the same position on chromosome $\mathrm{N} 18(\sim \mathrm{C} 08)$ which was detected in three different oilseed rape populations (YE1-DH, YE2-F2 and YE2-DH) in multiple 
environments. In the present study, a QTL associated with NDF, ADF, and cellulose content in population I (Fig 3.5, Sollux x Gaoyou) and population III (Table 3.8, SG DH14 x Express 617) was also detected on linkage group C08. The confidence interval of QTL with NDF, ADF and cellulose content in population I overlapped with the confidence interval of a QTL for oil content (OilC8-2) which was reported by Zhao et al. (2012) with an opposite direction of additive effect (Fig 3.5). In this case, an allele from Gaoyou parent decreased fibre content and simultaneously increased oil content. However, the exact position of QTL for ADF content on linkage group N18 reported by Badani et al. (2006) could not be compared with present results due to a lack of common molecular markers.

Badani et al. (2006) also reported a QTL for ADF content on linkage group N13 ( C03) in the DH population YE1-DH derived from a cross between yellow-seeded line 25629-3 and blackseeded DH line K26-96. A comparable result was also found in the present study, where a QTL for ADF content mapped together with other fibre fractions on linkage group C03 of population II (Express 617 x R53, Fig 3.5) as well as on linkage group C03 of population III (SG DH14 x Express 617). These results show that QTL positions for ADF content located on linkage group C03 may be conserved in different DH populations. In the present study a QTL for ADL content was detected at $37.1 \mathrm{cM}$ on linkage group A09 of the DH population Express 617 x R53 (population II). This result is in accordance with Liu et al. (2012) who found a major QTL for ADL content in a DH population derived from yellow-seeded GH06 and black-seeded P174. The QTL for ADL content on linkage group A09 mapped in the vicinity of marker KBrH090019.5 (Liu et al. 2012). This marker was located close to the B. rapa orthologue of the major lignin biosynthesis gene, CINNAMOYL CO-A REDUCTASE (CCR), and designated as Bna.CCR1.A9 (Liu et al. 2012). More recently, Stein et al. (2013) also identified a QTL for ADL content on linkage group A09 in the black-seeded DH population ExpV8-DH, in which Bna.CCR1.A9 was localized near the peak of a corresponding seed fibre QTL.

Three QTL for seed hull proportion were detected on linkage groups A05, C01 and C03 in population II (Table 3.7), and two QTL located on linkage group A08 and C05 in population III (Table 3.8). Jin et al. (2007) identified four QTL responsible for seed hull content that have individual contribution to phenotypic variance ranging from $4.9 \%$ to $6.8 \%$ in RIL population of yellow-seeded B. napus and located in linkage group N10 ( A10) and N13 ( C03). Yan et al. (2009) reported twelve QTL associated with seed hull content that contributed 5.8 to $22.7 \%$ of the variation in the RIL population developed from a cross between yellow-seeded GH06 and black-seeded parents P174. Yan et al. (2009) found co-localization between QTL for seed hull, seed coat colour and seed oil content on chromosome N8 ( A08), as also found in population III. In the present study, QTL for seed hull proportion mostly collocated with QTL for fibre 
content and had the same direction of the additive effect. This is supported by the strong positive correlation of seed hull proportion with fibre fractions, in particular with ADL content.

Favorable QTL that reduced seed fibre content and simultaneously increased seed oil content as well as protein content of defatted meal were found in population III on A08 and C05 (Fig 3.6). On linkage group A08, QTL for fibre content collocated with a QTL for protein content of defatted meal, while the QTL for oil content was located in adjacent position. However, colocalization of QTL for erucic acid on linkage group A08 should be carefully considered due to the increase of oil content might be related to the increase of erucic acid. In this case, selection based on markers on linkage group C05 is more favorable, because reduction of fibre content is related to a reduction of seed hull proportion and an increase in oil content.

\section{A08}

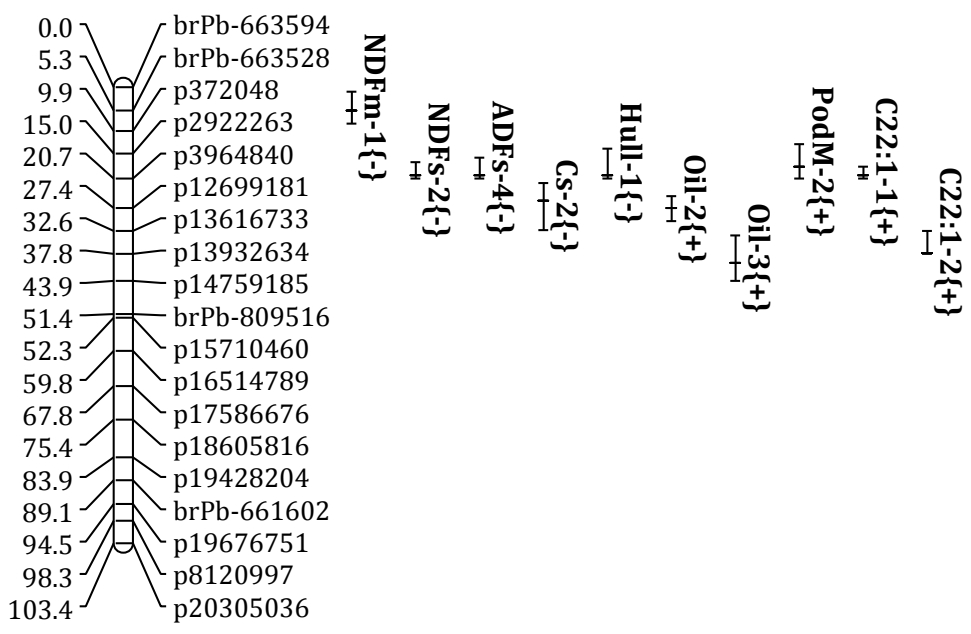

C05
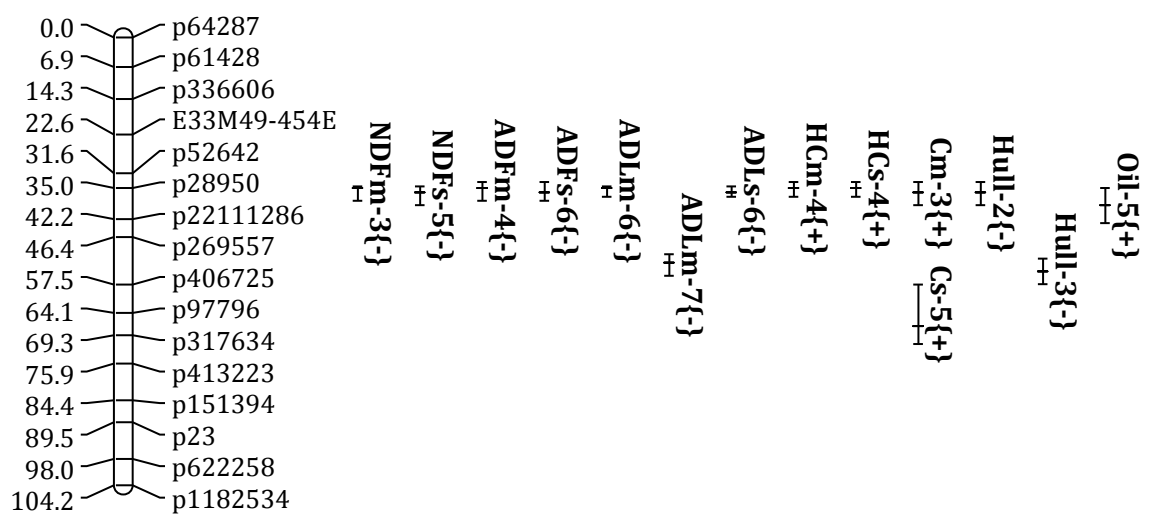

Figure 3.6 Linkage group in Population III SG DH14 x Express 617 showed favorable QTL that have an effect to reducing fibre content and simultaneously increasing oil content (A08 and C05) and protein of defatted meal (A08) 


\subsection{Application for practical breeding}

To meet the increasing demand of oil and oilseed rape meal as feedstuff for animal diets, breeding research in black-seeded winter oilseed rape is directed to simultaneously increasing seed oil and protein content as well reducing the fibre content. Our findings show relatively large variation in fibre content among the DH populations of black-seeded winter oilseed rape. The use of one of the fibre-related traits (NDF, ADF or ADL) is sufficient for identification of genotypes with low fibre content due to strong positive correlation among them. However, when screening a larger germplasm collection it should be possible to identify genotypes which are low either in hemicellulose, cellulose or lignin. Those can then be crossed to each other to identify among the offsprings genotypes with an even further reduced content of all three constituents. The NIRS calibrations developed specifically for predicting fibre content in blackseeded winter oilseed rape could be used for screening large numbers of genotypes in a fast, reliable, cost efficient and non-destructive way. This appears appealing since other seed traits like oil, protein, glucosinolate content etc. are already routinely predicted in breeding programs using NIRS. Results from present study show that selection for high oil, high protein and low fibre content in winter oilseed rape is possible to be applied to populations which show positive correlations between seed oil content and protein content of defatted meal, as shown by DH population III of SG DH14 x Express 617. In this population, the increase in oil content occurs at the expense of fibre content instead of protein content.

\subsection{Acknowledgements}

The technical assistance of Rolf Jeromin, Uwe Ammermann, Gunda Asselmeyer and Carmen Mensch as well as Jianyi Zhao and Jixiang Huang for conducting QTL analysis in Sollux x Gaoyou population is greatly appreciated. ES would like to acknowledge the financial support from the Indonesian Oil Palm Research Institute (IOPRI) for PhD scholarship.

\subsection{References}

Abbadi A, Leckband G (2011) Rapeseed breeding for oil content, quality, and sustainability. Eur J Lipid Sci Technol 113:1198-1206

Badani AG, Snowdon RJ, Wittkop B, Lipsa FD, Baetzel R, Horn R, Haro A, Font R, Lühs W (2006) Colocalization of a partially dominant gene for yellow seed colour with a major QTL influencing acid detergent fibre (ADF) content in different crosses of oilseed rape (Brassica napus). Genome 49:1499-1509

Behnke, N (2014) Increase of seed oil content in winter oilseed rape (Brassica napus L.) by using Chinese genetic resources. Georg-August-Universität Göttingen

Bell JM (1993) Factors affecting the nutritional value of canola meal: A review. Can J Anim Sci 73:689-697 
Bell JM, Shires A (1982) Composition and digestibility by pigs of hull fractions from rapeseed cultivars with yellow or brown seed coats. Can J Anim Sci 62:557-565

Burbulis N, Kott LS (2005) A new yellow-seeded canola genotype originating from double low black-seeded Brassica napus cultivars. Can J Plant Sci 85:109-114

Clark WD, Classen HL, Newkirk RW (2001) Assessment of tail-end dehulled canola meal for use in broiler diets. Can J Anim Sci 81:379-386

Deynze A, Beversdorf W, Pauls K (1993) Temperature effects on seed color in black-and yellowseeded rapeseed. Can J Plant Sci 7:383-388

Dimov Z, Suprianto E, Hermann F, Möllers C (2012) Genetic variation for seed hull and fibre content in a collection of European winter oilseed rape material (Brassica napus L.) and development of NIRS calibrations. Plant Breed 131:361-368

Gonzalez N, Beemster GTS, Inzé D (2009) David and Goliath: what can the tiny weed Arabidopsis teach us to improve biomass production in crops? Curr Opin Plant Biol $12: 157-64$

Guo R, Qian H, Shen W, Liu L, Zhang M, Cai C, Zhao Y, Qiao J, Wang Q (2013) BZR1 and BES1 participate in regulation of glucosinolate biosynthesis by brassinosteroids in Arabidopsis. J Exp Bot 64:2401-2412

Hill J, Becker HC, Tigerstedt PMA (1998) Quantitative and ecological aspects of plant breeding. Chapman and Hall, London, UK

Jensen SK, Liu YG, Eggum BO (1995) The influence of seed size and hull content on the composition and digestibility of rapeseeds in rats. Anim Feed Sci Technol 54:9-19

Jin M, Li J, Fu F, Zhang Z, Zhang X, Liu L (2007) QTL analysis of oil and hull content in Brassica napus L. Sci Agric Sin 40:677-684

Jung HG, Mertens DR, Payne AJ (1997) Correlation of acid detergent lignin and Klason lignin with digestibility of forage dry matter and neutral detergent fiber. J Dairy Sci 80:16221628

Khajali F, Slominski BA (2012) Factors that affect the nutritive value of canola meal for poultry. Poult Sci 91:2564-2575

Li M, Bahn SC, Guo L, Musgrave W, Berg H, Welti R, Wang X (2011) Patatin-related phospholipase pPLAIII $\beta$-induced changes in lipid metabolism alter cellulose content and cell elongation in Arabidopsis. Plant Cell 23:1107-1123

Liu L, Stein A, Wittkop B, Sarvari P, Li J (2012) A knockout mutation in the lignin biosynthesis gene CCR1 explains a major QTL for acid detergent lignin content in Brassica napus seeds. Theor Appl Genet 124:1573-1586

Möller J (2008) Animal feeding stuff: Global standard for the determination of acid detergent fibre (ADF) and lignin. Focus FOSS Gr J Technol Food, Dairy Agric Anal 32:22-24.

Radoev M, Becker HC, Ecke W (2008) Genetic analysis of heterosis for yield and yield components in rapeseed (Brassica napus L.) by quantitative trait locus mapping. Genetics 179:1547-1558 
Rahman M (2001) Production of yellow seeded Brassica napus through interspecific crosses. Plant Breed 120:463-472

Rakow G, Relf-Eckstein J, Raney J (2007) Rapeseed genetic research to improve its agronomic performance and seed quality. Helia 30:199-206

Saun RJ Van (2006) Determining Forage Quality: Understanding Feed Analysis. Lamalink.com $3: 25-26$

Schatzki J, Ecke W, Becker HC, Möllers C (2014) Mapping of QTL for the seed storage proteins cruciferin and napin in a winter oilseed rape doubled haploid population and their inheritance in relation to other seed traits. Theor Appl Genet, 127:1213-1222

Schatzki J, Schoo B, Ecke W, Herrfurth C, Feussner I, Becker HC, Möllers C (2013) Mapping of QTL for seed dormancy in a winter oilseed rape doubled haploid population. Theor Appl Genet 126:2405-2415

Shen B, Li C, Tarczynski MC (2002) High free-methionine and decreased lignin content result from a mutation in the Arabidopsis S-adenosyl-L-methionine synthetase 3 gene. Plant J 29:371-380

Shirzadegan M, Röbbelen G (1985) Influence of seed color and hull proportion on quality properties of seeds in Brassica napus L. Fette, Seifen, Anstrichm 87:235-237

Si P, Mailer R, Galwey N, Turner D (2003) Influence of genotype and environment on oil and protein concentrations of canola (Brassica napus L.) grown across southern Australia. Aust J Agric Res 54:397-407

Simbaya J, Slominski B, Rakow G, Campbell LD, Downey RK, Bell JM, Bello JM (1995) Quality characteristics of yellow-seeded Brassica seed meals: Protein, carbohydrate, and dietary fiber components. J Agric Food Chem 43:2062-2066

Slominski BA, Jia W, Rogiewicz A, Nyachoti CM, Hickling D (2012) Low-fiber canola. Part 1. chemical and nutritive composition of the meal. J Agric Food Chem 60:12225-12230

Snowdon R, Wittkop B, Rezaidad A, Hasan MH, Lipsa F, Stein A, Friedt W, Francki M (2010) Regional association analysis delineates a sequenced chromosome region influencing antinutritive seed meal compounds in oilseed rape. Genome 53:917-928

Van Soest PJ, Robertson JB, Lewis BA (1991) Methods for dietary fiber, neutral detergent fiber, and nonstarch polysaccharides in relation to animal nutrition. J Dairy Sci 74:3583-3597

Stein A, Wittkop B, Liu L, Obermeier C, Friedt W, Snowdon RJ (2013) Dissection of a major QTL for seed colour and fibre content in Brassica napus reveals colocalization with candidate genes for phenylpropanoid biosynthesis and flavonoid deposition. Plant Breed 132:382389

Stringam G, McGregor D, Pawlowski. S (1974) Chemical and morphological characteristics associated with seedcoat color in rapeseed. Proc. 4. Int. Rapskongress, Giessen, West Ger. pp 99-108

Tan SH, Mailer RJ, Blanchard CL, Agboola SO (2011) Canola proteins for human consumption: extraction, profile, and functional properties. J Food Sci 76:R16-R28 
Tang Z, Li J, Zhang X, Chen L, Wang R (1997) Genetic variation of yellow-seeded rapeseed lines (Brassica napus L.) from different genetic sources. Plant Breed 116:471-474

Tanska M, Konopka I, Rotkiewicz D (2008) Relationships of rapeseed strength properties to seed size, colour and coat fibre composition. J Sci Food Agric 88:2186-2193

Utz HF (2011) PLABSTAT, A computer program for statistical analysis of plant breeding experiments. Institute of Plant Breeding, Seed Science, and Population Genetics, University of Hohenheim, Stuttgart, Germany. https://plant-breeding.uni-hohenheim.de/software.html Site visited March 09, 2014

Wittkop B, Snowdon R, Friedt W (2012) New NIRS calibrations for fiber fractions reveal broad genetic variation in Brassica napus seed quality. J Agric Food Chem 60:2248-2256

Xie L, Yang C, Wang X (2011) Brassinosteroids can regulate cellulose biosynthesis by controlling the expression of CESA genes in Arabidopsis. J Exp Bot 62:4495-4506

Yan XY, Li JN, Fu FY, Jin MY, Chen L, Liu LZ (2009) Co-location of seed oil content, seed hull content and seed coat color QTL in three different environments in Brassica napus L. Euphytica 170:355-364

Yang J, Hu C, Hu H, Yu R, Xia Z, Ye X, Zhu J (2008) QTLNetwork: mapping and visualizing genetic architecture of complex traits in experimental populations. Bioinformatics 24:721-723

Yang J, Zhu J, Williams RW (2007) Mapping the genetic architecture of complex traits in experimental populations. Bioinformatics 23:1527-1536

Zhao J (2002) QTLs for oil content and their relationships to other agronomic traits in an European x Chinese oilseed rape population. PhD Thesis. Georg-August-Universität Göttingen. http://ediss.uni-goettingen.de/handle/11858/00-1735-0000-0006-AEBB-2 Site visited March 10, 2014

Zhao J, Becker HC, Zhang D, Zhang Y, Ecke W (2005) Oil content in a European $x$ Chinese rapeseed population: QTL with additive and epistatic effects and their genotype environment interactions. Crop Sci 45:51-59

Zhao J, Becker HC, Zhang D, Zhang Y, Ecke W (2006) Conditional QTL mapping of oil content in rapeseed with respect to protein content and traits related to plant development and grain yield. Theor Appl Genet 113:33-38

Zhao J, Huang J, Chen F, Xu F, Ni X, Xu H, Wang Y, Jiang C, Wang H, Xu A, Huang R, Li D, Meng J (2012) Molecular mapping of Arabidopsis thaliana lipid-related orthologous genes in Brassica napus. Theor Appl Genet 124:407-421 


\title{
CHAPTER 4
}

\section{Genetic variation and association mapping for seed fibre content in canola quality winter oilseed rape cultivars (Brassica napus L.)}

\begin{abstract}
Fibre fractions in oilseed rape meal are poorly digested and are limiting factors for using oilseed rape meal in animal diets. To increase the value of oilseed rape meal for feeding, breeding efforts are undertaken to develop cultivars having lower fibre content and lower seed hull proportion. The objectives of this study were (i) to investigate genetic variation and genotype $\mathrm{x}$ environment interactions for fibre content and seed hull proportion in canola quality winter oilseed rape cultivars, (ii) to study the correlation between fibre content and other seed quality traits, and (iii) to identify molecular markers associated with fibre content by association analysis. The seeds from 81 canola quality winter oilseed rape cultivars harvested from 19 locations in Germany over two planting years were used for the analysis. Fibre content in defatted meal was analyzed by using ANKOM Technology methods for determining the content of neutral detergent fiber (NDF), acid detergent fiber (ADF) and acid detergent lignin (ADL). Seed hull proportion was determined as hull fraction (in \%) of the seed. Large and significant genetic variations were found for different fibre fractions and seed hull proportion. Strong positive correlation between seed hull proportion and fibre content were observed, confirming that non-digestible fibre is mostly located in the seed hull. In this population, the increase in oil content occured at the expense of protein content instead of fibre content. Association mapping detected 74 markers associated with fibre-related traits representing 2 to 22 QTL for respective traits. A QTL associated with NDF content and a QTL for hemicellulose content detected in association mapping were located within confidence interval with QTL for these traits previously mapped in doubled haploid population Express 617 x R53 indicating that those might be the same QTL.
\end{abstract}

Keywords: seed hull, fibre, NDF, ADF, ADL, cellulose, hemicellulose, black-seeded, oilseed rape, canola 


\subsection{Introduction}

The presence of comparatively high fibre content is one of the limiting factors for the use of oilseed rape meal as protein source in animal diets. Fibre fraction including cellulose, hemicellulose and lignin is less digestible and essentially dilutes the available energy and protein. Consequently, oilseed rape meal has less metabolizable energy (Bell 1993) and a reduced value of the meal compared to soybean. Seed hull is known as major source of fibre, contributing up to $51 \%$ to the total seed fibre content in black-seeded B. napus (Slominski et al. 2012). Therefore, genetically reducing seed hull proportion of the seed should result in a major reduction of seed fibre content.

Fibre content is usually measured as neutral detergent fibre (NDF), acid detergent fibre (ADF) and acid detergent lignin (ADL) according to Van Soest et al. (1991). NDF comprises predominantly hemicellulose, cellulose and lignin, ADF represents cellulose and lignin, and ADL accounts for the un-digestible lignin fraction. To increase quality and value of oilseed rape meal, breeding efforts are directed to develop cultivars with low fibre content as well as high oil and protein content. Selection for low fibre content genotypes among existing canola quality winter oilseed rape cultivars and breeding lines is promising since the material is mostly high yielding and adapted to north-western European growing conditions.

In recent years, molecular markers have increasingly been used in plant breeding to select for quantitative traits such as fibre content and seed hull proportion, which are controlled by many genes (Rahman and McVetty 2011). Determination of quantitative trait loci (QTL) associated with desired traits can be undertaken through linkage analysis by using a bi-parental mapping population and through association analysis in a collection of individuals derived from wild populations, germplasm collections, or cultivars (Rafalski 2010). Unlike linkage analysis in biparental populations where familiar relationships are used to predict correlations between phenotype and genotype, association analysis method relies on previous, unrecorded sources of linkage disequilibrium to study the relationship between phenotypic variation and genetic polymorphisms (Flint-Garcia et al. 2003). Linkage disequilibrium (LD) is the nonrandom combination of alleles at two genetic loci, which in random mating populations is mostly generated by mutation and genetic drift, and decays by recombination (Breseghello and Sorrells 2006). Detection of QTL in association analysis is based on LD between QTL and linked markers and strongly depends on the extent and structure of LD in the population analyzed (Honsdorf et al. 2010). Association analysis holds a promising strategy to implement marker assisted selection and can be directly applied in plant breeding programs (Breseghello and Sorrells 
2006; Jannink et al. 2010). In oilseed rape, association analysis has been performed to identify QTL associated with phenological and morphological traits (Honsdorf et al. 2010), yield-related traits (Cai et al. 2013) as well as for a number of seed quality traits like seed oil (Zou et al. 2010) and seed glucosinolate content (Hasan et al. 2008), contents of condensed tannins (Rezaeizad et al. 2010), sinapine, proanthocyanidins and seed colour (Snowdon et al. 2010).

For dissection of the genetic basis of fibre content in oilseed rape, QTL analyses have been performed in segregating populations derived from biparental crosses. Some QTL were detected in different genetic backgrounds of B. napus responsible for ADF (Badani et al. 2006), ADL (Liu et al. 2013; Liu et al. 2012; Stein et al. 2013), hemicellulose and cellulose (Liu et al. 2013) and seed hull content (Jin et al. 2007; Yan et al. 2009). So far, the number of association studies conducted for detecting QTL responsible for fibre content in oilseed rape is still limited. Snowdon et al. (2010) have identified three SSR markers associated with NDF content and one SSR marker associated with ADF and ADL content in a panel of 49 genetically diverse winter oilseed rape breeding lines. Association mapping to detect QTL for fibre content has also been performed in other crops such as alfalfa ( $\mathrm{Li}$ et al. 2011) and maize (Andersen et al. 2007). The objectives of this research were (a) to identify genetic variation and genotype $\mathrm{x}$ environment interactions for fibre content and seed hull proportion in canola quality winter oilseed rape cultivars, (b) to study the correlation between fibre content and other seed quality traits, and (c) to identify markers associated with fibre content by association mapping.

\subsection{Materials and Methods}

\section{Plant materials, markers and genetic map}

The seed materials consisted of 81 canola quality winter oilseed rape cultivars from different breeding programs (Table S1). The 81 genotypes were a subset of a population of 85 genotypes used by Ecke et al. (2010) and Honsdorf et al. (2010). Those cultivars have previously been characterized by 685 AFLP markers and 7 single nucleotide polymorphism markers with allele frequencies $\geq 0.1$. The AFLP markers have also been mapped in a doubled haploid population derived from the cross Express 617 x R53 segregating for glucosinolate and erucic acid content (Radoev et al. 2008; Schatzki et al. 2013). The details about genotypes, marker analysis and genetic map are described in Ecke et al. (2010).

\section{Field trials}

Field trials were conducted in Germany during growing season 2007/2008 at nine locations (Reinshof, Kirchlengern, Lundsgaard, Hadmersleben, Einbeck, Hohenlieth, Schliestedt, Bad Salzuflen and Thüle) and in 2008/2009 at ten locations (Reinshof, Kirchlengern, Lundsgaard, 
Malchow, Einbeck, Schliestedt, Hadmersleben, Bad Salzuflen, Thüle and Rauischholzhausen). Experiments were performed without replicates. Plants were cultivated in observation plots and at maturity seeds were harvested as a bulk from ten open pollinated plants of each genotype.

\section{Determination of fibre content}

Seed samples of about $3 \mathrm{~g}$ were scanned with a NIRS monochromator model 6500 (NIR Systems mod. 6500, NIRSystems Inc., Silversprings, MD, USA). Spectra were recorded between 400 and $2498 \mathrm{~nm}$, registering the absorbance values $\log (1 / \mathrm{R})$ at $2 \mathrm{~nm}$ intervals for each sample. The content of neutral detergent fibre (NDF), acid detergent fibre (ADF) and acid detergent lignin (ADL) of defatted meal were extrapolated from NIR spectra using the calibrations developed specifically for measurement of fibre content in black-seeded B. napus (Dimov et al. 2012). Hemicellulose (HC) content was determined by subtracting ADF from NDF, and cellulose (C) content was determined by subtracting ADL from ADF. The calibration equation developed by Dimov et al. (2012) contained spectra data from 28 European winter oilseed rape cultivars and 289 DH lines of Express $617 \times$ R53, and was improved with additional samples of each $60 \mathrm{DH}$ lines of SG DH14 x Express 617 and of Sollux x Gaoyou (cf Chapter 3) as well as of 81 canola quality winter oilseed rape cultivars tested at six locations in 2008 and 2009. The SEP (C) of extended calibration in predicting NDF, ADF, and ADL content in defatted meal of the subset of validation set from 81 cultivars from four locations were 3.9\%, 1.9\% and 1.6\%, respectively. All fibre content values are given as percentage of fibre in the defatted meal. The percentage of fibre fractions on seed basis was calculated by using this formula:

$\%$ Fibre in the seed $(\% \mathrm{DM})=(\%$ Fibre of defatted meal $/ 100) *(100-\%$ Oil content $)$

\section{Oil, protein content and protein content of defatted meal}

Oil and protein content of the seeds were determined by NIRS using the calibration raps2012.eqa provided by VDLUFA Qualitätssicherung NIRS GmbH (Teichstr. 35, D-34130 Kassel, http://h1976726.stratoserver.net/cms, accessed on 24 February 2014). Oil and protein content are expressed as percentage on a seed basis at $91 \%$ dry matter content. Protein content of the defatted meal was calculated by using the seed oil and protein content data obtained from NIRS prediction as follows:

$\%$ Protein of the defatted meal $(\operatorname{PodM})=[\%$ Seed protein $/(100-\%$ Oil content $)] * 100$ 


\section{Seed hull proportion and thousand kernel weight}

Determination of seed hull proportion and thousand kernel weight was performed for seed samples from six locations: Thüle, Reinshof and Hohenlieth of growing season 2007/2008, and Thüle, Reinshof and Rauischholzhausen of growing season 2008/2009. Seed hull proportion (in $\%$ ) was determined from 100 seeds (approx. $500 \mathrm{mg}$ ) per sample. Seeds were dried at $105{ }^{\circ} \mathrm{C}$ for $8 \mathrm{hrs}$ and then imbibed in water for 15 to $20 \mathrm{hr}$. Seed hulls were separated from embryos by using a dissecting needle. Both fractions were dried at $105^{\circ} \mathrm{C}$ overnight, and dry weights were determined. Thousand kernel weight (TKW) in grams was measured from 500 seeds using a seed counter (model Contador, Pfeuffer GmbH, D-97318 Kitzingen, http://www.pfeuffer.com).

\section{Statistical analyses}

\section{Analysis of variance}

Variance components, heritability, means and phenotypic correlations were estimated by using PLABSTAT software version 3Bwin (Utz 2011). Analysis of variance was performed using the following model:

$$
Y_{i j}=\mu+g_{i}+e_{j}+g e_{i j}
$$

Where $Y_{i j}$ is observation of genotype $i$ in environment $j$; $\mu$ is general mean; $g_{i}$ and $e_{j}$ are effects of genotype $\mathrm{i}$ and environment $\mathrm{j} ; g e_{i j}$ is genotype $\mathrm{x}$ environment interaction of genotype $i$ with environment $j$. The genotypes were considered as fixed factor. Broad sense heritability $\left(h^{2}\right)$ for mean values over environment was calculated from components of variance:

$$
h^{2}=\sigma_{\mathrm{g}}^{2} /\left(\sigma_{\mathrm{g}}^{2}+\sigma_{\mathrm{ge}}^{2} / E\right)
$$

Where $\sigma_{g}^{2}$ and $\sigma^{2}$ ge are variance components for $g$ and $g e ; E$ is number of environment. Mean values of the genotypes across the environments were used to calculate Spearman's rank correlation coefficients between traits.

\section{Association analysis}

The general linear model procedure for association analysis was performed by using the program TASSEL version 3.0 (Bradbury et al. 2007) with the means over 19 locations as phenotypic traits. Association analysis was undertaken without considering population structure because in previous studies no population structure was detected in this population (Ecke et al. 2010; Honsdorf et al. 2010). The statistical significance of marker-trait associations was tested against a false discovery rate which is the expected proportion of errors committed by falsely rejecting the null hypothesis (Benjamini and Hochberg 1995). In this study, the false discovery rate was set at $q^{*}=0.2$. Phenotypic effects at the marker loci were calculated as 
differences between means of the marker classes. In this case, a positive value indicates that the visible marker allele increases the trait and negative value indicates that the visible marker allele reduces the trait. Identification of linkage disequilibrium (LD) between markers based on $R^{2}$ values for pair wise marker combinations was presented as LD map by Ecke et al. (2010). Multiple linear regression analysis was applied using R statistical software (R Core Team 2012) for determining the total variance explained by the identified QTL. In the case where many significant markers on one linkage group were closely linked, the representative marker for QTL used in multiple linear regression analysis was selected based on the criteria: (i) linkage disequilibrium (LD) between pairs of associated markers on linkage group is significant $\left(r^{2} \geq\right.$ 0.6) and (ii) significant marker has the lowest $P$-value which will account for a higher phenotypic variation. The threshold for declaring linkage disequilibrium between two markers significant was derived by a Bonferroni correction from $\alpha$-level of 0.1 , resulting in a per test threshold of $P=2.8 \times 10^{-7}$ (Ecke et al. 2010).

\subsection{Results}

\section{Variance components}

Analysis of variance showed significant effects of the genotype and the environment on all fibre fractions, seed hull proportion and thousand kernel weight (Table 4.1). Larger environmental effects and genotype $x$ environment (GxE) interaction effects were observed for contents of NDF of defatted meal (NDFm), hemicellulose, cellulose, oil, seed protein and protein content of defatted meal compared to the effect of the genotype. For seed hull proportion and thousand kernel weight (TKW), variance components of GxE interactions were smaller than those of the genotype, but larger than the effects of the environment. Heritabilities were high for all traits ranging from 0.85 to 0.98 . 
Table 4.1 Variance components and heritabilities for NDF, ADF, ADL, hemicellulose (HC) and cellulose (C) content (\% of defatted meal - suffix m and \% of seed basis - suffix s), seed hull proportion (Hull, \%), thousand kernel weight (TKW, g), seed oil and seed protein content (\%), and protein content of defatted meal (PodM, \%) of 81 canola quality winter oilseed rape cultivars

\begin{tabular}{|c|c|c|c|c|}
\hline \multirow[t]{2}{*}{ Traits } & \multicolumn{3}{|c|}{ Variance components } & \multirow{2}{*}{$\begin{array}{c}\text { Heritability } \\
h^{2}\end{array}$} \\
\hline & $\sigma^{2} \mathrm{~g}$ & $\sigma_{\mathrm{e}}^{2}$ & $\sigma_{\mathrm{ge}}^{2}$ & \\
\hline NDFm & $1.07^{* *}$ & $1.88^{* *}$ & 1.48 & 0.93 \\
\hline NDFs & $0.27^{* *}$ & $0.19^{* *}$ & 0.19 & 0.98 \\
\hline $\mathrm{ADFm}$ & $1.44^{* *}$ & $0.79^{* *}$ & 1.05 & 0.96 \\
\hline ADFs & $0.43^{* *}$ & $0.07^{* *}$ & 0.16 & 0.98 \\
\hline ADLm & $1.61^{* *}$ & $0.38^{* *}$ & 0.72 & 0.98 \\
\hline ADLs & $0.49^{* *}$ & $0.05^{* *}$ & 0.16 & 0.98 \\
\hline $\mathrm{HCm}$ & $0.22^{* *}$ & $0.86^{* *}$ & 0.29 & 0.94 \\
\hline $\mathrm{HCs}$ & $0.06^{* *}$ & $0.22^{\text {** }}$ & 0.08 & 0.93 \\
\hline $\mathrm{Cm}$ & $0.16^{* *}$ & $0.19^{* *}$ & 0.15 & 0.95 \\
\hline Cs & $0.05^{* *}$ & $0.05^{* *}$ & 0.03 & 0.97 \\
\hline Hull $^{1}$ & $1.14^{* *}$ & $0.16^{* *}$ & 0.66 & 0.91 \\
\hline TKW $^{1}$ & $0.24^{* *}$ & $0.05^{* *}$ & 0.17 & 0.85 \\
\hline Oil & $1.34^{* *}$ & $3.21^{* *}$ & 2.18 & 0.92 \\
\hline Protein & $0.91^{* *}$ & $2.36^{* *}$ & 1.76 & 0.91 \\
\hline PodM & $1.84^{* *}$ & 3.53 ** & 2.72 & 0.93 \\
\hline
\end{tabular}

\section{Variation for fibre content, seed hull proportion and other traits}

Large variation for fibre fractions was identified among the cultivars (Table 4.2). The NDF content of defatted meal ranged from 28.5 to $34.4 \%$, ADF content ranged from 20.9 to $27.1 \%$ and ADL content ranged from 6.9 to 13.5\%. Large variation was also observed for seed hull proportion and TKW as well as for oil and seed protein content. Seed hull proportion varied between $12.2 \%$ and $18.3 \%$. 
Table 4.2 Minimum, maximum and mean values for NDF, ADF, ADL, hemicellulose (HC) and cellulose (C) content (\% of defatted meal - suffix $\mathrm{m}$ and $\%$ of seed basis - suffix s), seed hull proportion (Hull, \%), thousand kernel weight (TKW, g), seed oil and seed protein content (\%), and protein content of defatted meal (PodM in \%) of 81 canola quality winter oilseed cultivars

\begin{tabular}{lccccc}
\hline Traits & Min & Max & Mean & $F_{\text {value }}$ & LSD 5\% \\
\hline NDFm & 28.5 & 34.4 & 31.8 & $14.81^{* *}$ & 0.77 \\
NDFs & 15.9 & 19.0 & 17.6 & $27.77^{* *}$ & 0.28 \\
ADFm & 20.9 & 27.1 & 24.4 & $27.03^{* *}$ & 0.65 \\
ADFs & 11.3 & 15.2 & 13.5 & $52.55^{* *}$ & 0.26 \\
ADLm & & & & & \\
ADLs & 6.9 & 13.6 & 11.0 & $43.36^{* *}$ & 0.54 \\
HCm & 3.7 & 7.4 & 6.1 & $58.38^{* *}$ & 0.26 \\
HCs & 6.3 & 9.7 & 7.4 & $16.04^{* *}$ & 0.34 \\
Cm & 3.7 & 7.5 & 4.1 & $14.72^{*}$ & 0.18 \\
Cs & 12.1 & 14.4 & 13.4 & $20.99^{* *}$ & 0.25 \\
Hull & 6.9 & 7.9 & 7.4 & $31.83^{* *}$ & 0.11 \\
TKW & 12.2 & 18.3 & 15.8 & $11.30^{* *}$ & 0.91 \\
Oil & 4.5 & 7.2 & 5.3 & $9.32^{* *}$ & 0.47 \\
Protein & 39.9 & 47.4 & 44.4 & $12.75^{* *}$ & 0.94 \\
PodM & 15.5 & 21.6 & 17.3 & $10.80^{* *}$ & 0.84 \\
\hline
\end{tabular}

LSD 5\% = least significant difference at $P<5 \% ;{ }^{*}, *$ denotes significance at $P<5 \%$ and $1 \%$

\section{Correlation between traits}

Spearman's rank correlations revealed highly significant positive correlations between NDF, ADF, ADL and seed hull proportion (Table 4.3). Hemicellulose was negatively correlated with $\mathrm{ADF}, \mathrm{ADL}$ and cellulose content and with seed hull proportion. NDF, ADF, ADL content in defatted meal were positively correlated with seed oil content and negatively correlated with protein content of defatted meal (Table 4.3). When the correlation was performed based on seed basis, weak negative correlations to oil content and seed protein content were observed for $\mathrm{NDF}, \mathrm{ADF}, \mathrm{ADL}$ and cellulose content. Seed hull proportion was negatively correlated with hemicellulose, seed oil, seed protein and protein content of defatted meal. Thousand kernel weight (TKW) showed negative correlations with seed oil, NDF, ADF, ADL and cellulose content as well as with seed hull proportion. Significant negative correlations were observed between seed oil and protein content both on seed basis and in defatted meal suggesting that an increase of oil content occurred at the expense of protein content. 
Table 4.3 Spearman's rank correlation between fibre fractions and other quality seed traits

\begin{tabular}{|c|c|c|c|c|c|c|c|c|c|c|c|c|c|c|}
\hline Traits & Oil & Protein & PodM & NDFm & NDFs & ADFm & ADFs & ADLm & ADLs & $\mathrm{HCm}$ & $\mathrm{HCs}$ & $\mathrm{Cm}$ & $\mathrm{Cs}$ & Hull \\
\hline Protein & $-0.58^{* *}$ & & & & & & & & & & & & & \\
\hline PodM & $-0.24^{* *}$ & $0.91^{* *}$ & & & & & & & & & & & & \\
\hline NDFm & $0.43^{* *}$ & $-0.71^{* *}$ & $-0.69 * *$ & & & & & & & & & & & \\
\hline NDFs & -0.16 & $-0.40^{* *}$ & $-0.60 * *$ & $0.78^{* *}$ & & & & & & & & & & \\
\hline ADFm & $0.24^{* *}$ & $-0.54^{* *}$ & $-0.58^{* *}$ & $0.92^{* *}$ & $0.84^{* *}$ & & & & & & & & & \\
\hline ADFs & -0.13 & $-0.33^{* *}$ & $-0.50 * *$ & $0.75^{* *}$ & $0.94^{* *}$ & $0.90^{* *}$ & & & & & & & & \\
\hline ADLm & 0.16 & $-0.36^{* *}$ & $-0.40^{* *}$ & $0.80^{* *}$ & $0.78^{* *}$ & $0.93^{* *}$ & $0.88^{* *}$ & & & & & & & \\
\hline ADLs & -0.02 & $-0.28^{*}$ & $-0.38^{* *}$ & $0.73^{* *}$ & $0.83^{* *}$ & $0.89^{* *}$ & $0.93^{* *}$ & 0.97 & & & & & & \\
\hline $\mathrm{HCm}$ & $0.36^{* *}$ & -0.19 & -0.04 & -0.15 & $-0.38^{* *}$ & $-0.47^{* *}$ & $-0.61^{* *}$ & $-0.55^{* *}$ & $-0.63^{* *}$ & & & & & \\
\hline $\mathrm{HCs}$ & 0.04 & -0.01 & 0.03 & -0.31 & $-0.35^{* *}$ & $-0.60^{* *}$ & $-0.61^{* *}$ & $-0.67^{* *}$ & $-0.68^{* *}$ & $0.93^{* *}$ & & & & \\
\hline $\mathrm{Cm}$ & $0.27^{*}$ & $-0.43^{* *}$ & $-0.43^{* *}$ & 0.15 & 0.01 & 0.01 & -0.10 & $-0.31^{*}$ & $-0.36^{* *}$ & $0.39^{* *}$ & $0.35^{*}$ & & & \\
\hline Cs & $-0.33^{* *}$ & -0.07 & $-0.27^{* *}$ & -0.09 & 0.12 & -0.14 & -0.02 & $-0.50 * *$ & $-0.40^{* *}$ & 0.17 & $0.33^{*}$ & 0.78 & & \\
\hline Hull & -0.17 & $-0.29 * *$ & $-0.47^{* *}$ & $0.58^{* *}$ & $0.77^{* *}$ & $0.67^{* *}$ & $0.76^{* *}$ & $0.61^{* *}$ & $0.65^{* *}$ & $-0.39 * *$ & $-0.36^{* *}$ & 0.02 & $0.14^{* *}$ & \\
\hline TKW & -0.21 & 0.15 & 0.07 & -0.17 & -0.20 & $-0.22^{*}$ & -0.10 & -0.19 & -0.16 & 0.12 & 0.21 & -0.08 & 0.06 & $-0.34^{* *}$ \\
\hline
\end{tabular}

$\mathrm{NDF}=$ neutral detergent fibre, $\mathrm{ADF}=$ acid detergent fibre, $\mathrm{ADL}=$ acid detergent lignin, $\mathrm{HC}=$ hemicellulose, $\mathrm{C}=$ cellulose.

Suffix ' $m$ ' on NDF, ADF, ADL, HC and C refers to $\%$ of defatted meal, and suffix 's' refers to $\%$ on seed basis.

PodM = protein of defatted meal

Hull = seed hull proportion

TKW = thousand kernel weight

$*, * *$ denotes significance at $P<5 \%$ and $1 \%$ 


\section{Association analysis}

Association analysis was performed using the means of phenotypic data from 19 locations. By testing against a false discovery rate (FDR) of 0.2, 74 significant associations were detected for fibre-related traits, 6 markers were associated with seed protein and protein content of defatted meal, and 22 markers associated with seed oil content (Table 4.4). No significant associations were observed for NDF of defatted meal (NDFm), ADF of defatted meal (ADFm), seed hull proportion and thousand kernel weight (TKW).

The location of associated markers on the linkage groups was determined based on the genetic map of the doubled haploid (DH) population Express 617 x R53 in which all markers used in the association analysis had been previously mapped. In cases in which more than one marker associated with the trait located in the same linkage group, markers that were closely linked and in significant linkage disequilibrium $\left(r^{2} \geq 0.6\right)$ were assumed to present the same QTL. Taking this into account, 1 to 22 QTL have been detected for the respective traits (Table 4.4). For determining the variance explained by QTL, a multiple regression analysis has been performed using one representative marker per QTL. The variance explained by the QTL ranged from $17 \%$ for protein content of defatted meal to $48 \%$ for cellulose content of defatted meal.

Table 4.4 Summary of the association analysis results by using the means of phenotypic data across 19 locations

\begin{tabular}{|c|c|c|c|c|c|c|}
\hline \multirow[t]{3}{*}{ Trait } & \multicolumn{4}{|c|}{ Association analysis } & \multicolumn{2}{|c|}{ Multiple regression } \\
\hline & \multirow{2}{*}{$\begin{array}{l}{ }^{1} \text { No. of } \\
\text { markers }\end{array}$} & \multirow{2}{*}{$\begin{array}{c}{ }^{2} \text { No. of } \\
\text { LG }\end{array}$} & \multicolumn{2}{|c|}{${ }^{3}$ Phenotypic effect } & \multirow{2}{*}{$\begin{array}{l}{ }^{4} \text { No. of } \\
\text { markers }\end{array}$} & \multirow[t]{2}{*}{${ }^{5} R^{2}$ adj. } \\
\hline & & & Min & Max & & \\
\hline NDFs & 32 & 10 & 0.31 & 0.60 & 22 & 0.46 \\
\hline ADFs & 6 & 4 & 0.52 & 0.68 & 5 & 0.34 \\
\hline ADLm & 2 & 2 & 1.02 & 1.04 & 2 & 0.24 \\
\hline ADLs & 8 & 5 & 0.52 & 0.67 & 7 & 0.33 \\
\hline $\mathrm{HCm}$ & 8 & 3 & 0.40 & 0.65 & 4 & 0.24 \\
\hline $\mathrm{Cm}$ & 18 & 5 & 0.27 & 0.58 & 11 & 0.48 \\
\hline Protein & 5 & 3 & 1.02 & 1.28 & 3 & 0.34 \\
\hline PodM & 1 & 1 & 1.82 & 1.82 & 1 & 0.17 \\
\hline Oil & 22 & 8 & 0.79 & 1.81 & 13 & 0.36 \\
\hline
\end{tabular}

NDFs $=$ NDF in seed basis, ADFs $=$ ADF in seed basis, ADLm $=$ ADL content of defatted meal, ADLs = ADL in seed basis, $\mathrm{HCm}=$ hemicellulose content of defatted meal; $\mathrm{Cm}$ = cellulose content of defatted meal; PodM = protein content of defatted meal; ${ }^{1}$ number of significant markers; ${ }^{2}$ number of linkage group with significant markers; ${ }^{3}$ Absolute minimum and maximum phenotypic effect (\%) of significant markers; ${ }^{4}$ Number of markers used in multiple linear regression, also represents number of QTL detected; ${ }^{5}$ phenotypic variance explained by QTL 
Results of association analysis in canola quality winter oilseed rape cultivars are described in detail in Table 4.5. QTL associated with NDF (NDFs-9_AM), ADF (ADFs-2_AM), and ADL (ADLs5_AM) content detected in canola quality winter oilseed rape cultivars were located on linkage group C03, close to the QTL responsible for NDF, ADF and ADL content detected in DH population Express 617 x R53 (Table 4.5, Fig 4.1). A QTL associated with NDF on linkage group C03 is within $11.3 \mathrm{cM}$ of QTL mapped in the DH population Express 617 x R53 indicating that this maybe the same QTL. Markers associated with hemicellulose content represented by a QTL HCm-4_AM located on linkage group C09 were also associated with QTL for oil content (Oil13_AM). QTL for oil and hemicellulose content have also been previously mapped in DH population Express 617 x R53 in the same location (Fig. 4.1). 
Table 4.5 Results from the association analysis in 81 canola quality winter oilseed rape cultivars

\begin{tabular}{|c|c|c|c|c|c|c|c|c|c|c|c|c|c|c|c|c|c|c|c|}
\hline \multirow[t]{3}{*}{ Traits } & \multirow[t]{3}{*}{${ }^{1} \mathrm{No}$} & \multirow[t]{3}{*}{ Markers } & \multirow[t]{3}{*}{${ }^{2} \mathrm{LG}$} & \multirow{3}{*}{$\begin{array}{l}\text { 3Pos } \\
\text { (cM) }\end{array}$} & \multirow{3}{*}{$\begin{array}{l}\text { Marker } \\
P \text { value }\end{array}$} & \multirow{3}{*}{$\begin{array}{l}{ }^{4} R^{2} \\
(\%)\end{array}$} & \multirow{3}{*}{$\begin{array}{l}{ }^{5} \text { Pheno. } \\
\text { Effect }\end{array}$} & \multirow[t]{3}{*}{${ }^{6} \mathrm{QTL}$} & \multirow{3}{*}{$\begin{array}{l}\text { 7Multi. } \\
\text { Reg. }\end{array}$} & \multirow{3}{*}{$\begin{array}{l}{ }^{8} \mathrm{R}^{2} \\
\text { adj. }\end{array}$} & \multicolumn{9}{|c|}{${ }^{9}$ Linkage disequilibrium $\left(r^{2}\right)$} \\
\hline & & & & & & & & & & & \multicolumn{9}{|c|}{ Marker No. } \\
\hline & & & & & & & & & & & 1 & 2 & 3 & 4 & 5 & 6 & 7 & 8 & 9 \\
\hline \multirow[t]{32}{*}{ NDFs } & 1 & E37M50-393 & $\mathrm{A} 03$ & 64.4 & 0.000997 & 0.13 & -0.44 & NDFs-1_AM & $\mathrm{X}$ & \multirow{32}{*}{0.46} & & & & & & & & & \\
\hline & 2 & E41M50-407 & $\mathrm{A} 03$ & 76.8 & 0.000008 & 0.22 & -0.60 & NDFs-2_AM & $\mathrm{X}$ & & 0.28 & & & & & & & & \\
\hline & 3 & E37M50-088 & $\mathrm{A} 03$ & 83.8 & 0.000052 & 0.19 & 0.47 & NDFs-3_AM & $\mathrm{X}$ & & 0.60 & 0.26 & & & & & & & \\
\hline & 1 & E38M56-078 & A05 & 129.5 & 0.009065 & 0.08 & -0.31 & NDFs-4_AM & $\mathrm{X}$ & & & & & & & & & & \\
\hline & 1 & E37M62-236 & A06 & 56.4 & 0.005516 & 0.09 & -0.45 & \multirow{4}{*}{ NDFs-5_AM } & & & & & & & & & & & \\
\hline & 2 & E32M49-205 & A06 & 56.9 & 0.004520 & 0.10 & 0.48 & & & & 0.68 & & & & & & & & \\
\hline & 3 & E39M49-368 & A06 & 56.9 & 0.003228 & 0.10 & 0.52 & & & & 0.75 & 0.90 & & & & & & & \\
\hline & 4 & E42M50-112 & $\mathrm{A} 06$ & 56.9 & 0.002490 & 0.11 & -0.51 & & $\mathrm{X}$ & & 0.92 & 0.74 & 0.82 & & & & & & \\
\hline & 5 & E32M49-467 & A06 & 56.9 & 0.000661 & 0.14 & -0.47 & \multirow[t]{2}{*}{ NDFs-6_AM } & $\mathrm{X}$ & & 0.49 & 0.40 & 0.45 & 0.56 & & & & & \\
\hline & 6 & E37M51-259 & $\mathrm{A} 06$ & 56.9 & 0.005824 & 0.09 & -0.41 & & & & 0.49 & 0.38 & 0.43 & 0.55 & 0.70 & & & & \\
\hline & 7 & E33M51-492 & $\mathrm{A} 06$ & 63.6 & 0.002490 & 0.11 & -0.51 & NDFs-7_AM & $x$ & & 0.83 & 0.65 & 0.72 & 0.91 & 0.50 & 0.49 & & & \\
\hline & 1 & E40M61-190 & A09 & 37.0 & 0.003684 & 0.11 & 0.44 & NDFs-8_AM & $\mathrm{X}$ & & & & & & & & & & \\
\hline & 1 & E34M56-429 & $\mathrm{A} 10$ & 60.1 & 0.003312 & 0.10 & -0.46 & NDFs-9_AM & $X$ & & & & & & & & & & \\
\hline & 1 & E40M50-184 & $\mathrm{C} 01$ & 99.0 & 0.008714 & 0.08 & -0.31 & NDFs-10_AM & $x$ & & & & & & & & & & \\
\hline & 1 & E32M52-452 & $\mathrm{C} 03$ & 65.6 & 0.002552 & 0.11 & -0.40 & \multirow{2}{*}{ NDFs-11_AM } & & & \multirow{4}{*}{0.82} & & & & & & & & \\
\hline & 2 & E32M52-443 & $\mathrm{C} 03$ & 67.7 & 0.001597 & 0.12 & 0.41 & & $\mathrm{X}$ & & & & & & & & & & \\
\hline & 3 & E32M47-245 & $\mathrm{C} 03$ & 147.7 & 0.003250 & 0.10 & -0.37 & NDFs-12_AM & $x$ & & & & & & & & & & \\
\hline & 1 & E32M59-237 & $\mathrm{C} 04$ & 56.9 & 0.005255 & 0.09 & -0.34 & \multirow{2}{*}{ NDFs-13_AM } & $\mathrm{X}$ & & & & & & & & & & \\
\hline & 2 & E36M49-115 & $\mathrm{C} 04$ & 56.9 & 0.008061 & 0.09 & 0.35 & & & & 0.63 & & & & & & & & \\
\hline & 3 & E45M60-334 & $\mathrm{C} 04$ & 73.4 & 0.004917 & 0.10 & -0.36 & NDFs-14_AM & $X$ & & 0.32 & 0.22 & & & & & & & \\
\hline & 1 & E39M57-317 & $\mathrm{C} 05$ & 68.0 & 0.003728 & 0.10 & 0.53 & NDFs-15_AM & $\mathrm{X}$ & & & & & & & & & & \\
\hline & 2 & E39M50-391 & $\mathrm{C} 05$ & 82.5 & 0.003381 & 0.10 & -0.51 & \multirow{2}{*}{ NDFs-16_AM } & & & 0.00 & & & & & & & & \\
\hline & 3 & E44M54-102 & $\mathrm{C} 05$ & 82.5 & 0.001512 & 0.12 & 0.58 & & $\mathrm{X}$ & & 0.05 & 0.79 & & & & & & & \\
\hline & 4 & E39M49-187 & $\mathrm{C} 05$ & 87.6 & 0.003985 & 0.10 & -0.48 & \multirow{2}{*}{ NDFs-17_AM } & & & 0.02 & 0.26 & 0.26 & & & & & & \\
\hline & 5 & E39M49-192 & $\mathrm{C} 05$ & 87.6 & 0.001820 & 0.12 & 0.50 & & $\mathrm{X}$ & & 0.03 & 0.23 & 0.31 & 0.82 & & & & & \\
\hline & 1 & E39M50-353 & C08 & 11.2 & 0.008965 & 0.08 & -0.33 & NDFs-18 AM & & & & & & & & & & & \\
\hline & 2 & E40M55-316 & C08 & 12.9 & 0.006612 & 0.09 & -0.35 & & $\mathrm{X}$ & & 0.94 & & & & & & & & \\
\hline & 3 & E32M47-341 & $\mathrm{C} 08$ & 124.5 & 0.001014 & 0.13 & -0.38 & NDFs-19_AM & $\mathrm{X}$ & & 0.00 & 0.00 & & & & & & & \\
\hline & 1 & E45M61-220 & $\mathrm{C} 09$ & 4.0 & 0.009310 & 0.08 & 0.31 & NDFs-20_AM & $x$ & & & & & & & & & & \\
\hline & 2 & E34M53-167 & C09 & 84.8 & 0.000287 & 0.16 & -0.46 & NDFs-21_AM & $x$ & & 0.25 & & & & & & & & \\
\hline & 3 & E38M60-106 & C09 & 95.0 & 0.006298 & 0.09 & 0.37 & NDFs-22 AM & $\mathrm{X}$ & & 0.26 & 0.20 & & & & & & & \\
\hline & 4 & E35M55-135 & $\mathrm{C} 09$ & 95.3 & 0.006298 & 0.09 & -0.37 & FS-LL_AVI & & & 0.24 & 0.23 & 0.94 & & & & & & \\
\hline
\end{tabular}


Table 4.5 (Continued)

\begin{tabular}{|c|c|c|c|c|c|c|c|c|c|c|c|c|c|c|c|c|c|c|c|}
\hline \multirow[t]{3}{*}{ Traits } & \multirow[t]{3}{*}{${ }^{1} \mathrm{No}$} & \multirow[t]{3}{*}{ Markers } & \multirow[t]{3}{*}{${ }^{2} \mathrm{LG}$} & \multirow{3}{*}{$\begin{array}{l}{ }^{3} \mathrm{Pos} \\
\text { (cM) }\end{array}$} & \multirow{3}{*}{$\begin{array}{l}\text { Marker } \\
P \text { value }\end{array}$} & \multirow{3}{*}{$\begin{array}{l}{ }^{4} R^{2} \\
(\%)\end{array}$} & \multirow{3}{*}{$\begin{array}{l}\text { 5Pheno. } \\
\text { Effect }\end{array}$} & \multirow[t]{3}{*}{${ }^{6} \mathrm{QTL}$} & \multirow{3}{*}{$\begin{array}{c}{ }^{7} \text { Multi. } \\
\text { Reg. }\end{array}$} & \multirow{3}{*}{$\begin{array}{l}{ }^{8} \mathrm{R}^{2} \\
\text { adj. }\end{array}$} & \multicolumn{9}{|c|}{${ }^{9}$ Linkage disequilibrium $\left(r^{2}\right)$} \\
\hline & & & & & & & & & & & \multicolumn{9}{|c|}{ Marker No. } \\
\hline & & & & & & & & & & & 1 & 2 & 3 & 4 & 5 & 6 & 7 & 8 & 9 \\
\hline \multirow[t]{6}{*}{ ADFs } & 1 & E41M50-407 & $\mathrm{A} 03$ & 76.8 & 0.000072 & 0.18 & -0.68 & ADFs-1_AM & $\mathrm{X}$ & \multirow{6}{*}{0.34} & & & & & & & & & \\
\hline & 2 & E37M50-088 & $\mathrm{A} 03$ & 83.8 & 0.000259 & 0.16 & 0.54 & ADFs-2_AM & $\mathrm{X}$ & & 0.26 & & & & & & & & \\
\hline & 1 & E32M52-452 & $\mathrm{C} 03$ & 65.6 & 0.000892 & 0.13 & -0.55 & \multirow{2}{*}{ ADFs-3_AM } & & & \multirow{4}{*}{0.82} & & & & & & & & \\
\hline & 2 & E32M52-443 & $\mathrm{C03}$ & 67.7 & 0.000632 & 0.14 & 0.55 & & $\mathrm{x}$ & & & & & & & & & & \\
\hline & 1 & E32M47-341 & $\mathrm{C} 08$ & 124.5 & 0.000728 & 0.14 & -0.50 & ADFs-4_AM & $\mathrm{X}$ & & & & & & & & & & \\
\hline & 1 & E34M53-167 & $\mathrm{C} 09$ & 84.8 & 0.001396 & 0.12 & -0.52 & ADFs-5_AM & $\mathrm{x}$ & & & & & & & & & & \\
\hline \multirow[t]{2}{*}{ ADLm } & 1 & E37M50-088 & $\mathrm{A} 03$ & 83.8 & 0.000231 & 0.16 & 1.04 & ADLm-1_AM & $\mathrm{X}$ & \multirow{2}{*}{0.24} & & & & & & & & & \\
\hline & 2 & E32M47-341 & $\mathrm{C} 08$ & 124.5 & 0.000307 & 0.15 & -1.02 & ADLm-2_AM & $\mathrm{X}$ & & & & & & & & & & \\
\hline \multirow[t]{8}{*}{ ADLs } & 1 & E37M50-393 & $\mathrm{A} 03$ & 64.4 & 0.000987 & 0.13 & -0.59 & ADLs-1_AM & $\mathrm{X}$ & \multirow{8}{*}{0.33} & & & & & & & & & \\
\hline & 2 & E41M50-407 & $\mathrm{A} 03$ & 76.8 & 0.000256 & 0.16 & -0.67 & ADLs-2_AM & $\mathrm{X}$ & & 0.28 & & & & & & & & \\
\hline & 3 & E37M50-088 & $\mathrm{A} 03$ & 83.8 & 0.000160 & 0.17 & 0.59 & ADLs-3_AM & $\mathrm{X}$ & & 0.60 & 0.26 & & & & & & & \\
\hline & 1 & E32M49-467 & $\mathrm{A} 06$ & 56.9 & 0.002242 & 0.11 & -0.57 & ADLs-4_AM & $\mathrm{X}$ & & & & & & & & & & \\
\hline & 1 & E32M52-452 & $\mathrm{C} 03$ & 65.6 & 0.001075 & 0.13 & -0.57 & \multirow{2}{*}{ ADLs-5_AM } & $\mathrm{X}$ & & \multirow{4}{*}{0.82} & & & & & & & & \\
\hline & 2 & E32M52-443 & $\mathrm{C} 03$ & 67.7 & 0.001201 & 0.13 & 0.56 & & & & & & & & & & & & \\
\hline & 1 & E32M47-341 & $\mathrm{C} 08$ & 124.5 & 0.000341 & 0.15 & -0.56 & ADLs-6_AM & $\mathrm{X}$ & & & & & & & & & & \\
\hline & 2 & E34M53-167 & $\mathrm{C09}$ & 84.8 & 0.002498 & 0.11 & -0.52 & ADLs-7_AM & $\mathrm{X}$ & & & & & & & & & & \\
\hline \multirow[t]{8}{*}{$\mathrm{HCm}$} & 1 & E44M48-413 & $\mathrm{A} 08$ & 43.8 & 0.002211 & 0.11 & 0.50 & HCm-1_AM & $\mathrm{X}$ & \multirow{8}{*}{0.24} & & & & & & & & & \\
\hline & 2 & E39M48-062 & $\mathrm{C} 01$ & 48.6 & 0.001017 & 0.13 & -0.40 & HCm-2_AM & $\mathrm{X}$ & & & & & & & & & & \\
\hline & 1 & E32M49-403 & $\mathrm{C} 09$ & 14.2 & 0.002018 & 0.11 & 0.45 & $\mathrm{HCm}-3 \mathrm{AM}$ & & & & & & & & & & & \\
\hline & 2 & E38M49-127 & $\mathrm{C} 09$ & 17.1 & 0.000547 & 0.14 & 0.52 & HCm-3_AlM & $\mathrm{X}$ & & 0.76 & & & & & & & & \\
\hline & 3 & E32M60-396 & C09 & 20.0 & 0.000167 & 0.17 & 0.64 & \multirow{4}{*}{ HCm-4_AM } & $\mathrm{X}$ & & 0.52 & 0.74 & & & & & & & \\
\hline & 4 & E34M53-139 & $\mathrm{C} 09$ & 21.2 & 0.000258 & 0.16 & 0.65 & & & & 0.60 & 0.66 & 0.89 & & & & & & \\
\hline & 5 & E39M55-408 & C09 & 26.1 & 0.000526 & 0.14 & 0.59 & & & & 0.52 & 0.74 & 0.79 & 0.68 & & & & & \\
\hline & 6 & E38M61-147 & $\mathrm{C} 09$ & 28.4 & 0.001662 & 0.14 & 0.50 & & & & 0.65 & 0.70 & 0.70 & 0.79 & 0.70 & & & & \\
\hline
\end{tabular}


Table 4.5 (Continued)

\begin{tabular}{|c|c|c|c|c|c|c|c|c|c|c|c|c|c|c|c|c|c|c|c|}
\hline \multirow[t]{3}{*}{ Traits } & \multirow[t]{3}{*}{${ }^{1} \mathrm{No}$} & \multirow[t]{3}{*}{ Markers } & \multirow[t]{3}{*}{${ }^{2} \mathrm{LG}$} & \multirow{3}{*}{$\begin{array}{l}{ }^{3} \text { Pos } \\
\text { (cM) }\end{array}$} & \multirow{3}{*}{$\begin{array}{l}\text { Marker } \\
P \text { value }\end{array}$} & \multirow{3}{*}{$\begin{array}{l}{ }^{4} R^{2} \\
(\%)\end{array}$} & \multirow{3}{*}{$\begin{array}{l}\text { 5Pheno. } \\
\text { Effect }\end{array}$} & \multirow[t]{3}{*}{${ }^{6} \mathrm{QTL}$} & \multirow{3}{*}{$\begin{array}{l}{ }^{7} \text { Multi. } \\
\text { Reg. }\end{array}$} & \multirow{3}{*}{$\begin{array}{l}{ }^{8 \mathrm{R}^{2}} \\
\text { adj. }\end{array}$} & \multicolumn{9}{|c|}{${ }^{9}$ Linkage disequilibrium $\left(r^{2}\right)$} \\
\hline & & & & & & & & & & & \multicolumn{9}{|c|}{ Marker No. } \\
\hline & & & & & & & & & & & 1 & 2 & 3 & 4 & 5 & 6 & 7 & 8 & 9 \\
\hline \multirow[t]{18}{*}{$\mathrm{Cm}$} & 1 & E44M50-242 & A05 & 0.0 & 0.001151 & 0.13 & -0.33 & Cm-1_AM & $\mathrm{x}$ & \multirow{18}{*}{0.48} & & & & & & & & & \\
\hline & 2 & E32M59-163 & A05 & 61.3 & 0.002568 & 0.11 & -0.27 & Cm-2_AM & $\mathrm{X}$ & & 0.05 & & & & & & & & \\
\hline & 3 & E36M51-302 & A05 & 79.9 & 0.001401 & 0.12 & 0.29 & & $\mathrm{x}$ & & 0.00 & 0.24 & & & & & & & \\
\hline & 4 & E37M49-451 & A05 & 79.9 & 0.000679 & 0.14 & 0.54 & & & & 0.03 & 0.00 & 0.00 & & & & & & \\
\hline & 5 & E38M53-240 & A05 & 79.9 & 0.002397 & 0.11 & 0.46 & Cm-3_AM & & & 0.02 & 0.00 & 0.00 & 0.65 & & & & & \\
\hline & 6 & E38M59-116 & A05 & 79.9 & 0.000289 & 0.16 & 0.58 & & & & 0.03 & 0.00 & 0.00 & 0.74 & 0.65 & & & & \\
\hline & 7 & E35M56-157 & A05 & 81.1 & 0.000893 & 0.13 & 0.50 & & & & 0.05 & 0.00 & 0.01 & 0.65 & 0.56 & 0.65 & & & \\
\hline & 1 & E38M50-129 & $\mathrm{C} 02$ & 26.1 & 0.005062 & 0.11 & 0.29 & Cm-4_AM & $\mathrm{X}$ & & & & & & & & & & \\
\hline & 1 & E42M60-145 & $\mathrm{C} 03$ & 48.8 & 0.001268 & 0.12 & 0.30 & Cm-5_AM & $\mathrm{X}$ & & & & & & & & & & \\
\hline & 2 & E36M57-132 & $\mathrm{CO3}$ & 57.0 & 0.000815 & 0.13 & -0.35 & Cm-6_AM & $\mathrm{X}$ & & 0.52 & & & & & & & & \\
\hline & 1 & E33M51-149 & $\mathrm{C} 06$ & 34.3 & 0.000248 & 0.16 & 0.36 & \multirow{2}{*}{ Cm-7_AM } & & & & & & & & & & & \\
\hline & 2 & E33M59-270 & $\mathrm{C} 06$ & 37.4 & 0.000037 & 0.19 & 0.40 & & $\mathrm{X}$ & & 0.89 & & & & & & & & \\
\hline & 3 & E33M52-221 & $\mathrm{C} 06$ & 40.7 & 0.002949 & 0.11 & -0.27 & Cm-8_AM & $\mathrm{X}$ & & 0.21 & 0.21 & & & & & & & \\
\hline & 4 & E44M48-103 & $\mathrm{C} 06$ & 50.2 & 0.002770 & 0.11 & -0.31 & Cm-9_AM & $\mathrm{X}$ & & 0.32 & 0.06 & 0.04 & & & & & & \\
\hline & 5 & E44M59-339 & $\mathrm{C} 06$ & 67.1 & 0.001324 & 0.12 & -0.30 & Cm-10_AM & $\mathrm{X}$ & & 0.01 & 0.10 & 0.16 & 0.07 & & & & & \\
\hline & 1 & E34M59-184 & $\mathrm{C} 08$ & 64.4 & 0.000535 & 0.14 & -0.45 & & $\mathrm{X}$ & & & & & & & & & & \\
\hline & 2 & E40M57-074 & C08 & 64.4 & 0.001068 & 0.13 & 0.45 & Cm-11_AM & & & 0.81 & & & & & & & & \\
\hline & 3 & E42M60-330 & $\mathrm{C} 08$ & 64.4 & 0.003644 & 0.10 & 0.36 & & & & 0.53 & 0.68 & & & & & & & \\
\hline PodM & 1 & E32M59-173 & $\mathrm{A} 01$ & 12.4 & 0.000152 & 0.17 & 1.82 & PodM-1_AM & $\mathrm{X}$ & 0.17 & & & & & & & & & \\
\hline \multirow[t]{5}{*}{ Protein } & 1 & E32M59-173 & $\mathrm{A} 01$ & 12.4 & 0.000187 & 0.16 & 1.28 & Prot-1_AM & $\mathrm{X}$ & \multirow{5}{*}{0.34} & \multirow{5}{*}{$\begin{array}{l}0.53 \\
0.68\end{array}$} & \multirow{5}{*}{0.81} & & & & & & & \\
\hline & 1 & E34M59-184 & $\mathrm{C} 08$ & 64.4 & 0.000805 & 0.13 & -1.06 & & $\mathrm{X}$ & & & & & & & & & & \\
\hline & 2 & E40M57-074 & $\mathrm{C} 08$ & 64.4 & 0.000536 & 0.14 & -1.14 & Prot-2_AM & & & & & & & & & & & \\
\hline & 3 & E42M60-330 & $\mathrm{C} 08$ & 64.4 & 0.000539 & 0.14 & -1.02 & & & & & & & & & & & & \\
\hline & 1 & E36M50-184 & $\mathrm{C} 09$ & 5.4 & 0.001297 & 0.12 & -1.06 & Prot-3_AM & $\mathrm{X}$ & & & & & & & & & & \\
\hline
\end{tabular}


Table 4.5 (Continued)

\begin{tabular}{|c|c|c|c|c|c|c|c|c|c|c|c|c|c|c|c|c|c|c|c|}
\hline \multirow[t]{3}{*}{ Traits } & \multirow[t]{3}{*}{${ }^{1} \mathrm{No}$} & \multirow{3}{*}{ Markers } & \multirow[t]{3}{*}{${ }^{2} \mathrm{LG}$} & \multirow{3}{*}{$\begin{array}{l}{ }^{3} \text { Pos } \\
\text { (cM) }\end{array}$} & \multirow{3}{*}{$\begin{array}{l}\text { Marker } \\
P \text { value }\end{array}$} & \multirow{3}{*}{$\begin{array}{l}{ }^{4} R^{2} \\
(\%)\end{array}$} & \multirow{3}{*}{$\begin{array}{l}\text { 5Pheno. } \\
\text { Effect }\end{array}$} & \multirow{3}{*}{${ }^{6} \mathrm{QTL}$} & \multirow{3}{*}{$\begin{array}{c}{ }^{7} \text { Multi. } \\
\text { Reg. }\end{array}$} & \multirow{3}{*}{$\begin{array}{l}{ }^{8} \mathrm{R}^{2} \\
\text { adj. }\end{array}$} & \multicolumn{9}{|c|}{${ }^{9}$ Linkage disequilibrium $\left(r^{2}\right)$} \\
\hline & & & & & & & & & & & \multicolumn{9}{|c|}{ Marker No. } \\
\hline & & & & & & & & & & & 1 & 2 & 3 & 4 & 5 & 6 & 7 & 8 & 9 \\
\hline \multirow[t]{22}{*}{ Oil } & 1 & E39M62-071 & $\mathrm{A} 01$ & 74.0 & 0.000066 & 0.18 & 1.50 & Oil-1_AM & $\mathrm{X}$ & \multirow{22}{*}{0.36} & & & & & & & & & \\
\hline & 1 & E38M59-213 & $\mathrm{A} 03$ & 32.1 & 0.000225 & 0.16 & 1.53 & Oil-2_AM & $\mathrm{X}$ & & & & & & & & & & \\
\hline & 2 & E42M55-230 & $\mathrm{A} 03$ & 64.1 & 0.004101 & 0.10 & -0.79 & Oil-3_AM & $\mathrm{X}$ & & & & & & & & & & \\
\hline & 3 & E38M51-252 & $\mathrm{A} 03$ & 70.7 & 0.000417 & 0.15 & -0.93 & Oil-4_AM & $\mathrm{X}$ & & & & & & & & & & \\
\hline & 1 & E39M55-143 & A06 & 56.9 & 0.003071 & 0.11 & -1.19 & Oil-5_AM & $\mathrm{X}$ & & & & & & & & & & \\
\hline & 1 & E44M48-413 & A08 & 43.8 & 0.000507 & 0.14 & 1.38 & Oil-6_AM & $\mathrm{X}$ & & & & & & & & & & \\
\hline & 1 & E44M62-227 & $\mathrm{C} 01$ & 98.1 & 0.004839 & 0.10 & 0.82 & Oil-7_AM & $\mathrm{X}$ & & & & & & & & & & \\
\hline & 2 & E33M61-120 & $\mathrm{C} 01$ & 104.5 & 0.002106 & 0.11 & -1.04 & Oil-8_AM & $X$ & & & & & & & & & & \\
\hline & 1 & E35M52-309 & $\mathrm{C} 02$ & 20.9 & 0.000804 & 0.13 & 1.47 & Oil-9_AM & $\mathrm{X}$ & & & & & & & & & & \\
\hline & 2 & E44M62-119 & $\mathrm{C} 02$ & 47.6 & 0.005991 & 0.09 & 1.06 & Oil-10_AM & $\mathrm{X}$ & & & & & & & & & & \\
\hline & 1 & E32M47-182 & $\mathrm{C} 04$ & 23.2 & 0.001160 & 0.13 & -0.99 & \multirow{2}{*}{ Oil-11_AM } & $\mathrm{X}$ & & & & & & & & & & \\
\hline & 2 & E33M57-167 & $\mathrm{C} 04$ & 23.2 & 0.006254 & 0.09 & -0.76 & & & & & & & & & & & & \\
\hline & 1 & E33M47-288 & C09 & 0.0 & 0.004848 & 0.10 & 1.09 & \multirow{5}{*}{ Oil-12_AM } & \multirow{5}{*}{$\mathrm{X}$} & & & & & & & & & & \\
\hline & 2 & E36M51-141 & C09 & 4.0 & 0.002350 & 0.11 & 1.22 & & & & 0.90 & & & & & & & & \\
\hline & 3 & E36M50-184 & C09 & 5.4 & 0.000041 & 0.19 & 1.60 & & & & 0.72 & 0.80 & & & & & & & \\
\hline & 4 & E45M53-229 & C09 & 5.4 & 0.001126 & 0.13 & 1.36 & & & & 0.81 & 0.90 & 0.90 & & & & & & \\
\hline & 5 & E33M59-100 & C09 & 8.8 & 0.000114 & 0.17 & 1.46 & & & & 0.82 & 0.90 & 0.90 & 0.81 & & & & & \\
\hline & 6 & E38M49-127 & C09 & 17.1 & 0.000144 & 0.17 & 1.39 & \multirow{5}{*}{ Oil-13_AM } & \multirow{5}{*}{$\mathrm{X}$} & & 0.45 & 0.51 & 0.66 & 0.57 & 0.59 & & & & \\
\hline & 7 & E32M60-396 & C09 & 20.0 & 0.000008 & 0.22 & 1.81 & & & & 0.34 & 0.39 & 0.53 & 0.44 & 0.48 & 0.74 & & & \\
\hline & 8 & E34M53-139 & C09 & 21.2 & 0.000325 & 0.15 & 1.57 & & & & 0.40 & 0.44 & 0.44 & 0.50 & 0.40 & 0.66 & 0.88 & & \\
\hline & 9 & E39M55-408 & C09 & 26.1 & 0.000108 & 0.17 & 1.59 & & & & 0.34 & 0.39 & 0.53 & 0.44 & 0.48 & 0.74 & 0.79 & 0.68 & \\
\hline & 10 & E38M61-147 & $\mathrm{C} 09$ & 28.4 & 0.005618 & 0.11 & 1.16 & & & & 0.41 & 0.01 & 0.46 & 0.52 & 0.41 & 0.65 & 0.70 & 0.79 & 0.70 \\
\hline
\end{tabular}

${ }^{1}$ Marker number in each linkage group; ${ }^{2}$ Linkage group; ${ }^{3}$ Position of the marker on the respective linkage group; ${ }^{4}$ Effect of the associated marker; ${ }^{5}$ Phenotypic effect of marker. Positive value indicate present marker increases trait and negative value indicates present marker reduces trait; ${ }^{6}$ Putative QTL; ${ }^{7}$ Markers used in the multiple regresssion analysis; 8Phenotypic variance explained by putative QTL; ${ }^{2}$ Linkage disequilibrium between marker pairs on the same linkage group, with the respective pairs indicated by the combination of marker numbers; ${ }^{9}$ Data from Ecke et al. (2010) 


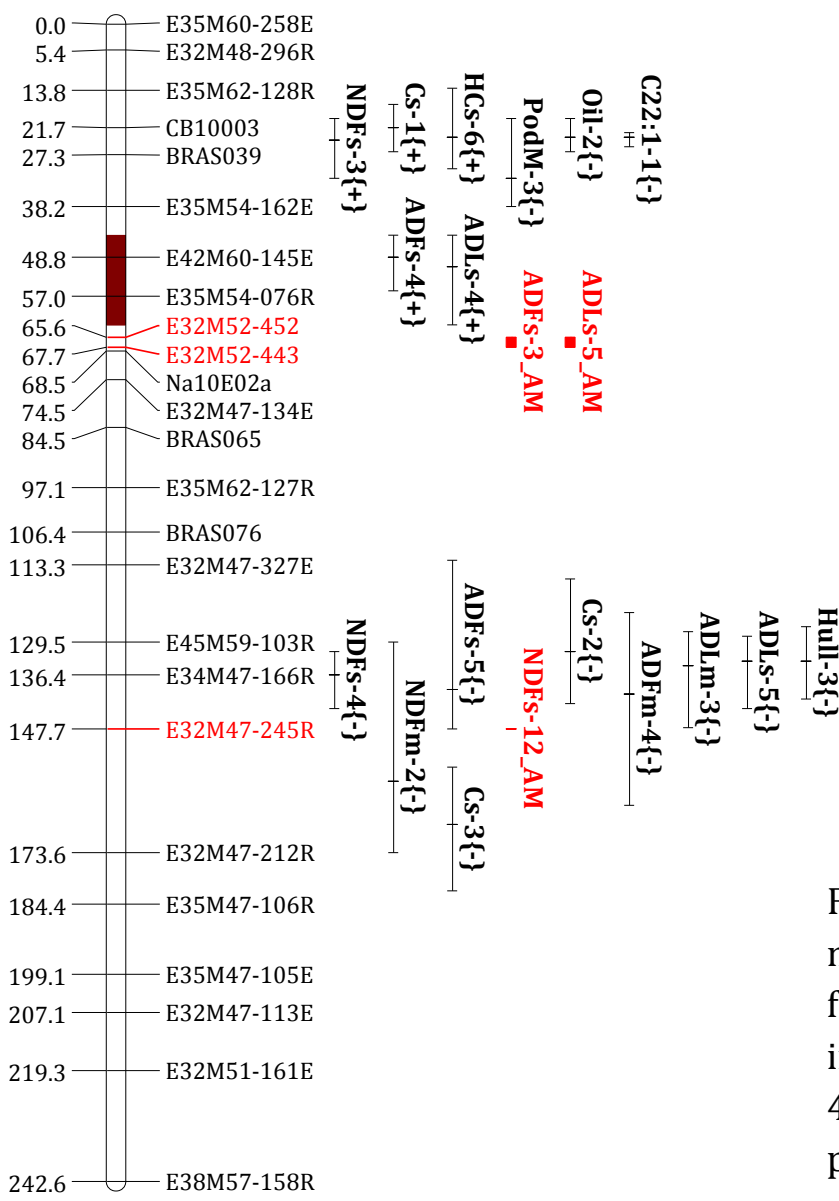

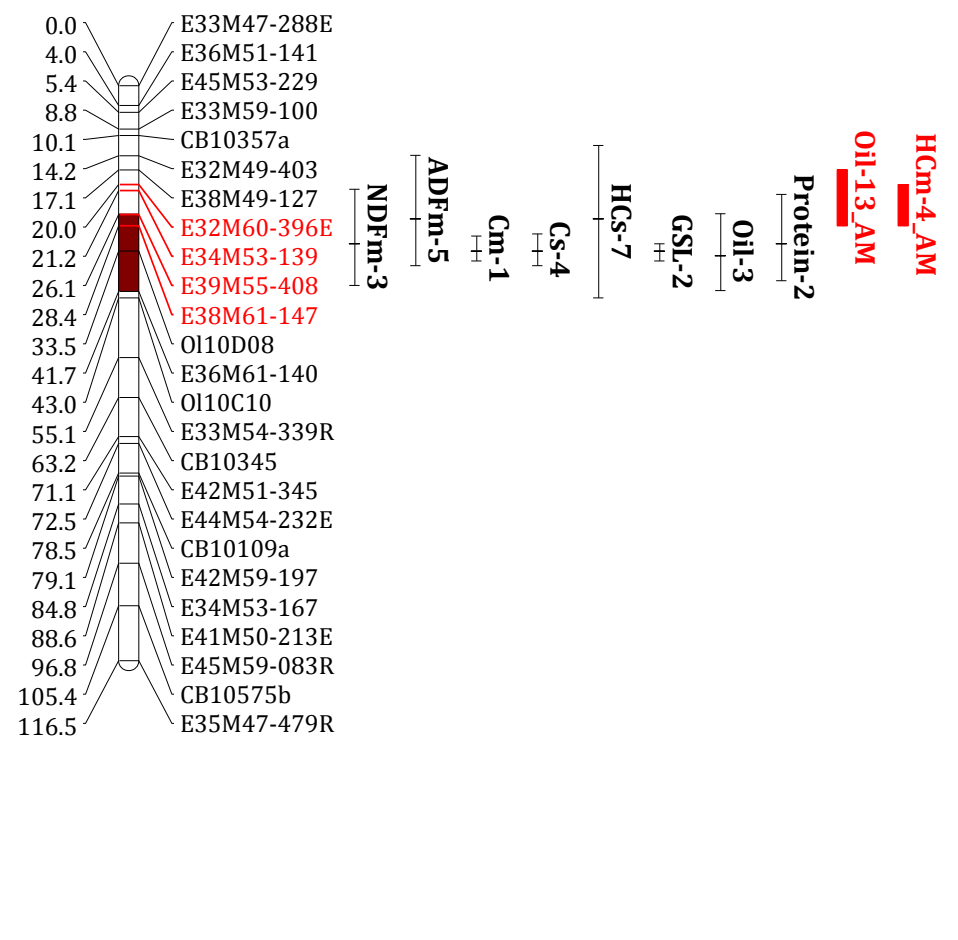

Figure 4.1 QTL associated with fibre-related traits (NDFs-12_AM, ADFs_3_AM, ADLs-5_AM markers in red) in canola quality winter oilseed rape cultivars collocated with QTL responsible for NDF, ADF and ADL previously mapped on linkage group C03 of Express 617 x R53 (markers in black), and QTL associated with oil content (Oil-13_AM) and hemicellulose content (HCm4_AM) collocated with QTL for oil and hemicellulose content on linkage group C09 in DH population Express 617 x R53 (see Chapter 3). Dark red area on linkage group C03 and C09 represents confidence interval of QTL for ADL content of seed and seed oil content in DH population Express 617 x R53, respectively. 


\subsection{Discussion}

\section{Variation of fibre content}

In the present study, considerable variation in the content of different fibre fractions and seed hull proportion were observed among 81 canola quality winter oilseed rape cultivars. The effects of the genotype were significant for fibre-related traits indicating that significant genetic variation in fibre content was present in the population (Table 4.1). Our findings show low genotype $x$ environment (GxE) effects resulting in a high heritability for all traits (see Table 4.1). These are in accordance with results obtained in previous studies by Dimov et al. (2012) and Snowdon et al. (2010) who found relatively high heritablility for NDF content $\left(h^{2}=0.75\right.$ and 0.74, respectively) among oilseed rape cultivars and inbred lines.

The NDF content of defatted meal in the present study ranged from $28.5 \%$ to $34.4 \%$. This range compares well with the $30.3-37.4 \%$ reported by Mailer et al. (2008) and the $26.1 \%$ to $32.7 \%$ reported by Dimov et al. (2012). When calculated on seed basis, the NDF content of these canola quality winter oilseed rape cultivars ranged from $15.9 \%$ to $19.0 \%$. This compares well with results of Wittkop et al. (2012) who reported NDF contents of $11.9 \%$ to $19.3 \%$ for a doubled haploid (DH) population derived from a cross between yellow- and black-seeded B. napus, and of $12.2 \%$ to $19.8 \%$ of a DH population derived from a cross between two black-seeded B. napus materials. The NDF content on seed basis in the present study is relatively low compared to the NDF content of $17.1 \%$ to $21.3 \%$ for 49 genetically diverse brown-/black-seeded winter oilseed rape inbred lines reported by Snowdon et al. (2010). This may be explained by environmental factors and by the different procedures applied to determine fibre related traits.

Among the 81 genotypes, ADF content of defatted meal ranged from $20.9 \%$ to $27.1 \%$. This is in the same range as the $20.5 \%$ to $26 \%$ reported previously for 28 European winter oil seed cultivars (Dimov et al. 2012) and larger than the $17.0 \%$ to $20.6 \%$ found in Australian canola quality oilseed rape (Mailer et al. 2008). Based on seed basis, ADF content in present study ranged from $11.3 \%$ to $15.2 \%$, which compares favorably with the ADF content of $6.8-13.5 \%$ of a black-seeded DH population (Wittkop et al. 2012), and with the $11.4 \%$ to $15.4 \%$ of 49 black seeded winter oilseed rape inbred lines reported by Snowdon et al. (2010).

The ADL content of the defatted meal ranged from $6.9 \%$ to $13.6 \%$ which corresponds to $3.7 \%$ to $7.4 \%$ of ADL content on seed basis. These results compare well with the $4.8 \%$ to $7.3 \%$ of ADL content in the seeds of 49 black seeded winter oilseed rape inbred lines (Snowdon et al. 2010), the $3.2 \%$ to $8.4 \%$ found in the black-seeded DH population (Wittkop et al. 2012), and the $4.1 \%$ to $6.4 \%$ determined in modern winter oilseed rape cultivars (Dimov et al. 2012). Liu et al. 
(2012) reported ADL contents of $2.8 \%$ to $8.0 \%$ on seed basis in recombinant inbred lines (RIL) derived from a cross between yellow-seeded GH06 and black-seeded P174 oilseed rape. The lowest ADL content observed in the present study was still higher compared to the range of $2.6 \%$ to $3.0 \%$ ADL content of yellow-seeded rapeseed (Wittkop et al. 2012). However, the minimum ADL content observed in the black-seeded cultivar 'Lord' (3.7\%) compares well with the $3.7 \%$ of lignin content of Canadian yellow-seeded B. napus (Slominski et al. 2012).

Seed hull plays an important role in affecting the quality of oilseed rape meal because antinutritive factors like condensed tannins and non-digestible lignin are located in the seed hull. Reduction of the proportion of seed hull should therefore lead to improvement of meal quality. A range of $12.2 \%$ to $18.3 \%$ of seed hull proportion was observed among the cultivars in the present study. Dimov et al. (2012) reported 14.9 to $17.6 \%$ of seed hull proportion in 28 modern winter oilseed rape cultivars, while Matthäus (1998) observed 13 to 18.5\% of seed hull proportion of eight oilseed rape cultivars grown at several locations in Germany. Mean value of seed hull proportion in this study (15.8\%) compares favorably with the $15.9 \%$ seed hull proportion of Canadian canola quality B. napus cultivars (Slominski et al. 2012).

\section{Correlation between traits}

Negative correlations were observed between fibre-related traits and both seed protein content and protein content of defatted meal, while oil content was positively correlated with fibre traits in defatted meal and negatively correlated with fibre traits on seed basis (Table 4.4). These results confirm that an increase of oil content in the seed will lead to a decrease both in seed protein and seed fibre content. The negative correlations between oil content and both seed protein content and protein content of defatted meal indicates that the increase in oil content occured at the expense of protein content instead of fibre content. This interpretation is supported by positive correlations between fibre traits of defatted meal and oil content. Si et al. (2003) have also observed a negative correlation between oil and both seed protein content and protein content of defatted meal of canola quality material tested at 7 to 9 locations across 4 states in southern Australia. Furthermore, Si et al. (2003) suggested that direct selection for high seed oil content and high protein concentration of meal would reduce the proportion of seed residue (fibre content).

Seed hull proportion correlated positively with NDF, ADF, ADL and cellulose content and negatively with hemicellulose content both in defatted meal and seed basis. These results confirm the seed hull as major source of indigestible components in oilseed rape. The seed coat of B. napus contains a palisade layer with thick secondary cell walls (Jiang and Deyholos 2010) which are developed from cellulose, hemicellulose and lignin (Zhong and Ye 2007). Marles and 
Gruber (2004) reported that the majority of lignin was present in the seed coat according to comparative measurements from seed coats and seed embryos of near isogenic lines of $B$. carinata. In their study, Marles and Gruber (2004) reported lignin concentration in seed coats of brown-seeded B. carinata to be about $29.4 \%$ compared to $1.73 \%$ observed in seed embryos. In a recent study, Slominski et al. (2012) reported that lignin and polyphenol content in seed hulls of black-seeded B. napus was $21.4 \%$ and in the embryos it was $2.0 \%$.

Negative correlation between seed hull proportion and hemicellulose content might be related to the proportion of embryo. The cell wall polysaccharides of the embryo are mainly pectic substances, cellulose and hemicellulose (Selvendran 1984). Hemicellulose comprises as much as $20-25 \%$ of the primary cell walls of dicotyledonous species (Albersheim et al. 2010; Hayashi 1989). An increase of seed embryo proportion, as an implication of reducing seed hull proportion as shown by negative correlation between seed hull proportion and thousand kernel weight (TKW), will lead to an increase in hemicellulose content as a component of embryonic cell walls. In their study, Slominski et al. (2012) observed that yellow-seeded B. napus with larger seed weight showed higher contents of non-starch polysaccharides (cellulose and hemicellulose) in the embryo and lower proportion of seed hulls compared to black-seeded $B$. napus.

\section{Association analysis}

Association analysis of 685 AFLP markers and 7 SNP markers was performed in a set of 81 canola quality winter oilseed cultivars using the mean data over 19 locations. A term for population structure was not included in the implementation of the general linear model for association analysis in the current study because no population structure was detected in this population in a previous study (Ecke et al. 2010). Oilseed rape cultivars used in this study are predominantly black-seeded winter oilseed rape and are mainly derived from breeding programs of German companies. That no population structure was detected may be related to the relatively narrow genetic background of winter oilseed rape used for the development of cultivars. Bus et al. (2011) also reported no distinct subgroups observed within a set of 183 winter oilseed rape genotypes from different European countries. Bus et al. (2011) further suggested that the lack of distinct subgroups within winter oilseed rape genotypes could be explained by the fact that until recently oilseed rape has been bred by line breeding and population breeding. In such breeding programs, population structure tends to be disregarded when choosing the parents for a cross (Bus et al. 2011). Nevertheless, the use of a larger set (population) of modern cultivars/elite lines was suggested for association analysis in oilseed rape because QTL may be identified that otherwise may remain undetected and which may be 
valuable for breeding purposes (Zou et al. 2010). In addition, elite lines/cultivars are desirable materials for association analysis of low heritable traits because elite lines are genetically stable and are well adapted to normal growing conditions (Breseghello and Sorrells 2006).

Current association analysis identified 32 markers representing 20 QTL associated with NDF content on seed basis located on 10 linkage groups (Table 4.5). The number of QTL for NDF content detected in this association analysis is higher compared to the number of QTL detected in linkage analysis of DH population Express 617 x R53 where seven QTL were observed (Chapter 3). Higher numbers of QTL have also been found for ADF, ADL, hemicellulose and cellulose content. Large numbers of QTL for fibre-related traits detected in association analysis indicates that there is still high allelic variation for these traits in canola quality winter oilseed rape cultivars. Results of association analysis also revealed QTL responsible for fibre-related traits that could not be detected in linkage analysis in three DH populations (Chapter 3). These can be explained that in bi-parental populations allelic variation is limited to that present between the two parents of the crosses, while in the association analysis allelic diversity was captured from 81 cultivars.

From twenty QTL detected for NDF content in association analysis, only one is close to a QTL mapped for this trait in DH population Express 617 x R53. The difference in genetic background as well as allelic diversity may also be a reason for low level of conformity between the QTL associated with fibre-related traits detected in association analysis with those QTL mapped in linkage analysis. On previous study in the same population of 84 canola quality winter oilseed rape cultivars, Honsdorf et al. (2010) had also found low level agreement for oil and protein content between the results of association analysis and linkage analysis of Radoev et al. (2008). Zou et al. (2010) reported only a small amount (11\%) of detected QTL for oil content in association analysis could be covered by detected QTL from linkage mapping approach.

For practical breeding, a QTL associated with NDF content (NDFs-10_AM) identified from current association mapping that was also mapped in DH population Express 617 x R53 might be used as a tool for selection of cultivars/breeding lines with low fibre content. As phenotypic effect of this QTL is negative (Table 4.5), the visible markers E32M47-245 which represented QTL NDFs-10_AM corresponds to the reduction of NDF content. Selection of cultivars with low fibre content could then be undertaken based on NDF content in phenotypic data and verified by presence of the marker in molecular analysis. From 81 cultivars that were evaluated, one cultivar Lord showed low fibre content and relatively high oil content (Fig 4.2). These cultivars seem promising to be used in further breeding program for improved meal quality. 


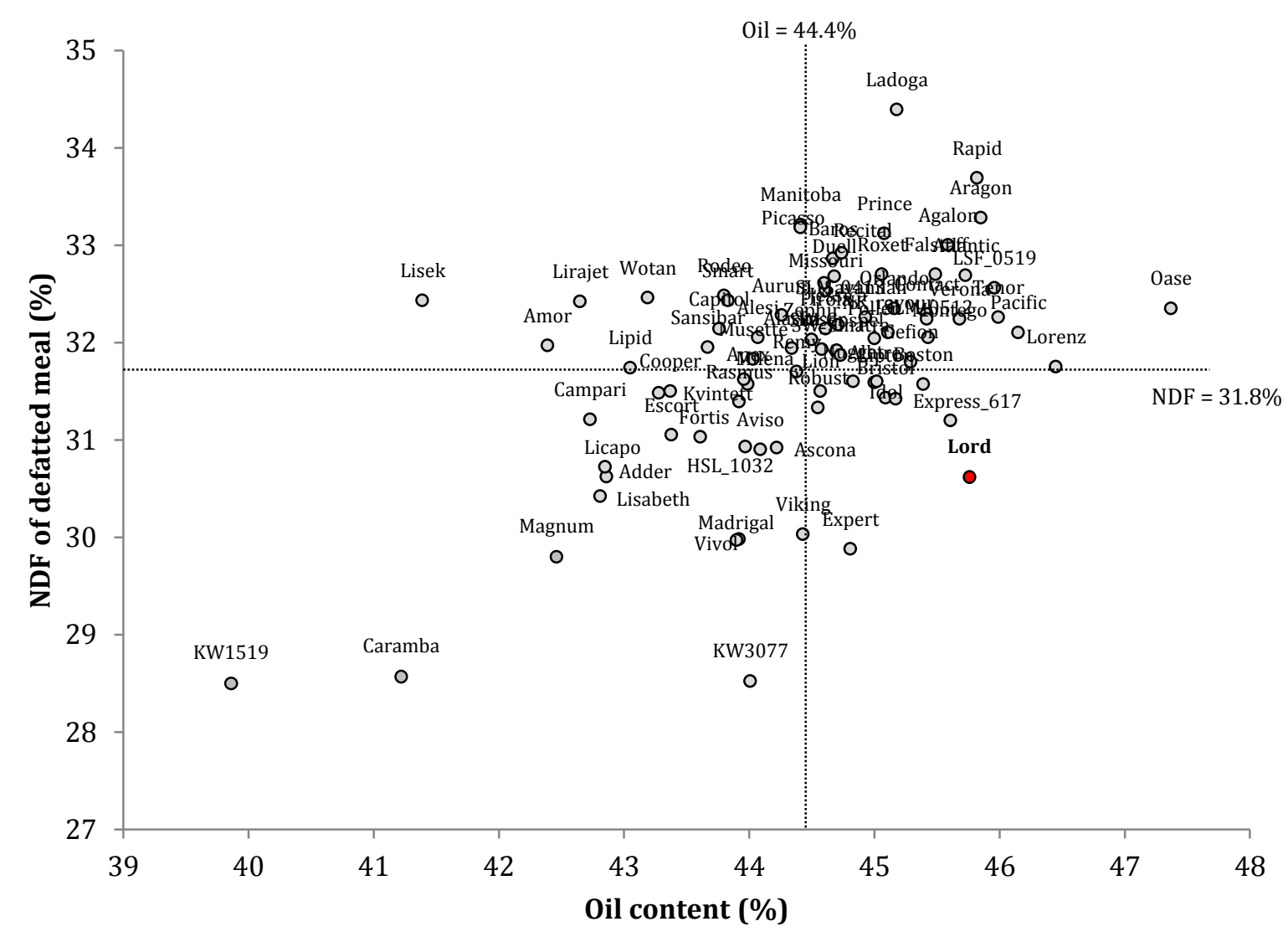

Figure 4.2 Selection of canola quality winter oilseed rape cultivars for further breeding in improved meal quality based on seed oil content and NDF of defatted meal. The dash lines represent the means of oil content and of NDF of defatted meal (see Table 4.2)

\subsection{Conclusions}

Considerable variation in the content of different fibre fractions and seed hull proportion was observed among 81 canola quality winter oilseed rape cultivars. The effects of the genotype were significant for fibre-related traits indicating that significant genetic variation in fibre content was present in the population. Negative correlations were observed between fibrerelated traits and both seed protein content and protein content of defatted meal, while oil content was positively correlated with fibre traits in defatted meal and negatively correlated with fibre traits on seed basis, which indicating that the increase in oil content occurred at the expense of protein content. Of the 692 markers used in the association analysis, 74 markers were identified being associated with fibre-related traits representing 2 to 20 QTL for the respective traits. QTL for NDF and hemicellulose content identified in association mapping were also mapped on the same location in DH population Express 617 x R53 suggesting that those might be the same QTL. 


\subsection{Acknowledgements}

The authors express their gratitude to the breeding companies Deutsche Saatveredelung AG, KWS SAAT AG, Nord-deutsche Pflanzenzucht Hans-Georg Lembke KG, Raps GbR, and Syngenta Agro $\mathrm{GmbH}$ for seed materials and carrying out field trials. The technical assistance of Rolf Jeromin, Uwe Ammermann, Gunda Asselmeyer and Julia Mühlhause is greatly appreciated. ES would like to acknowledge the financial support from the Indonesian Oil Palm Research Institute (IOPRI) for PhD scholarship.

\subsection{References}

Albersheim P, Darvill A, Roberts K, Sederoff R, Staehelin A (2010) Plant cell walls: From chemistry to biology. Garland Science, Taylor and Francis Group, LLC

Andersen JR, Zein I, Wenzel G, Krützfeldt B, Eder J, Ouzunova M, Lübberstedt T (2007) High levels of linkage disequilibrium and associations with forage quality at a phenylalanine ammonia-lyase locus in European maize (Zea mays L.) inbreds. Theor Appl Genet 114:307319.

ANKOM (2011a) Method 6 - Neutral Detergent Fiber in Feeds Filter Bag Technique. http://www.ankom.com/media/documents/Method_6_NDF_4013011_A200,A200I.pdf Site accessed March 9, 2014

ANKOM (2011b) Method 5 - Acid Detergent Fiber in Feeds Filter Bag Technique. http://www.ankom.com/media/documents/Method_5_ADF_4-13-11_A200,A200I.pdf. Site accessed March 9, 2014

ANKOM (2013) Method 8 - Determining acid detergent lignin in beakers. http://www.ankom.com/media/documents/Method_8_Lignin_in_beakers_3_13_13.pdf Site accessed March 9, 2014

Badani AG, Snowdon RJ, Wittkop B, Lipsa FD, Baetzel R, Horn R, Haro A, Font R, Lühs W (2006) Colocalization of a partially dominant gene for yellow seed colour with a major QTL influencing acid detergent fibre (ADF) content in different crosses of oilseed rape (Brassica napus). Genome 49:1499-1509

Bell J (1993) Factors affecting the nutritional value of canola meal: a review. Can J Anim Sci 73:679-697

Benjamini Y, Hochberg Y (1995) Controlling the false discovery rate: a practical and powerful approach to multiple testing. J R Stat Soc 57:289-300

Bradbury PJ, Zhang Z, Kroon DE, Casstevens TM, Ramdoss Y, Buckler ES (2007) TASSEL: software for association mapping of complex traits in diverse samples. Bioinformatics 23:2633-2635

Breseghello F, Sorrells ME (2006) Association analysis as a strategy for improvement of quantitative traits in plants. Crop Sci 46:1323-1330 
Bus A, Körber N, Snowdon RJ, Stich B (2011) Patterns of molecular variation in a species-wide germplasm set of Brassica napus. Theor Appl Genet 123:1413-1423

Cai D, Xiao Y, Yang W, Ye W, Wang B, Younas M, Wu J, Liu K (2013) Association mapping of six yield-related traits in rapeseed (Brassica napus L.). Theor Appl Genet 125:437-447

Dimov Z, Suprianto E, Hermann F, Möllers C (2012) Genetic variation for seed hull and fibre content in a collection of European winter oilseed rape material (Brassica napus L.) and development of NIRS calibrations. Plant Breed 131:361-368

Ecke W, Clemens R, Honsdorf N, Becker HC (2010) Extent and structure of linkage disequilibrium in canola quality winter rapeseed (Brassica napus L.). TAG Theor Appl Genet 120:921-931

Flint-Garcia SA, Thornsberry JM, Buckler ES (2003) Structure of linkage disequilibrium in plants. Annu Rev Plant Biol 54:357-374

Hasan M, Friedt W, Pons-Kühnemann J, Freitag NM, Link K, Snowdon RJ (2008) Association of gene-linked SSR markers to seed glucosinolate content in oilseed rape (Brassica napus ssp. napus). Theor Appl Genet 116:1035-1049

Hayashi T (1989) Xyloglucans in the primary cell wall. Annu Rev Plant Biol 40:139-168

Honsdorf N, Becker HC, Ecke W (2010) Association mapping for phenological, morphological, and quality traits in canola quality winter rapeseed (Brassica napus L.). Genome 53:899907

Jannink J-LL, Lorenz AJ, Iwata H, J Lorenz A (2010) Genomic selection in plant breeding: from theory to practice. Brief Funct Genomics 9:166-177

Jiang Y, Deyholos MK (2010) Transcriptome analysis of secondary-wall-enriched seed coat tissues of canola ( Brassica napus L .). Plant Cell Rep 29: 327-342

Jin M, Li J, Fu F, Zhang Z, Zhang X, Liu L (2007) QTL analysis of oil and hull content in Brassica napus L. Sci Agric Sin 40:677-684

Li X, Wei Y, Moore KJ, Michaud R, Viands DR, Hansen JL, Acharya A, Brummer EC (2011) Association mapping of biomass yield and stem composition in a tetraploid alfalfa breeding population. Plant Genome J 4:24-35

Liu L, Qu C, Wittkop B, Yi B, Xiao Y, He Y, Snowdon RJ, Li J (2013) A high-density SNP map for accurate mapping of seed fibre QTL in Brassica napus L. PLoS One 8:e83052.

Liu L, Stein A, Wittkop B, Sarvari P, Li J (2012) A knockout mutation in the lignin biosynthesis gene CCR1 explains a major QTL for acid detergent lignin content in Brassica napus seeds. Theor Appl Genet 124:1573-1586

Mailer RJ, McFadden A, Ayton J, Redden B (2008) Anti-nutritional components, fibre, sinapine and glucosinolate content, in Australian canola (Brassica napus L.) meal. J Am Oil Chem Soc 85:937-944 
Marles MS, Gruber MY (2004) Histochemical characterisation of unextractable seed coat pigments and quantification of extractable lignin in the Brassicaceae. J Sci Food Agric 84:251-262

Matthäus B (1998) Effect of dehulling on the composition of antinutritive compounds in various cultivars of rapeseed. Lipid/Fett 92:139-144

R Core Team (2012) R: A language and environment for statistical computing. R Foundation for Statistical Computing, Vienna, Austria. ISBN 3-900051-07-0, URL http://www.Rproject.org/.

Radoev M, Becker HC, Ecke W (2008) Genetic analysis of heterosis for yield and yield components in rapeseed (Brassica napus L.) by quantitative trait locus mapping. Genetics 179:1547-1558

Rafalski JA (2010) Association genetics in crop improvement. Curr Opin Plant Biol 13:174-180

Rahman M, McVetty PBE (2011) A review of Brassica seed color. Can J Plant Sci 91:437-446

Rezaeizad A, Wittkop B, Snowdon R, Hasan M, Mohammadi V, Zali A, Friedt W (2010) Identification of QTLs for phenolic compounds in oilseed rape (Brassica napus L.) by association mapping using SSR markers. Euphytica 177:335-342

Schatzki J, Schoo B, Ecke W, Herrfurth C, Feussner I, Becker HC, Möllers C (2013) Mapping of QTL for seed dormancy in a winter oilseed rape doubled haploid population. Theor Appl Genet 126:2405-2415

Selvendran RR (1984) The plant cell wall as a source of dietary fiber: Chemistry and structure. Am J Clin Nutr 39:320-337

Si P, Mailer R, Galwey N, Turner D (2003) Influence of genotype and environment on oil and protein concentrations of canola (Brassica napus L.) grown across southern Australia. Aust J Agric Res 54:397-407

Slominski BA, Jia W, Rogiewicz A, Nyachoti CM, Hickling D (2012) ) Low-fiber canola Part 1 Chemical and nutritive composition of the meal. J Agric Food Chem 60:12225-12230

Snowdon R, Wittkop B, Rezaidad A, Hasan MH, Lipsa F, Stein A, Friedt W, Francki M (2010) Regional association analysis delineates a sequenced chromosome region influencing antinutritive seed meal compounds in oilseed rape. Genome 53:917-928

Van Soest PJ, Robertson JB, Lewis BA (1991) Methods for dietary fiber, neutral detergent fiber, and nonstarch polysaccharides in relation to animal nutrition. J Dairy Sci 74:3583-3597

Stein A, Wittkop B, Liu L, Obermeier C (2013) Dissection of a major QTL for seed colour and fibre content in Brassica napus reveals colocalization with candidate genes for phenylpropanoid biosynthesis and flavonoid deposition. Plant Breed 132:382-389

Tanksley S (1993) Mapping polygenes. Annu Rev Genet 27:205-233 
Vales MI, Schön CC, Capettini F, Chen XM, Corey a E, Mather DE, Mundt CC, Richardson KL, Sandoval-Islas JS, Utz HF, Hayes PM (2005) Effect of population size on the estimation of QTL: a test using resistance to barley stripe rust. Theor Appl Genet 111:1260-1270

Yan XY, Li JN, Fu FY, Jin MY, Chen L, Liu LZ (2009) Co-location of seed oil content, seed hull content and seed coat color QTL in three different environments in Brassica napus L. Euphytica 170:355-364

Zhao J, Becker HC, Zhang D, Zhang Y, Ecke W (2006) Conditional QTL mapping of oil content in rapeseed with respect to protein content and traits related to plant development and grain yield. Theor Appl Genet 113:33-38

Zhong R, Ye Z-H (2007) Regulation of cell wall biosynthesis. Curr Opin Plant Biol 10:564-572

Zou JZ, Jiang C, Cao Z, Li R, Long Y, Chen S, Meng J (2010) Association mapping of seed oil content in Brassica napus and comparison with quantitative trait loci identified from linkage mapping. Genome 53:908-916 
Table S1. List of cultivars

\begin{tabular}{|c|c|c|}
\hline No. & Cultivar & Breeder \\
\hline 1 & Pollen & Adrien Momont \\
\hline 2 & Bristol & DSV \\
\hline 3 & Capitol & DSV \\
\hline 4 & Contact & DSV \\
\hline 5 & Idol & DSV \\
\hline 6 & Licapo & DSV \\
\hline 7 & Lion & DSV \\
\hline 8 & Lipid & DSV \\
\hline 9 & Lipton & DSV \\
\hline 10 & Lirajet & DSV \\
\hline 11 & Lisabeth & DSV \\
\hline 12 & Lisek & DSV \\
\hline 13 & Oase & DSV \\
\hline 14 & Vivol & DSV \\
\hline 15 & Adder & KWS \\
\hline 16 & Agalon & KWS \\
\hline 17 & Alaska & KWS \\
\hline 18 & Alesi & KWS \\
\hline 19 & Allure & KWS \\
\hline 20 & KW 1519 & KWS \\
\hline 21 & KW 3077 & KWS \\
\hline 22 & Lord & KWS \\
\hline 23 & Milena & KWS \\
\hline 24 & Picasso & KWS \\
\hline 25 & Pirola & KWS \\
\hline 26 & Remy & KWS \\
\hline 27 & Robust & KWS \\
\hline 28 & Rodeo & KWS \\
\hline 29 & Atlantic & Limagrain-Nickerson \\
\hline 30 & Boston & Limagrain-Nickerson \\
\hline 31 & Cooper & Limagrain-Nickerson \\
\hline 32 & Escort & Limagrain-Nickerson \\
\hline 33 & Ladoga & Limagrain-Nickerson \\
\hline 34 & Manitoba & Limagrain-Nickerson \\
\hline 35 & Missouri & Limagrain-Nickerson \\
\hline 36 & Montego & Limagrain-Nickerson \\
\hline 37 & Pacific & Limagrain-Nickerson \\
\hline 38 & Rapid & Limagrain-Nickerson \\
\hline 39 & Savannah & Limagrain-Nickerson \\
\hline 40 & Aragon & NPZ \\
\hline 41 & Aurum & NPZ \\
\hline
\end{tabular}

\begin{tabular}{|c|c|c|}
\hline No. & Cultivar & Breeder \\
\hline 42 & Baros & NPZ \\
\hline 43 & Campari & NPZ \\
\hline 44 & Caramba & NPZ \\
\hline 45 & Express 617 & NPZ \\
\hline 46 & Gefion & NPZ \\
\hline 47 & HSL 1032 & NPZ \\
\hline 48 & Lorenz & NPZ \\
\hline 49 & LSF 0519 & NPZ \\
\hline 50 & Nugget & NPZ \\
\hline 51 & Prince & NPZ \\
\hline 52 & Rasmus & NPZ \\
\hline 53 & SLM 0413 & NPZ \\
\hline 54 & SLM 0512 & NPZ \\
\hline 55 & Viking & NPZ \\
\hline 56 & Wotan & NPZ \\
\hline 57 & Zephir & NPZ \\
\hline 58 & Amor & Raps Gbr \\
\hline 59 & Duell & Raps Gbr \\
\hline 60 & Orlando & Saaten Union \\
\hline 61 & Ascona & SW Seed \\
\hline 62 & Aviso & SW Seed \\
\hline 63 & Expert & SW Seed \\
\hline 64 & Falstaff & SW Seed \\
\hline 65 & Kvintett & SW Seed \\
\hline 66 & Musette & SW Seed \\
\hline 67 & Sansibar & SW Seed \\
\hline 68 & SW_Gospel & SW Seed \\
\hline 69 & SW_Sinatra & SW Seed \\
\hline 70 & Tenor & SW Seed \\
\hline 71 & Verona & SW Seed \\
\hline 72 & Apex & Syngenta \\
\hline 73 & Fortis & Syngenta \\
\hline 74 & Laser & Syngenta \\
\hline 75 & Madrigal & Syngenta \\
\hline 76 & Magnum & Syngenta \\
\hline 77 & NK Bravour & Syngenta \\
\hline 78 & Recital & Syngenta \\
\hline 79 & Roxet & Syngenta \\
\hline 80 & Smart & Syngenta \\
\hline 81 & Jessica & Unknown \\
\hline
\end{tabular}




\section{CHAPTER 5}

\section{General Discussion}

The use of oilseed rape meal as protein source in animal diets is limited by the presence of its high fibre content and other anti-nutritional components like sinapine and condensed tannins. Fibre consists of cellulose, hemicellulose and lignin, which are mostly located in the seed hull. It is generally agreed that oilseed rape could be more competitive in marketplace if it had more protein, more energy and lower fibre content (Bell 1993; Simbaya et al. 1995; Slominski et al. 2012). Improvement of oilseed rape meal quality could be undertaken through breeding approach by selection of genotypes with low fibre content.

Selection for low fibre content among black-seeded winter oilseed rape genotypes is interesting because those genotypes are high yielding and adapted to north-western European growing conditions. For conducting the selection, information about genetic variation of fibre content is required as well as a fast and reliable method for selection. Since the objective of oilseed rape breeding program is mainly to increase oil content, genetic dissection to understand the inheritance of fibre content in relation to seed oil and protein content of the meal would be useful to facilitate breeding. According to this framework, current study has been conducted with the objectives: (i) to assess genetic variation of fibre content among black-seeded winter oilseed rape genotypes, (ii) to investigate correlation between fibre content and other important seed quality traits, and (iii) to identify quantitative trait loci (QTL) associated with fibre content by linkage analysis and association mapping.

Fibre content in oilseed rape meal is quantified as neutral detergent fibre (NDF), acid detergent fibre (ADF) and acid detergent lignin (ADL) following Van Soest et al. (1991). NDF consists largely of cellulose, hemicellulose and lignin, ADF comprises cellulose and lignin, and ADL represents un-digestible lignin content. Fibre content in oilseed rape can be expressed on a seed basis and on the basis of the oil-free (defatted) meal. Fibre content on a seed basis in oilseed rape is often used in genetic studies (Badani et al. 2006; Liu et al. 2013; Liu et al. 2012; Snowdon et al. 2010; Stein et al. 2013; Wittkop et al. 2012) and only few studies described fibre content on the basis of defatted meal (Dimov et al. 2012; Mailer et al. 2008). Since the value of fibre content is regarded for determining meal quality, the use of fibre content expressed on the basis of defatted meal would be more useful for animal nutritionist and of practical relevance to plant breeders. To provide more comparable results, both terms of fibre content on a seed basis and on the basis of defatted meal have been used in this study. 


\subsection{Variation in seed fibre content and seed hull proportion}

Relatively large variation of fibre content and seed hull proportion has been observed among black-seeded oilseed rape cultivars and doubled haploid (DH) populations. The variation of ADF content on seed basis ranged from $9.1 \%$ to $15.9 \%$ in oilseed rape cultivars (Chapter 2 and 4 ), and from $8.8 \%$ to $16.3 \%$ in three DH populations (Chapter 3). A comparable variation of ADF content in other black-seeded winter oilseed rape inbred lines and the $\mathrm{DH}$ and $\mathrm{F}_{2}$ populations derived from a cross between yellow-seeded and black-seeded has been previously reported (Badani et al. 2006; Snowdon et al. 2010; Wittkop et al. 2012). For seed hull proportion, larger variation has been observed in DH populations ranging from $9.0 \%$ to $19.4 \%$ (Chapter 3), while in winter oilseed rape cultivars the variation of seed hull proportion ranged between $12.2 \%$ to 18.3\% (Chapter 2 and Chapter 4). The effect of genotype on fibre content and seed hull proportion was significant in all populations as well as the effect of environment. The effect of genotype $x$ environment (GxE) interaction was comparatively low indicating that the rank of genotypes across the environments did not differ largely. Low GxE interactions resulted in moderate to high heritabilities for fibre content and seed hull proportion both in cultivars and DH populations, suggesting that it is possible to make a selection for genotypes with low fibre content among black-seeded winter oilseed rape.

\subsection{Correlation between traits}

Different types of relationships between seed oil, protein of defatted meal and fibre content of defatted meal have been observed in winter oilseed rape cultivars and DH populations. A set of 28 European winter oilseed rape cultivars (Chapter 2) and DH population SG DH14 x Express 617 (Chapter 3) showed positive correlation between seed oil and protein content of defatted meal and negative correlation between seed oil and fibre content of defatted meal. On the contrary, in a set of 81 canola quality winter oilseed rape cultivars (Chapter 4) and two other DH populations, Sollux x Gaoyou and Express 617 x R53, negative correlation was observed between seed oil and protein content of defatted meal while seed oil was positively correlated with fibre content. For breeding of improved meal quality, the type of relationship between oil, protein and fibre content found in a set of 28 European winter oilseed rape cultivars and DH population SG DH14 x Express 617 is preferred, because in these populations the increase of oil content occurred at the expense of fibre content instead of protein content.

Negative correlations between protein and fibre content, both on seed basis and on basis of defatted meal were observed in all populations. This is supported by the data taken from Schatzki et al. (2014) who studied seed storage protein content in the DH population Express 
617 x R53, where negative correlations were found between napin (a methionine-rich storage protein) and ADL ( $r=-0.15^{*}$ ) content of defatted meal (Chapter 3). Stombaugh et al. (2000) and Stombaugh et al. (2003) found a negative correlation between cell wall polysaccharide and protein content in soybean seeds, and suggested that a decrease in cotyledon cell wall polysaccharide may increase carbon available for protein deposition. For practical breeding, negative correlation between protein content of the meal and fibre content is expected because selection for low fibre content will lead to an increase of protein content in the meal.

Seed hull proportion was found to be negatively correlated with oil content and positively correlated with lignin content on a seed basis in all populations. This result may be explained by the fact that decreasing seed hull proportion will lead to an increase of embryo proportion, which in turn should result in an increase in oil content. Decreasing seed hull proportion will also affect the content of anti-nutritive components located in seed hull, such as condensed tannins and lignin. Condensed tannins is known to form oxidized complexes with cell wall polysaccharides, other phenolics and/or proteins during seed maturation, thus imparting a dark colour to the seed tissues (Moïse et al. 2005; Nesi et al. 2009). The association between seed hull and condensed tannins has been demonstrated by Chen et al. (2012) who found that the mutation on TRANSPARENT TESTA2 (TT2) gene that regulates the biosynthesis of condensed tannins (proanthocyanidins) decreased seed coat proportion in Arabidopsis. Recent study by Wang et al. (2014) confirmed that TT2 gene promotes condensed tannin synthesis and inhibits fatty acid production in embryos by down-regulating the genes in the fatty acid biosynthesis pathway in Arabidopsis. The results from Chen et al. (2012) and Wang et al. (2014) emphasize the importance of reducing seed hull proportion in oilseed rape because of its indirect effect in reducing the content of condensed tannins and increasing seed embryo proportion that will give a benefit to the increasing of oil content. In addition, it will simultaneously improve meal quality by reducing the lignin content. More practical aspect in reducing seed hull proportion is by selecting genotype with larger thousand kernel weight (TKW) since a negative correlation has been observed for both traits in all populations (Chapter 2, Chapter 3, and Chapter 4).

The present study found a negative correlation between glucosinolate and cellulose content in DH population segregating for glucosinolate content (Chapter 3, Fig 3.4). This was corroborated by the fact that a QTL for glucosinolate content showed overlapping confidence interval with QTL for cellulose content in DH population Express 617 x R53 and SG DH14 x Express 617 (Chapter 3, Table 3.7 and Table 3.8). The mean of cellulose content in canola quality winter oilseed rape cultivars (14.4\%, Chapter 4, Table 4.2) is higher than that in DH population segregating for glucosinolate $(12.1 \%$, Chapter 3, Table 3.2). Furthermore, in DH population 
Express $617 \times$ R53, the mean of cellulose content of DH lines with low glucosinolate content $(12.7 \%)$ is higher than that of DH lines with high glucosinolate content $(11.8 \%)$. These findings have consequences when screening genetic resources for reduced cellulose content. In this case some adjustment should be performed depending on the glucosinolate content in the seed, as Amar et al. (2008) suggested for determining phytosterol content in high erucic acid population.

\subsection{Identification of QTL associated with fibre content by linkage analysis and association mapping}

Linkage analysis in three DH populations and association mapping in 81 canola quality winter oilseed rape cultivars have detected 9 to 32 QTL associated with fibre fractions across 19 linkage groups. QTL detected on linkage group C03 at the interval 13.8-27.3 cM and 113.3-147.7 cM in Express 617 x R53 population might represent major QTL for fibre content. These QTL have also been detected on linkage group C03 in SG DH14 x Express 617 population (Chapter 3) and in canola quality winter oilseed rape cultivars (Chapter 4). A chromosomal region at the interval 13.8-27.3 cM with a QTL for fibre content showed an association with oil content, protein content of defatted meal and erucic acid (Chapter 3, Fig. 3.5, Express 617 x R53 and SG DH14 x Express 617) with an opposite direction of the additive effect. This QTL may be useful in breeding for low fibre content and simultaneous improvement of oil and protein content. In another chromosomal region on linkage group C03 at the interval 113.3 - 147.7cM, QTL associated with fibre fractions showed overlapping confidence interval with QTL for seed hull proportion and the effects had the same direction (Chapter 3, Fig 3.5, Express 617 x R53 population). At this locus, allele from Express 617 parent contributes to the reduction of fibre content and seed hull proportion, and showing no association with QTL for oil and protein. This QTL might be useful for detecting genotypes with low seed hull proportion. Overlapping confidence intervals of different QTL may indicate that a gene located in this region has a pleiotropic effect on two or more traits (Schatzki et al. 2013) and are corroborating the results of correlation analysis between traits.

Most promising QTL was detected on linkage group C05 at the interval $31.6-46.4 \mathrm{cM}$ in the population SG DH14 x Express 617, in where QTL for fibre content showed overlapping confidence interval with the QTL for seed hull proportion with the same direction of additive effect, as well as with the QTL for seed oil content with the opposite direction of additive effect (Chapter 3, Table 3.8, Fig. 3.6). An allele from SG DH14 parent at this locus reduces fibre content and seed hull proportion and simultaneously increases oil content. Selection of genotypes with low fibre content among the DH lines could be undertaken by identifying of lines having an SG DH14 allele at this locus using the associated marker (Fig 5.1). The black dots in the red cloud 
probably represent scoring errors. Interesting to note is the positive correlation between oil and ADL content of the genotypes with the SG DH14 allele $\left(r=0.32^{* *}\right)$.

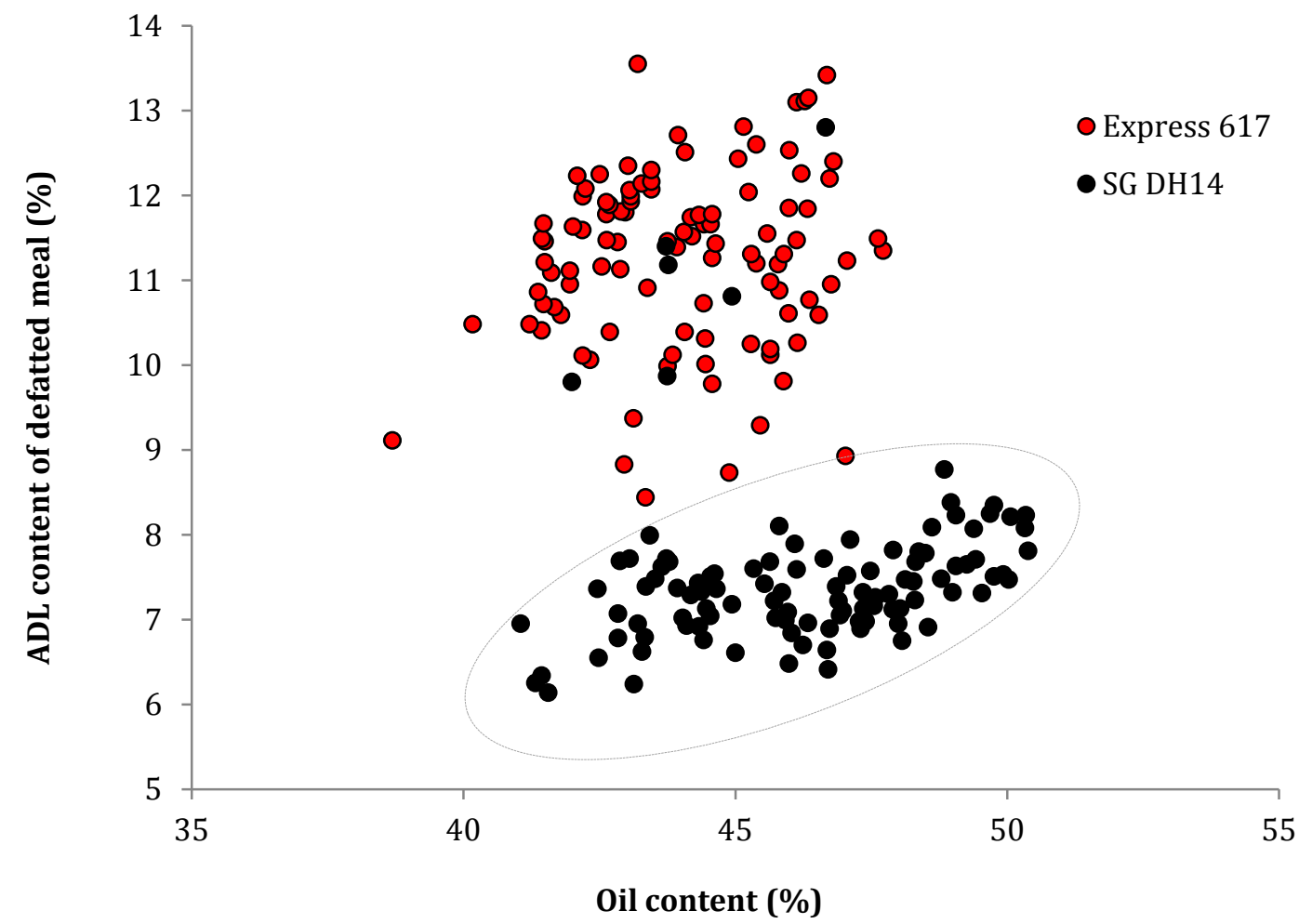

Figure 5.1 A SNP marker p28950 associated with fibre content located on linkage group C05 at the position $35 \mathrm{cM}$ showed clustering of genotypes with SG DH14 allele (black colour) and Express 617 allele (red colour) based on ADL content. This marker will be useful for selecting genotypes with low fibre content in DH population SG DH14 x Express 617

\subsection{NIRS calibration for fibre content}

Regarding the development of NIRS calibrations for fibre content developed in this study, the results indicate that NIRS can be used to select in segregating black-seeded winter oilseed rape for low fibre content (Chapter 1). The new extended NIRS calibration, which includes additional samples from Sollux x Gaoyou and SG DH14 x Express 617 populations resulted in a good prediction of fibre content, in particular for ADL content as shown by low standard error of performance corrected for bias [SEP(C)] ranging from $0.72 \%$ to $1.21 \%$ for this trait in validation sets (Chapter 3). The current NIRS calibration provides a good alternative to the conventional fibre analysis (Van Soest et al. 1991) for high throughput, fast, and non-destructive estimation of 
fibre content in oilseed rape. Further improvement could be achieved by including different genetic materials, e.g. brown- and yellow-seeded types to extend the NIRS calibration to capture more variation in fibre content.

\subsection{Conclusion and Outlook}

Results from this study show that there is a large variation of fibre-related traits among blackseeded winter oilseed rape genotypes. Heritabilities are high and the availability of a sufficiently accurate NIRS calibration allow for a selection for genotypes with low fibre content in breeding programs. Promising genotypes with low fibre content have been identified among three DH populations and a set of canola quality winter oilseed rape cultivars. Those genotypes can be used in future breeding programs aimed at improving meal quality. Furthermore, with the availability of high-density genetic map including sequence characterized SNP and DArT markers in SG DH14 x Express 617 DH population, it would be possible to verify the genes underlying QTL associated with fibre content. Further studies in this direction could be focused on a chromosomal region on linkage group C05 of SG DH14 x Express 617 at the interval 31.6 $46.4 \mathrm{cM}$ in which a QTL with a large additive effect on fibre content has been detected.

\subsection{References}

Amar S, Ecke W, Becker HC, Möllers C (2008) QTL for phytosterol and sinapate ester content in Brassica napus L. collocate with the two erucic acid genes. Theor Appl Genet 116:10511061

Badani AG, Snowdon RJ, Wittkop B, Lipsa FD, Baetzel R, Horn R, Haro A, Font R, Lühs W (2006) Colocalization of a partially dominant gene for yellow seed colour with a major QTL influencing acid detergent fibre (ADF) content in different crosses of oilseed rape (Brassica napus). Genome 49:1499-1509

Bell J (1993) Factors affecting the nutritional value of canola meal: a review. Can J Anim Sci 697:679-697

Chen M, Wang Z, Zhu Y, Li Z, Hussain N, Xuan L, Guo W, Zhang G, Jiang L (2012) The effect of transparent TESTA2 on seed fatty acid biosynthesis and tolerance to environmental stresses during young seedling establishment in Arabidopsis. Plant Physiol 160:1023-1036

Dimov Z, Suprianto E, Hermann F, Möllers C (2012) Genetic variation for seed hull and fibre content in a collection of European winter oilseed rape material (Brassica napus L.) and development of NIRS calibrations. Plant Breed 131:361-368

Liu L, Qu C, Wittkop B, Yi B, Xiao Y, He Y, Snowdon RJ, Li J (2013) A high-density SNP map for accurate mapping of seed fibre QTL in Brassica napus L. PLoS One 8:e83052 
Liu L, Stein A, Wittkop B, Sarvari P, Li J (2012) A knockout mutation in the lignin biosynthesis gene CCR1 explains a major QTL for acid detergent lignin content in Brassica napus seeds. Theor Appl Genet 124:1573-1586

Mailer RJ, McFadden A, Ayton J, Redden B (2008) Anti-nutritional components, fibre, sinapine and glucosinolate content in Australian canola (Brassica napus L.) meal. J Am Oil Chem Soc 85:937-944

Moïse J, Han S, Gudynaite-Savitch L, Johnson D, Miki B (2005) Seed coats: structure, development, composition, and biotechnology. In Vitro Cell Dev Biol Plant 41:620-644

Nesi N, Lucas M, Auger B, Baron C, Lécureuil A, Guerche P, Kronenberger J, Lepiniec L, Debeaujon I, Renard M (2009) The promoter of the Arabidopsis thaliana BAN gene is active in proanthocyanidin-accumulating cells of the Brassica napus seed coat. Plant Cell Rep 28:601-617

Schatzki J, Ecke W, Becker HC, Möllers C (2014) Mapping of QTL for the seed storage proteins cruciferin and napin in a winter oilseed rape doubled haploid population and their inheritance in relation to other seed traits. Theor Appl Genet 127:1213-1222

Schatzki J, Schoo B, Ecke W, Herrfurth C, Feussner I, Becker HC, Möllers C (2013) Mapping of QTL for seed dormancy in a winter oilseed rape doubled haploid population. Theor Appl Genet 126:2405-2415

Simbaya J, Slominski B, Rakow G, Campbell LD, Downey RK, Bell JM, Bello JM (1995) Quality characteristics of yellow-seeded Brassica seed meals: Protein, carbohydrate, and dietary fiber components. J Agric Food Chem 43:2062-2066

Slominski BA, Jia W, Rogiewicz A, Nyachoti CM, Hickling D (2012) Low-fiber canola. Part 1. Chemical and nutritive composition of the meal. J Agric Food Chem 60:12225-12230

Snowdon RJ, Wittkop B, Rezaidad A, Hasan MH, Lipsa F, Stein A, Friedt W, Francki M (2010) Regional association analysis delineates a sequenced chromosome region influencing antinutritive seed meal compounds in oilseed rape. Genome 53:917-928

Van Soest PJ, Robertson JB, Lewis BA (1991) Methods for dietary fiber, neutral detergent fiber, and nonstarch polysaccharides in relation to animal nutrition. J Dairy Sci 74:3583-3597

Stein A, Wittkop B, Liu L, Obermeier C, Friedt W, Snowdon RJ (2013) Dissection of a major QTL for seed colour and fibre content in Brassica napus reveals colocalization with candidate genes for phenylpropanoid biosynthesis and flavonoid deposition. Plant Breed 132:382389

Stombaugh S, Orf J, Jung H, Somers D (2003) Relationships between soybean seed cell wall polysaccharides, yield, and seed traits. Crop Sci 43:571-576

Stombaugh SK, Jung HG, Orf JH, Somers DA (2000) Genotypic and environmental variation in soybean seed cell wall polysaccharides. Crop Sci 40:408-412 
Wang Z, Chen M, Chen T, Xuan L, Li Z, Du X, Zhou L, Zhang G, Jiang L (2014) TRANSPARENT TESTA2 regulates embryonic fatty acid biosynthesis by targeting FUSCA3 during the early developmental stage of Arabidopsis seeds. Plant J 77:757-769

Wittkop B, Snowdon R, Friedt W (2012) New NIRS calibrations for fiber fractions reveal broad genetic variation in Brassica napus seed quality. J Agric Food Chem 60:2248-2256 


\section{S U M MARY}

The meal from oilseed rape is a valuable product as substitution for soybean meal in animal diets due to its high protein content and its excellent balanced composition of essential amino acids. However, the presence of high fibre fraction in oilseed rape meal, which is mostly located in seed hull, is the major obstacle for its use in animal feeding. The fibre fraction is poorly digestible and essentially dilutes the available energy and protein. Consequently, oilseed rape meal has less metabolizable energy and reduces the value of the meal relatively to soybean meal. Fibre contents are related to plant cell walls components, namely cellulose, hemicellulose and lignin. The proportion of hemicellulose, cellulose and lignin can be quantified as neutral detergent fibre (NDF), acid detergent fibre (ADF) and acid detergent lignin (ADL). The NDF fraction consists (predominantly) of hemicellulose, cellulose and lignin content, while the ADF fraction comprises cellulose and lignin. ADL represents the non-digestible lignin fraction. NDF, $\mathrm{ADF}$ and $\mathrm{ADL}$ are used as indicators for forage quality, whereby NDF is used as indicator for feed intake, and ADF and ADL are used to characterize feed digestibility.

To improve the quality of oilseed rape meal, breeding research has been undertaken to select genetic material with lower fibre content. Selection for improved meal quality has been focused on yellow-seeded B. napus which is characterized by a thinner seed coat, less fibre and higher oil content. Breeding for yellow-seeded B. napus, however, still encounters difficulties because of strong environmental effects. Recently, selection for low fibre content has also been conducted in black-seeded B. napus material. Taking advantage of natural genetic variation for fibre content among black-seeded germplasm may complement ongoing approaches to reduce fibre content in oilseed rape meal as well as to increase oil and protein content in the seed. Selection for low fibre content in canola quality winter oilseed rape cultivars is promising since the material is high yielding and adapted.

The objectives of this study were: (i) to analyse genetic variation for fibre content and seed hull proportion in a set of European winter oilseed rape cultivars and to develop near-infrared reflectance spectroscopy (NIRS) calibrations for fibre content, (ii) to analyse genetic variation of fibre content and seed hull proportion, to investigate correlations between fibre content and other quality traits, and to identify quantitative trait loci (QTL) associated with fibre content by linkage analysis in three doubled haploid populations of black-seeded winter oilseed rape; (iii) to analyse genetic variation and genotype $\mathrm{x}$ environment interactions for fibre content and seed hull proportion and to conduct association analysis in a larger set of canola quality winter oilseed rape cultivars. 
Populations used in this study consisted of black-seeded winter oilseed rape materials from different genetic backgrounds including: (i) a collection of 28 European winter oilseed rape cultivars, (ii) 282 doubled haploid (DH) lines of Sollux x Gaoyou, (iii) 229 DH lines of Express 617 x R53, (iv) 213 DH lines of SGDH 14 x Express 617, and (v) a set of 81 canola quality winter oilseed rape cultivars. Identification of QTL responsible for fibre content has been carried out through linkage analysis in those three DH populations and through association mapping in a set of 81 canola quality winter oilseed rape cultivars. Seed material from all genotypes obtained from open pollinated plants of field experiments previously performed in different environments were used for the analysis.

The results of the present study revealed that the effect of genotype on fibre content and seed hull proportion was significant in all populations as well as the effect of environment. The effect of genotype $\mathrm{x}$ environment ( $\mathrm{GxE}$ ) interaction was comparatively low indicating that the rank of genotypes across the environments did not differ largely. Low GxE interactions resulted in moderate to high heritabilities for fibre content and seed hull proportion both in winter oilseed rape cultivars and DH populations. The heritabilities for NDF, ADF, ADL and seed hull proportion ranged from 0.78 to $0.93,0.75$ to $0.96,0.41$ to 0.98 and 0.56 to 0.91 , respectively.

Different types of relationships between seed oil, protein of defatted meal and fibre content of defatted meal have been observed in winter oilseed rape cultivars and DH populations. A set of 28 European winter oilseed rape cultivars and DH population SG DH14 x Express 617 showed positive correlation between seed oil and protein content of defatted meal and negative correlation between seed oil and fibre content of defatted meal. On the contrary, in a set of 81 canola quality winter oilseed rape cultivars and two other DH populations, Sollux x Gaoyou and Express 617 x R53, negative correlations were observed between seed oil and protein content of defatted meal while seed oil was positively correlated with fibre content. For breeding of improved meal quality, the type of relationship between oil, protein and fibre content found in a set of 28 European winter oilseed rape cultivars and DH population SG DH14 x Express 617 is preferred, because in these populations the increase of oil content occurred at the expense of fibre content instead of protein content. Negative correlations between protein content of the meal and fibre content found in all populations is expected because selection for low fibre content will lead to an increase of protein content in the meal. Seed hull proportion was found to be negatively correlated with oil content and positively correlated with seed lignin content in all populations. Reducing seed hull proportion will give a benefit to increasing oil content because of its indirect effect in reducing the content of condensed tannins and increasing seed embryo proportion. In addition, it will simultaneously improve meal quality by reducing the 
lignin content. Thousand kernel weight is an important trait that should be considered in selection due to its indirect effect to lower fibre content by reducing seed hull proportion as shown by negative correlation between these two traits.

Favorable QTL that reduced seed fibre content and seed hull proportion, and simultaneously increased seed oil content were detected in population SGDH 14 x Express 617 located on linkage group C05 at the interval 31.6 - 46.4 cM. QTL for fibre content in this interval showed overlapping confidence interval with the QTL for seed hull proportion with the same direction of additive effect, as well as with the QTL for seed oil content with an opposite direction of additive effect. Association mapping performed in a set of 81 canola quality winter oilseed rape cultivars revealed 74 markers being associated with fibre-related traits representing 2 to 20 QTL for respective traits. QTL for NDF and hemicellulose content on linkage group C03 identified in association mapping were also mapped on the same location in DH population Express 617 x R53 suggesting that those might be the same QTL. The QTL located on linkage group $\mathrm{C} 03$ and $\mathrm{C} 05$ could be used in future breeding programs aimed at improving meal quality. Further study could be focused to verify the genes underlying QTL associated with fibre content detected in linkage group C03 and C05 in SG DH14 x Express 617 DH population.

The NIRS calibrations developed specifically for predicting NDF, ADF and ADL content in blackseeded winter oilseed rape could be used for screening large numbers of genotypes in a fast, reliable, cost efficient and non-destructive way. With relatively large genetic variation, medium to high heritabilities for fibre fractions, and the availability of NIRS calibration, selection for low fibre content in black-seeded winter oilseed rape could be performed in commercial breeding programs. 


\section{CURRICULUM VITAE}

\section{Personal Data}

Name

Place, date of birth

Address

Nationality

Marital status

\section{Education}

Oct 2004 - Jan 2007

Sept 1993 - Sept 1998

\section{Working Experiences}

1998 - present

\section{Workshop}

20-30 Nov 2012

17-19 Jan 2012
Edy Suprianto

Jakarta - Indonesia, 18 March 1974

Indonesian Oil Palm Research Institute

Jl. Brigjen Katamso No. 51 Medan 20158 North Sumatera Indonesia

Email : espriantos@yahoo.com, edygrey@gmail.com

Indonesian

Married, 2 children

Master Program in Tropical and International Agriculture, Faculty of Agricultural Sciences, Georg-August-Universität Göttingen, Germany

Bachelor program in Agronomy, Faculty of Agriculture, Bogor Agricultural University, Bogor, Indonesia

Researcher in Plant Breeding Division, Indonesian Oil Palm Research Institute (IOPRI)

Workshop on Exploitation of Oil Palm Genome Project Results for Breeding Applications and Bioinformatic Analyses of Sequence Data. CIRAD CP, Montpellier, France

Workshop on Advance Methods in Crop Breeding - NUE Crops Project. Newcastle University, Newcastle upon Tyne, UK

\section{Publications during PhD study}

Suprianto E, Schatzki J, Hermann F, Ecke W, Becker HC, Möllers C (2011) Mapping of QTL for NDF, ADF and ADL content in a winter oilseed rape doubled haploid population. Proc 13th International Rapeseed Congress, Prague, Czech Republic, pp 761-766

Dimov Z, Suprianto E, Hermann F, Möllers C (2012) Genetic variation for seed hull and fibre content in a collection of European winter oilseed rape material (Brassica napus L.) and development of NIRS calibrations. Plant Breed 131:361-368 
Suprianto E, Ecke W, Becker HC, Möllers C (2012) Genetic variation and genotype $\mathrm{x}$ environment interactions for seed hull and seed fibre content in winter oilseed rape cultivars (Brassica napus L.). The 2012 German Society for Plant Breeding (GPZ) Conference "Breeding crops for sustainaible agricultural production", 28 February - 1 March 2012, Giessen, Germany

Suprianto E, Schatzki J, Becker HC, Ecke W, Möllers C (2013) Genetic analysis and QTL mapping for seed fibre content in a black seeded doubled haploid population of winter oilseed rape (Brassica napus L.). 48. Vortragstagung Deutsche Gessellschaft für Qualitätforschung (Pflanzliche Nahrungsmittel) e.V. „Von Anbau zum Verbraucher: Qualität in der Wertschöpfungskette“, 18 - 19 March 2013, Göttingen, Germany

ooOoo 